This accepted manuscript of article: Újvári, G., Kok, J.F., Varga, Gy., Kovács, J., The physics of windblown loess: implications for grain size proxy interpretations in Quaternary paleoclimate studies, is copyrighted and published by Elsevier.

It is posted here based on an agreement between Elsevier and MTA.

The definitive version of the text was subsequently published in: Earth-Science Reviews, 2016, Volume 154 , pp. $247-278$.

doi: $10.1016 /$ j.earscirev.2016.01.006

Available under license CC-BY-NC-ND

Submitted version after R2 
$6 \quad{ }^{1}$ Institute for Geological and Geochemical Research, Research Centre for Astronomy and

7 Earth Sciences, Hungarian Academy of Sciences, H-1112 Budapest, Budaörsi u. 45., Hungary

$8{ }^{2}$ Geodetic and Geophysical Institute, Research Centre for Astronomy and Earth Sciences,

9 Hungarian Academy of Sciences, H-9400 Sopron, Csatkai E. u. 6-8., Hungary

\section{The physics of wind-blown loess: implications for grain size proxy interpretations in Quaternary paleoclimate studies}

\author{
Gábor Újvári $^{1,2}$, Jasper F. Kok ${ }^{3}$, György Varga ${ }^{4}$, János Kovács ${ }^{5,6}$
}

${ }^{3}$ Department of Atmospheric and Oceanic Sciences, University of California, 405 Hilgard Ave, Los Angeles, 90095 California, USA

${ }^{4}$ Geographical Institute, Research Centre for Astronomy and Earth Sciences, Hungarian Academy of Sciences, H-1112 Budapest, Budaörsi út 45., Hungary

${ }^{5}$ Department of Geology and Meteorology, University of Pécs, H-7624 Pécs, Ifjúság u. 6., Hungary

${ }^{6}$ Environmental Analytical and Geoanalytical Laboratory, Szentágothai Research Centre, University of Pécs, H-7624 Pécs, Ifjúság u. 20., Hungary 


\section{Abstract}

Loess deposits are recorders of aeolian activity during past glaciations. Since the size distribution of loess deposits depends on distance to the dust source, and environmental conditions at the source, during transport, and at deposition, loess particle size distributions and derived statistical measures are widely used proxies in Quaternary paleoenvironmental studies. However, the interpretation of these proxies often only consider dust transport processes. To move beyond such overly simplistic proxy interpretations, and toward proxy interpretations that consider the range of environmental processes that determine loess particle size distribution variations we provide a comprehensive review on the physics of dust particle mobilization and deposition. Furthermore, using high-resolution bulk loess and quartz grain size datasets from a last glacial/interglacial sequence, we show that, because grain size distributions are affected by multiple, often stochastic processes, changes in these distributions over time allow multiple interpretations for the driving processes. Consequently, simplistic interpretations of proxy variations in terms of only one factor (e.g. wind speed) are likely to be inaccurate. Nonetheless using loess proxies to understand temporal changes in the dust cycle and environmental parameters requires (i) a careful site selection, to minimize the effects of topography and source distance, and (ii) the joint use of bulk and quartz grain size proxies, together with high resolution mass accumulation rate calculations if possible.

Keywords: loess; grain size proxy; quartz; wind; aeolian dynamics; Quaternary 
Appearing in the main text

$A_{2}$

$A_{B}$

$A_{c}$

$A_{\text {Col }}$

$A_{\mathrm{Co} 2}$

$A_{\mathrm{Co} 3}$

$A_{N}$

$b_{r}$

$c_{a}$

$C_{1}$

$C_{2}$

$C_{B}$

$C_{c}$

$C_{d}$

$C_{D K}$

$C_{K}$

$C_{p}$

$C_{R}$

$C_{S}$

$d$

$D_{B}$

$D_{p}$

$D_{r}$

$D_{r d}$

$D_{r d-r}$

$D_{w}$

$E_{B}$

$E_{B w}$

$E_{D P_{W}}$

$E_{E S W}$

$E_{I M}$

$E_{\text {Imw }}$

$E_{I N}$

$E_{\text {Inw }}$

EM

EMMA

$E_{T P w}$ constant in mean charge calculations for raindrops and particles

coefficient including factors like particle shape, sorting, packing and bed roughness

dimensionless threshold friction velocity (Bagnold, 1941)

the contact area between adjacent grains

model parameter associated aerodynamic forces (Cornelis et al., 2004a,b) $\left(\mathrm{N} \mathrm{m}^{-1}\right)$

model parameter associated inter-particle forces (Cornelis et al., 2004a,b) $\left(\mathrm{N} \mathrm{m}^{-1}\right.$ )

geometry factor (Cornelis et al., 2004a) $\left(\mathrm{N}^{-1} \mathrm{~m}^{-1}\right)$

dimensionless threshold friction velocity (Shao and Lu, 2000)

width of an individual roughness element (m)

heat capacity of air $\left(\mathrm{m}^{2} \mathrm{~s}^{-2} \mathrm{~K}^{-1} / \mathrm{J} \mathrm{kg}^{-1} \mathrm{~K}^{-1}\right)$

coefficient in the Ferguson and Chruch (2004) model, a constant for laminar settling for $R e_{p t}<1$

coefficient in the Ferguson and Chruch (2004) model, a constant $C_{d}$ for $R e_{p t}>10^{3}$

constant for the saltation mass flux model of Bagnold (1941)

Cunningham slip correction factor

drag coefficient

parameter for the saltation mass flux model of Kok et al. (2012)

constant for the saltation mass flux model of Kawamura (1951)

local concentration of depositing particles $\left(\mathrm{g} \mathrm{m}^{-3}\right)$

roughness element drag coefficient

surface drag coefficient

zero plane displacement height $(\mathrm{m})$

Brownian diffusivity of particles $\left(\mathrm{m}^{2} \mathrm{~s}^{-1}\right)$

particle diameter $(\mathrm{m})$

typical roughness element size (Nikuradse roughness)

raindrop diameter $(\mathrm{m})$

representative raindrop diameter $(\mathrm{m})$

water vapour diffusivity in air $\left(\mathrm{m}^{2} \mathrm{~s}^{-1}\right)$

collection efficiency from Brownian diffusion

collection/collision efficiency from Brownian diffusion in below-cloud scavenging

collection/collision efficiency due to diffusiophoresis in below-cloud scavenging

electrostatic collection/collision efficiency in below-cloud scavenging

collection efficiency from impaction

collection/collision efficiency from inertial impaction in below-cloud scavenging

collection efficiency from interception

collection/collision efficiency from interception in below-cloud scavenging

end member

end member modeling algorithm

collection/collision efficiency due to thermophoresis in below-cloud scavenging 


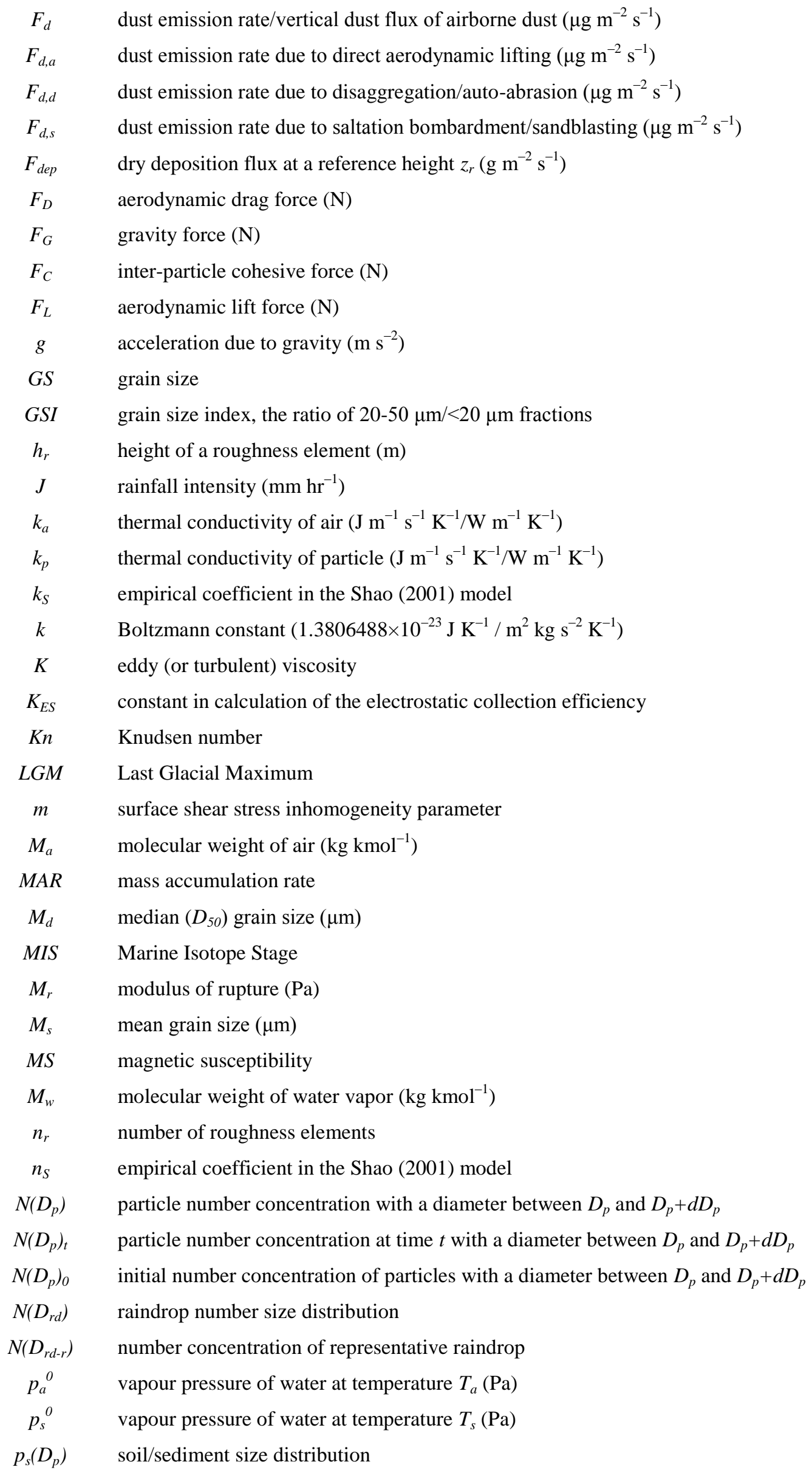




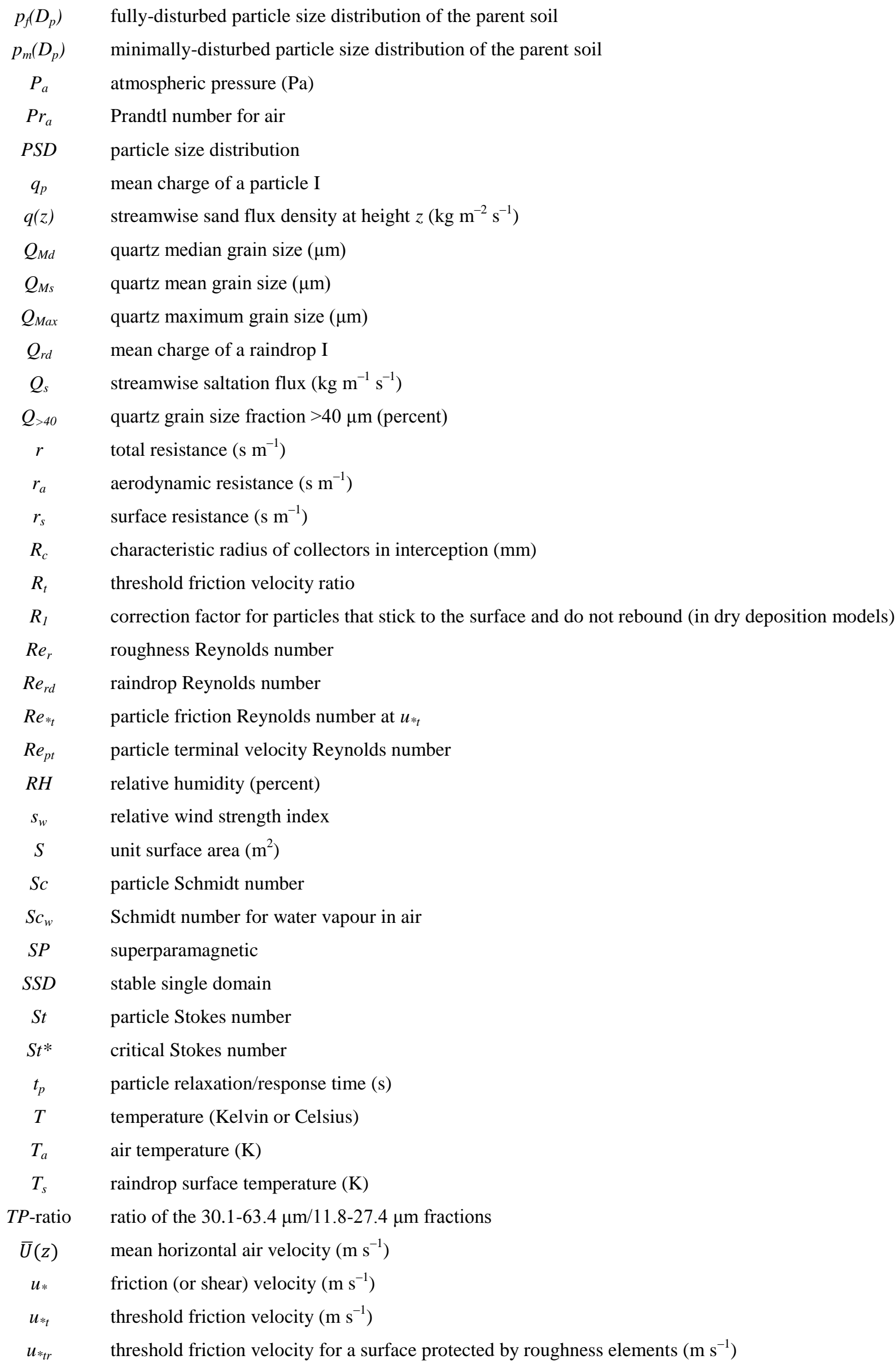




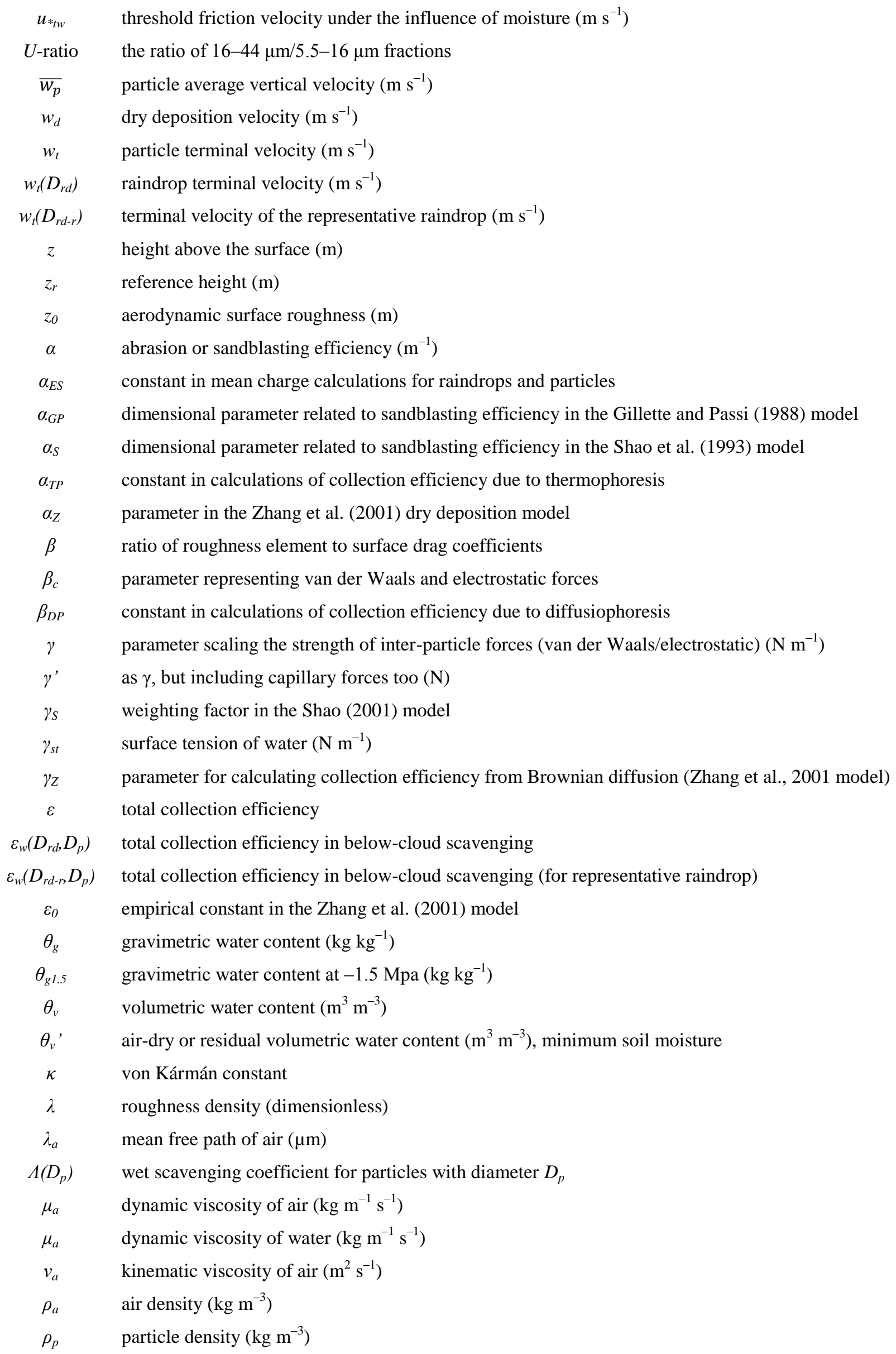




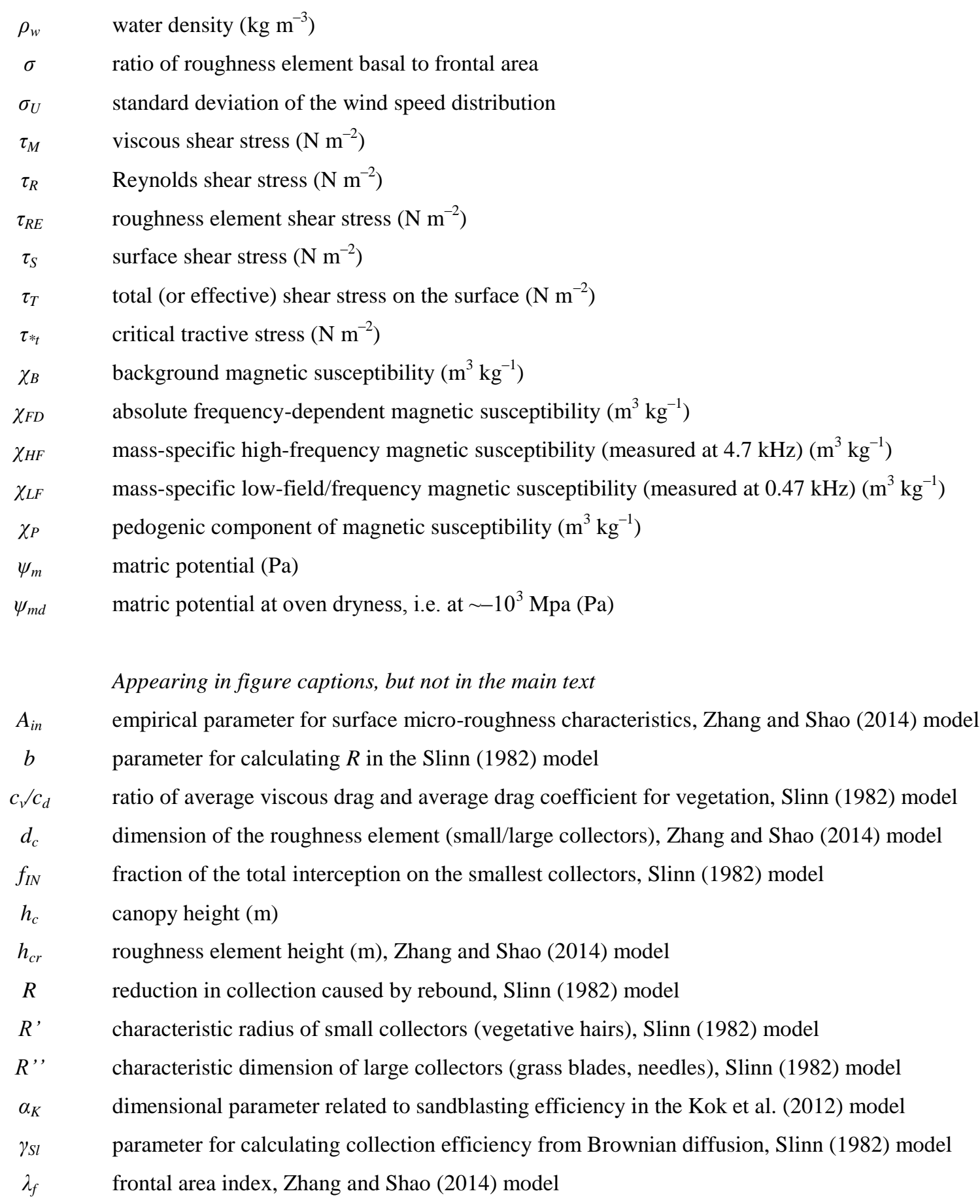




\section{Contents}

1. Introduction 10

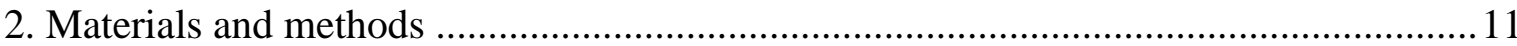

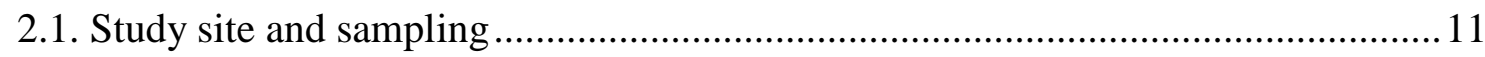

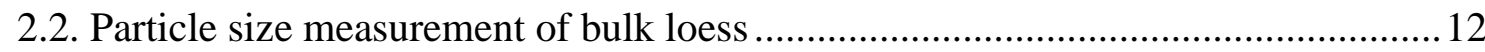

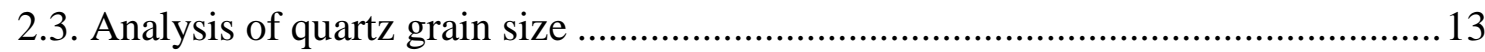

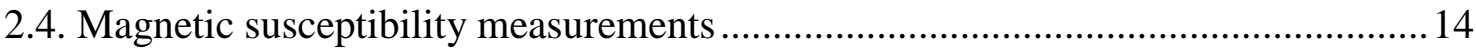

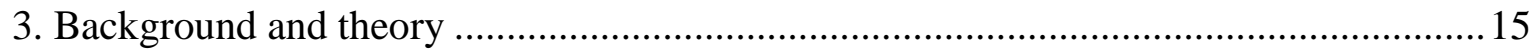

3.1. The physics of loess particle mobilization, transport and deposition...................... 15

3.1.1. Particle mobilization and transport by wind ................................................ 16

3.1.1.1. Wind, turbulence and shear stress in the atmospheric

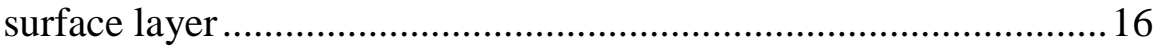

3.1.1.2. Threshold of particle motion .............................................................. 18

3.1.1.3. Soil moisture effects on the fluid threshold ...................................20

3.1.1.4. Temperature effects on the fluid threshold ...................................23

3.1.1.5. Surface crust, soil salts and the fluid threshold..............................24

3.1.1.6. Roughness elements and the fluid threshold ..................................26

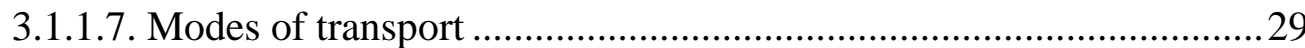

3.1.1.8. Saltation under transport- and supply-limited conditions .................32

3.1.1.9. Dust emission and resuspension mechanisms.................................37

3.1.2. Deposition of air-borne mineral particles ............................................... 42

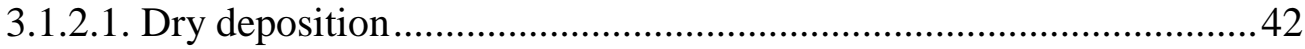

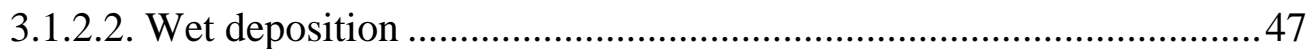

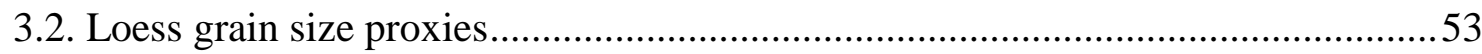

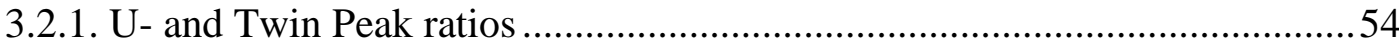


4. Results and discussion .58

4.2. Processes and mechanisms affecting bulk loess particle size distributions and to be considered in bulk grain size proxy interpretations 61 


\section{Introduction}

Loess is a terrestrial clastic sediment, composed predominantly of silt-sized particles deposited by winds during glacial periods (Fig. 1; Pye, 1995; Smalley et al., 2011). In many loess sequences there is a continuum of non-modified to modified loess ranging from typical primary loess, through weakly developed leached layers to intensely-weathered paleosols, reflecting changing climatic/environmental conditions (Pye, 1995; Kemp, 2001). Variations of the particle size distributions (PSDs) and some grain size (GS) proxies have widely been used in Quaternary loess research to reconstruct paleoenvironmental changes on both longer, glacial/interglacial $\left(10^{5}-10^{6}\right.$ years; e.g. Liu et al., 1989; Ding et al., 1992, 1999, 2001, 2002; Vandenberghe et al., 1997; Liu and Ding, 1998; An, 2000; Nugteren and Vandenberghe, $2004)$ and shorter, millennial to multi-millennial time scales $\left(10^{3}-10^{4}\right.$ years; e.g. Porter and An, 1995; Xiao et al., 1995; An and Porter, 1997; Porter, 2001; Rousseau et al., 2002; Shi et al., 2003). Grain size measurements have also been used to identify aeolian dust records from earlier in the Cenozoic (Licht et al., 2014) and longer loess/dust records extend into the Miocene in some areas (Guo et al., 2002; Qiao et al., 2006).

Although the physical background of loess particle transport and deposition mechanisms was reviewed and discussed in detail in the late nineteen eighties by Pye (1987), Tsoar and Pye (1987) and Pye and Tsoar (1987), this knowledge does not always seem to be reflected in loess grain size proxy interpretations, which tend to be overly simplistic (Wang and Lai, 2014) and only consider transport mechanisms while essentially disregarding mobilization and deposition processes. As a considerable amount of novel information on the physics of dust/sand particle mobilization, transport and deposition has been accumulated since the publication of the works by Pye and Tsoar, we attempt to provide a novel review of the topic. This is done by focusing on the critical evaluation of the most widely-used loess grain size proxies in order to improve their interpretations in Quaternary environmental change 
reconstructions. This evaluation is aided by, and based on, high-quality and high-resolution datasets of bulk and quartz GS and magnetic susceptibility from a well-dated loess-paleosol record in Hungary.

After discussing the methodology of grain size and magnetic susceptibility measurements in section 2, we provide a review of aeolian sediment mobilization, transport and deposition (section 3.1.) with particular emphasis on the substantial progress made over the past 25 years, which is followed by an overview of the most widely-used loess grain size proxies and indices (section 3.2.). In the 'Results and Discussion' section (section 4) we build on the insights provided in section 3.1. to evaluate the GS proxies using bulk loess and quartz particle size data to obtain an improved understanding of how the different factors determine the major characteristics of loess particle size distributions. Basic questions we address include: 1) which, if any, grain size proxy best reflects wind speed variations, 2) what other factors exert control on the proxies, and 3) which proxies are the most powerful for tracking environmental changes on glacial/interglacial and millennial timescales?

\section{Material and methods}

\subsection{Study site and sampling}

The studied loess-paleosol section is located at Dunaszekcső (Fig. 2), Southern Hungary, on the right bank of the Danube river $\left(46^{\circ} 05^{\prime} 25^{\prime \prime} \mathrm{N}, 18^{\circ} 45^{\prime} 45^{\prime \prime} \mathrm{E}\right.$, and $135 \mathrm{~m}$ a.s.1.) and exposes last glacial-interglacial sediments with a thickness of $17 \mathrm{~m}$. A detailed sedimentological description of the profile can be found in Újvári et al. (2014). In 2008, an enormous bank failure exposed the uppermost 15-20 m part of the ca. $70 \mathrm{~m}$ thick Quaternary loess-paleosol sequence at Dunaszekcső (Újvári et al., 2009), thereby allowing the sampling of a fresh profile. After cleaning of the sediment surface 314 samples were collected in 5 to $2 \mathrm{~cm}$ resolution for grain size and magnetic measurements. 


\subsection{Particle size measurement of bulk loess}

134

135

Before the laser diffraction measurements, $3 \mathrm{~g}$ of loess/paleosol samples were pretreated with $10 \mathrm{ml} 20 \% \mathrm{H}_{2} \mathrm{O}_{2}$ and $10 \mathrm{ml} 10 \% \mathrm{HCl}$ to remove organic matter and carbonates. Subsequently, $10 \mathrm{ml}$ of $0.05 \mathrm{~N} \mathrm{Na}\left(\mathrm{PO}_{3}\right)_{6}$ was added to the samples, which were finally ultrasonicated for about $1 \mathrm{~min}$. These are chemically fully dispersed samples and all the presented bulk loess GS proxies are based on fully dispersed PSDs. For comparison, however, some loess samples were minimally dispersed, i.e. no chemical pretreatment was applied and the samples were mixed only with deionized water during the measurements.

Grain size of bulk loess and paleosol samples was analyzed using a Malvern Instruments Mastersizer 3000 laser diffractometer with a Hydro LV wet dispersion unit having a measurement range of $0.01-3500 \mu \mathrm{m}$ divided into 100 size bins. Two light sources were utilized, a red He-Ne laser at a wavelength of $0.633 \mathrm{~mm}$ and a blue LED at $0.470 \mathrm{~mm}$. Diffracted light intensity was measured by 50 sensors over a wide range of angles. Constants of 1.33 for the refractive index of water, 1.544 for the refractive index of solid phases (valid for quartz, and most clay minerals and feldspars), and an absorption index of 0.1 was applied. The default acceptable range of obscuration on the Mastersizer 3000 is from 0.1 to $20 \%$. We adopted a 15 to $20 \%$ range as a working obscuration target for our standard operating procedure. The Hydro LV pump unit has variable-speed capabilities to compensate for differences in particle size, density, or sample reservoir volume. In our experiments we maintained a pump speed of 2300-2700 rpm. The Mastersizer 3000 takes 1000 readings (snaps) per second and each measurement run was set to run for 10 seconds or 10,000 snaps. Bulk grain size analyses reported in this paper are the average of seven successive laser diffraction runs (total of 70,000 snaps). The recorded data were processed using the Malvern's 
Mastersizer 3000 software (version 3.10), which transformed the scattered light data to particle size information based on the Mie Scattering Theory.

As an assessment of measurement uncertainties it must be noted that the applied optical parameter settings in laser diffraction may have considerable effects on the grain size results for some sediment types, in particular for the clay fractions (Varga et al., 2015). At the same time, the clay $(<2 \mu \mathrm{m})$ content of sediments is typically underestimated by the laser diffraction method compared to other methods such as pipette analyses (Konert and Vandenberghe, 1997; Beuselinck et al., 1998; Mason et al., 2003, 2011; Polakowski et al., 2014).

\subsection{Analysis of quartz grain size}

As a first step in quartz separation, air-dried bulk sediment samples ( $2 \mathrm{~g}$ each) were treated with $30 \% \mathrm{H}_{2} \mathrm{O}_{2}(10 \mathrm{ml} / \mathrm{sample})$ for 24 hours to remove organic matter. Subsequently, $50 \mathrm{ml}$ of $6 \mathrm{~N}$ hydrochloric acid $(\mathrm{HCl})$ was added and the solution boiled at $90-100{ }^{\circ} \mathrm{C}$ for 1 hour to remove carbonates and iron oxides (Xiao et al., 1995; Sun et al., 2000). Quartz was isolated by the sodium pyrosulfate fusion-hydrofluorosilicic acid method (Syers et al., 1968). In this procedure $10 \mathrm{~g}$ of $\mathrm{Na}_{2} \mathrm{~S}_{2} \mathrm{O}_{7}$ was mixed with $1 \mathrm{~g}$ of the pretreated samples and fused in ceramic crucibles to remove clay minerals, micas and other layer silicates. The resulting residue was washed 3 times with $10 \% \mathrm{HCl}$, then boiled with $0.5 \mathrm{~N} \mathrm{NaOH}$ for 2.5 minutes, washed again in $10 \% \mathrm{HCl}(3$ times) and subsequently washed in distilled water. To remove feldspars and amorphous silica relics, the residue was treated with $20 \mathrm{ml}$ of $30 \% \mathrm{H}_{2} \mathrm{SiF}_{6}$ for 3 to 6 days at room temperature and finally washed with distilled water. The above procedure resulted in pure quartz separates without affecting the grain size, grain shape and surface textures of the quartz crystals, as has been proven by SEM imaging (Fig. 3). Quartz GS measurements were done using the same Malvern Mastersizer 3000 laser analyzer that was used for analyzing 
bulk loess and paleosol samples. Samples were measured 3 times in wet dispersion mode and finally averaged to yield particle size distributions.

All particle size statistics (mean: $M_{s}$, median: $M_{d} / D_{50}, D_{90}$, etc.) and the volume percentage values of various grain size fractions for both bulk loess and the quartz separates were calculated from the Mastersizer 3000 software outputs using the latest, 8.0 version of GRADISTAT (Blott and Pye, 2001).

\subsection{Magnetic susceptibility measurements}

Mass-specific magnetic susceptibility (MS) was measured at two operating frequencies $(0.47$ and $4.7 \mathrm{kHz}$ ) using an MS2B Dual Frequency Sensor linked to a Bartington Ltd. MS3

Susceptibility Bridge. Sample powders were filled in $10 \mathrm{ml}$ plastic containers and empty container and sample masses were measured using a Kern PCB 250-3 high precision balance (reproducibility: $\pm 0.001 \mathrm{~g}$ ).

The absolute frequency-dependent susceptibility, $\chi_{\mathrm{FD}}=\chi_{\mathrm{LF}}-\chi_{\mathrm{HF}}$, allows the determination of the concentration of magnetic particles over a small grain size window across the superparamagnetic (SP)/stable single domain (SSD) boundary (Liu et al., 2012). By changing the observation time (i.e. frequency) a fraction of SSD grains turn superparamagnetic at a decreased frequency causing a sharp increase in magnetic susceptibility (Maher, 1986; Heller et al., 1991; Dearing et al., 1996; Worm, 1998). Since these grains are thought to form in situ in soils during pedogenesis (Maher and Taylor, 1988; Zhou et al., 1990), $\chi_{\mathrm{FD}}$ is considered as a proxy of pedogenesis (Heller et al., 1993; Maher and Thompson, 1995; Liu et al., 2007;

Buggle et al., 2014). To calculate the magnetic susceptibility contribution from SP/SSD particles, called the pedogenic susceptibility $\left(\chi_{\mathrm{P}}=\chi_{\mathrm{LF}}-\chi_{\mathrm{B}}\right)$, we used an $\chi_{\mathrm{LF}}$ vs. $\chi_{\mathrm{FD}}$ diagram to estimate the background susceptibility $\left(\chi_{\mathrm{B}}\right)$ representing the eolian detrital input (Forster et al., 1994). From this diagram $\chi_{\mathrm{B}}=1.82 \times 10^{-7} \mathrm{~m}^{3} \mathrm{~kg}^{-1}$ (Fig. 4) and $\chi_{\mathrm{P}}$ can be calculated, which 
records pedogenesis quantitatively (Forster et al., 1994). Using the $\chi_{\mathrm{P}}$ record, the effects of pedogenesis on grain size proxies can be separated from other factors. This can be done by examining the major down-profile variations and trends of $\chi_{P}$ qualitatively, and of course not on a quantitative basis.

\section{Background and theory}

\subsection{The physics of loess particle mobilization, transport and deposition}

To reach robust and solid interpretations of loess PSD variations in the context of paleoenvironmental changes, the nature and characteristics of major factors exerting control on grain size distributions must be clearly understood. Such influential factors include the main flow characteristics of the atmospheric boundary layer, the mobilization and transport modes of particles, and properties of soils and aeolian surfaces. These issues will be reviewed in this section below. Note, however, that in this paper we avoided discussing the production mechanisms of silt-sized mineral particles, but the interested reader is referred to works by Smalley and Vita Finzi (1968), Whalley et al. (1982), Wright and Smith (1993), Wright (1995, 2001), Smalley (1995), Assallay et al. (1998), Wright et al., (1998), Smith et al. (2002), and Muhs (2013). It must also be noted here that some of these mechanisms, such as frost weathering or granitoid weathering, produce quartz grains with different size characteristics. While frost weathering is capable of producing more silt-sized quartz grains, granitoid weathering profiles are often considered to be deficient in silt-sized material and rich in sand- and clay-sized particles (Wright, 2007). Subsequently, these grains are released to sedimentary systems by glacial, fluvial and/or aeolian erosion and become the starting material of loess formation. Although the effect of these production mechanisms on loess PSDs is likely to be diminished by sorting during aeolian transport and depositional 
processes, they may still exert control on PSDs through sediment availability, as will be discussed below.

\subsubsection{Particle mobilization and transport by wind}

\subsubsection{Wind, turbulence and shear stress in the atmospheric surface layer}

The layer of air that is strongly affected by the atmosphere-surface exchanges of momentum, energy and mass on time scales less than a day is called the atmospheric boundary layer, and has a typical depth of $1 \mathrm{~km}$ (Stull, 1988). In this layer the flow is turbulent (Greeley and Iversen, 1985; Wyngaard, 2010). The lowermost layer of the atmospheric boundary layer in which wind speed, temperature and aerosol concentration vary rapidly with height is named the atmospheric surface layer. In the atmospheric surface layer turbulent kinetic energy is generated mainly by wind shear, with a secondary contribution from buoyancy due to air heated at the surface, and dissipated through a cascade process from large to small eddies and eventually to molecular motion (Stull, 1988; Shao, 2008). Wind in this layer increases with height and horizontal wind momentum is transferred downwards by viscosity and turbulent eddies, where it is dissipated at the surface. This vertical flux of horizontal air momentum is also known as the wind shear stress and since momentum transfer in the flow is realized by both turbulent and molecular motions, the total wind shear stress equals to

$$
\tau_{T}=\tau_{R}+\tau_{M}
$$

, where $\tau_{R}$ and $\tau_{M}$ are the Reynolds and viscous shear stress, respectively (Shao, 2008).

Considering that the turbulent momentum flux exceeds the viscous momentum flux by several orders of magnitude for turbulent flows (White, 2006), the total shear stress is almost identical to the Reynold stress, i.e. (Stull, 1988)

$$
\tau_{T} \approx K \rho_{a} \frac{\partial \bar{U}(z)}{\partial z}
$$


Here $K$, the eddy (or turbulent) viscosity quantifies the transport of momentum in turbulent flows and $U(z)$ is the mean horizontal air velocity at a height $z$ above the surface (Kok et al., 2012). Under conditions of neutral atmospheric stability, the eddy viscosity can be written as (Prandtl, 1935; Stull, 1988)

$$
K=\kappa u_{*} Z
$$

, where $\kappa=0.4$ is the von Kármán constant and

$$
u_{*}=\sqrt{\tau_{T} / \rho_{a}}
$$

is the friction (or shear) velocity (Greeley and Iversen, 1985), with $\rho_{a}$ being the air density. It must be noted here that $u *$ is not the speed of the airflow but another expression for the shear stress at the surface (Raupach and Lu, 2004; Shao, 2008). Using the above expressions, $u *$ can be related to the mean wind speed $U(z)$ at height $z$ by the logarithmic law of the wall (also called the Prandtl-von Kármán equation; von Kármán, 1930; Prandtl, 1935; Coles, 1956; Stull, 1988)

$$
\bar{U}(z)=\frac{u_{*}}{\kappa} \ln \left(\frac{z}{z_{0}}\right)
$$

, where $z_{0}$ is the aerodynamic surface roughness.

As mentioned above, turbulent flows are predominant in the atmospheric boundary layer, but very close to a smooth surface (see below) the flow is dominated by viscosity, meaning that most of the shear stress is produced through shearing of successive (laminar) fluid layers. This viscous or laminar sublayer has a typical thickness of $\sim 0.5 \mathrm{~mm}$ for wind conditions relevant for aeolian transport (Stull, 1988; Shao, 2008; Kok et al., 2012). The exact thickness, and even the existence, of the viscous sublayer depends on the surface roughness, as denoted by the roughness Reynolds number (Shao, 2008; Kok et al., 2012)

$$
R e_{r}=\frac{u_{*} D_{r}}{v_{a}}
$$


with $D_{r}$ being the typical roughness element size, called the Nikuradse roughness, and $v_{a}$ being the kinematic viscosity of air $\left(v_{\mathrm{a}}=\mu_{a} / \rho_{a}\right.$, where $\mu_{a}$ is the dynamic viscosity of air). For closely and homogeneously packed, nearly spherical elements such as sand particles $D_{r} \approx D_{p}$ (particle diameter) and the surface roughness is $\sim D_{p} / 30$ (Greeley and Iversen, 1985; Kok et al., 2012). For $R e_{r}>\sim 60-70$, the turbulent mixing generated by the roughness elements is sufficient to destroy the viscous sublayer and the flow is termed aerodynamically rough (Nikuradse 1933). In contrast, for $R e_{r}<\sim 4-5$ the roughness elements are too small to substantially perturb the viscous sublayer and the flow is termed aerodynamically smooth (Nickling and McKenna Neuman, 2009; Kok et al., 2012).

\subsubsection{Threshold of particle motion}

Wind erosion and associated sediment entrainment on a surface occurs when aerodynamic lift and drag forces $\left(F_{L}\right.$ and $\left.F_{D}\right)$ acting on a stationary particle are able to overcome the gravity and inter-particle cohesive forces $\left(F_{G}, F_{C}\right)$ resisting the sediment movement (Shao and Lu, 2000). Particle lift-off is driven by $F_{L}$ and $F_{D}$, and since these forces are related to the wind shear near the surface, they are also functions of the friction velocity, $u *$ (Iversen and White, 1982; Shao, 2008). The minimum velocity at which the wind erosion of a surface is initiated and exposed soil particles are set in motion called the threshold friction velocity, $u * *_{t}$ (also called the fluid threshold shear velocity, Greeley and Iversen, 1985; Shao, 2008; Nickling and McKenna Neuman, 2009), which is affected by many factors including soil texture, soil moisture, soil salt content and mineralogy, surface crust and the distribution of vegetation and roughness elements (Shao and Lu, 2000). For soils with uniform and spherical particles spread loosely over a dry and bare surface, $u_{* t}$ can be expressed as a function of particle size. Simply considering the balance between the aerodynamic drag and the gravity force, Bagnold (1941) suggested an expression of $u_{*}(d)$ 


$$
u_{* t}=A_{B} \sqrt{\frac{\rho_{p}-\rho_{a}}{\rho_{a}} g D_{p}}
$$

, where $g$ is acceleration due to gravity, $\rho_{p}$ is particle density, and $A_{B} \approx 0.10$ is an empirical coefficient. Later results by Iversen and White (1982) indicated that $A_{B}$ depends on cohesive forces and the particle friction Reynolds number at the threshold friction velocity, defined as

$$
R e_{* t}=\frac{u_{* t} D_{p}}{v_{a}}
$$

While equation (3.7) is thus in good agreement with the experimental data for $>100 \mu \mathrm{m}$ grains, it is unable to capture the $u_{*_{t}}$ minimum at $75-100 \mu \mathrm{m}$ and its rapid increase with decreasing particle size, $D_{p}$ (Fig. 5). Iversen et al. (1976) and Iversen and White (1982) recognized that this latter phenomenon is related to inter-particle cohesion and proposed an improved expression of $u_{*_{t}}(d)$ (shown in Fig 5, but not detailed here) by including aerodynamic lift and inter-particle cohesion forces $\left(F_{L}, F_{C}\right)$ beyond gravity and drag forces $\left(F_{G}\right.$ and $\left.F_{D}\right)$ considered by Bagnold (1941). Later on, by showing that $A_{B}$ is only weakly dependent on $R e_{*_{t}}$ and arguing that the inter-particle cohesive force should be proportional to $D_{p}^{-1}$, Shao and Lu (2000) obtained a simple expression for calculating $u_{* t}$

$$
u_{* t}=A_{N} \sqrt{\frac{\rho_{p}-\rho_{a}}{\rho_{a}} g D_{p}+\frac{\gamma}{\rho_{a} D_{p}}}
$$

, with $A_{N}$ being $0.0123^{1 / 2}$ and $\gamma$ being $3 \times 10^{-4} \mathrm{~N} \mathrm{~m}^{-1}$ (Shao and Lu, 2000; Kok and Renno, 2006). As shown in Fig. 5, in which the different threshold curves are compared with observed data, a minimum of the fluid threshold occurs at particle sizes of $\sim 75-100 \mu \mathrm{m}$. For larger particles, the balance between the aerodynamic forces and the gravity force determine the magnitude of the threshold friction velocity, while for smaller particles $u_{* t}$ is determined by the balance between the aerodynamic and cohesive forces. The occurrence of the threshold minimum at $\sim 100 \mu \mathrm{m}$ implies that relatively high wind speeds are required to aerodynamically lift dust particles $(<20 \mu \mathrm{m})$. Since sand-sized and very coarse silt particles 
are thus lifted well before dust is, dust aerosols (i.e. fine silt and clay particles in loess) are predominantly emitted by the impacts of saltating particles on the soil surface (Gillette et al., 1974; Shao et al., 1993; Sow et al., 2009), which provide the necessary additional force to overcome inter-particle cohesive forces. However, as will be discussed later in section 3.1.1.9 direct aerodynamic resuspension of dust may often occur without saltation (Loosmore and Hunt, 2000; Roney and White, 2004; Macpherson et al., 2008; Klose and Shao, 2014). Although the above expressions are useful to understand the underlying physics of particle mobilization, their applicability is limited to dry, bare surfaces of sand. A number of surface and soil-related factors are able to strongly affect the magnitude of $u * t$, including soil texture, soil moisture, salt concentration, surface crust and the presence of roughness elements on the surface such as vegetation. The effects of these factors are discussed below.

\subsubsection{Soil moisture effects on the fluid threshold}

The near-surface moisture content strongly contributes, through adhesion and capillary effects, to the binding forces keeping particles together and thereby inhibiting the initiation of particle motion (Chepil, 1956; Belly, 1964; McKenna Neuman and Nickling, 1989; Cornelis and Gabriels, 2003). Inter-particle cohesion in the two phase solid-air state results from electrostatic and van der Waals forces (Smalley, 1970), while bonding forces between two particles in the three-phase state solid-air-liquid (i.e. for wet sediments) are due to liquidbridge bonding (capillary forces) and adsorbed-layer bonding (adhesion forces) (Cornelis et al., 2003; Shao, 2008). In the Shao and Lu (2000) threshold model presented above in 3.1.1.2., in which ideal conditions (dry soil, spherical particles) are assumed, the inter-particle forces, $F_{i}$, are attributed to only van der Waals and electrostatic forces and $F_{i}$ is proportional to particle size, $D_{p}$,

$$
F_{i}=\beta_{c} D_{p}
$$


, leading to Eq. (3.9). Considering the effect of soil moisture McKenna Neuman (2003)

suggested a modified form of Eq. (3.10) as

$$
F_{i}=\beta_{c} D_{p}+\psi_{m} A_{c}
$$

342 , with $\psi_{m}$ being the matric potential (matric suction, in $\mathrm{Pa}$ ), defined as the energy required to

343 remove the capillary water to the vapor phase, and $A_{c}$ is the contact area between adjacent

344 grains. While the parameter $\beta_{c}$ includes the van der Waals and electrostatic forces, the second

345 term represents capillary forces associated with soil moisture. Based on this modification, the

346 threshold friction velocity under the influence of moisture, $u *_{t w}$, can be written as

$$
u_{* t w}=A_{2} A_{N} \sqrt{\frac{\rho_{p}-\rho_{a}}{\rho_{a}} g D_{p}+\frac{\gamma^{\prime}}{\rho_{a} D_{p}}}
$$

347 For further details on parameters $A_{2}$ and $\gamma^{\prime}$ included in Eq. (3.12) the reader is referred to 348 McKenna Neuman (2003).

349 For sandy soils the inter-particle forces contributed by adsorbed layers of water are negligible 350 when the soil is relatively wet, while adsorbed water may have a significant influence in relatively dry, clayey soils. Thus, the model by McKenna Neuman and Nickling (1989) (not discussed here) and that of McKenna Neuman (2003) is applicable only to sandy soils. The McKenna Neuman and Nickling (1989) model was generalized by Fécan et al. (1999) for clay soils, obtaining the empirical expressions of

$$
\begin{array}{cc}
u_{* t w}=u_{* t} & \text { for } \theta<\theta^{\prime} \\
u_{* t w}=u_{* t} \sqrt{1+1.21\left(\theta_{v}-\theta_{v}^{\prime}\right)^{0.68}} & \text { for } \theta>\theta^{\prime}
\end{array}
$$

, where $\theta_{v}$ is the volumetric water content of soil, and the air-dry soil moisture, $\theta_{v}{ }^{\prime}$, is related

to the soil clay content, $c_{s}$, through

$$
\theta_{v}^{\prime}=0.0014 c_{s}^{2}+0.17 c_{s}
$$

357 Although this parameterization ignores inter-particle adhesion forces, it is widely used in dust 358 emission modeling (e.g. Zender et al., 2003). 
While capillary forces caused by liquid-bridge bonding dominate at high soil moisture conditions, these forces are negligible at low humidity conditions $\left(\psi_{m}<-10 \mathrm{MPa}\right.$; Tuller and Or, 2005), and thus adhesion forces are substantial for soils with either a high clay content and/or a low soil moisture content (Cornelis and Gabriels, 2003; Cornelis et al., 2004a; Ravi et al., 2004, 2006). In the model developed by Cornelis et al. (2004a), both the capillary and adhesion forces are included, and $u *_{t w}$ is given by

$$
u_{* t w}=A_{C o} \sqrt{\frac{\rho_{p}-\rho_{a}}{\rho_{a}} g D_{p}}
$$

, where

$$
A_{C o}=\sqrt{A_{C o 1}\left[1+\theta_{g}+A_{C o 2} \frac{1}{\left(\rho_{p}-\rho_{a}\right) g D_{p}^{2}}\left(1+A_{C o 3} \frac{\gamma_{s t}^{2} D_{p}}{\left.\left|\psi_{m d}\right| e^{-6.5 \frac{\theta_{g}}{\theta_{g 1.5}}}\right)}\right)\right.}
$$

, with model parameters of $A_{C o l}, A_{C o 2}$ and $A_{C o 3}$ being $0.013 \mathrm{~N} \mathrm{~m}^{-1}, 1.7 \times 10^{-4} \mathrm{~N} \mathrm{~m}^{-1}$, and $3 \times 10^{-14} \mathrm{~N}^{-1} \mathrm{~m}^{-1}$ (Cornelis et al., 2004a,b). $\psi_{m d}$ is the matric potential at oven dryness $\left(\approx-10^{3}\right.$ $\mathrm{MPa}), \theta_{g}$ is gravimetric water content, $\theta_{g}$ is the gravimetric water content at $-1.5 \mathrm{MPa}$, and $\gamma_{s t}$ is the surface tension of water (Cornelis et al., 2003, 2004a,b). As shown in Fig. 6 which represents measured data and three models including that of Cornelis et al. (2004a), soil moisture significantly affects the threshold friction velocity of different soil surfaces. Compared to their uniform oven-dried value of $0.31 \mathrm{~m} \mathrm{~s}^{-1}$ the threshold friction velocities required to initiate particle motion for soils from loamy fine sand to clays are higher by $\sim 20-220 \%$ for gravimetric water contents ranging from 1.2 to $16.4 \%$ (Selah and Fryrear, 1995; Fig. 6a).

Air-dry soils with soil matric potentials of $\psi_{m}<-30$ to $-100 \mathrm{MPa}$ are characteristic for arid/semi-arid regions during the dry season (Ravi et al., 2004). For rainless periods of this season in such regions, which were major depositional areas of loess sediments during 
glaciations (Pye, 1995), changes of the surface soil moisture are strongly related to air humidity fluctuations. Ravi et al. (2006) found that for relative humidity (RH) below $40 \%$ and above $65 \% u_{*}$ increases with air humidity for air-dry soils (Ravi et al., 2006). The reason for the increase of $u_{* t w}$ for $\mathrm{RH}>65 \%$ is that water starts condensing into liquid bridges from RH 65-70\% leading to an increase of inter-particle cohesive forces, and eventually $u_{*}$. Indeed, measurements of the threshold friction velocity of five silt loams on the Columbia Plateau reveal that significant increase in $u_{* t w}$ occurs from $\sim 6 \%$ gravimetric water content and matric potentials of -25 to $-1 \mathrm{MPa}$ (Sharratt et al., 2013).

\subsubsection{Temperature effects on the fluid threshold}

It was recognized early that the carrying capacity of a cold air stream of a given velocity is higher than that of a warm one (Selby et al., 1973; Pye and Tsoar, 1990), as the aerodynamic drag force, $F_{D}$,

$$
F_{D}=K_{D} \rho_{a} u_{*}^{2} D_{p}^{2}
$$

is directly proportional to air density $\rho_{a}$, which increases as temperature drops (Greeley and Iversen, 1985; McKenna Neuman, 1993, 2003; Shao, 2008). With cooling, the kinematic viscosity of air, $v_{a}$, decreases and since $K_{D}$, which is a dimensionless coefficient of order $1-10$, is viscosity dependent at low particle friction Reynolds numbers $\left(R e_{*_{t}}<3.5\right)$ the magnitude of $F_{D}$ is affected by viscosity, but its effect on $F_{D}$ is opposite to that of air density (McKenna Neuman, 2003; Shao, 2008). Interestingly, it was shown in wind tunnel experiments of McKenna Neuman (2003) that $K_{D}$ is unaffected by the reduced kinematic viscosity at lower temperatures. This was explained with the observation that both $v_{a}$ and $u_{*}$ were found to decrease by $20-30 \%$ with reduced temperatures and this way the temperature effect 'cancels out' in the Reynolds number (McKenna Neuman, 2003). Although it thus seems that the drag force is not affected by the reduced viscosity of air at lower temperatures 
through $K_{D}$ at low Reynolds numbers, it plays a role in modifying the turbulent wake shed by individual particles (McKenna Neuman, 2003).

A further effect of lower temperatures on the threshold friction velocity is associated with the reduced inter-particle cohesion. The wind tunnel experiments by McKenna Neuman (2003) demonstrated that the primary effect of climate on the fluid threshold is through the interparticle cohesion force. This is because cooling reduces the amount of water vapor in air and also the matric potential at which this water adsorbed on surface particles. In the study cited above, the critical tractive stress $\left(\tau_{* t}=\rho_{a} u_{* t}^{2}\right)$ was found to be lower by $25-30 \%$ at $-12{ }^{\circ} \mathrm{C}$ as compared to $32^{\circ} \mathrm{C}$. Evidence from the McKenna Neuman (2003) experiments reveal that colder airflows of a given velocity are able to entrain larger particles than warmer winds of the same velocity. Since particles are set in motion at lower threshold friction velocities aeolian surfaces are more active at lower temperatures, i.e. particle transport is less intermittent (see section 3.1.1.8., and Stout and Zobeck, 1997).

Loess deposits were formed during glacial periods characterized by significant surface cooling and reduction of precipitation, reaching $5-10{ }^{\circ} \mathrm{C}$ and $100-300 \mathrm{~mm}$ for the mid-latitude loess regions during the LGM (Kageyama et al., 2006; Ramstein et al., 2007; Wu et al., 2007; Bartlein et al., 2011). Based on the discussion above, coarser loess grain size may at least partly be explained by decreasing air temperatures during glaciations, while considerable drops in both temperature and rainfall may have led to more frequent and larger dust emissions from aeolian surfaces, and consequently, increased loess sedimentation.

\subsubsection{Surface crust, soil salts and the fluid threshold}

As moisture evaporates from a soil, discrete sedimentary particles are able to aggregate into erosion-resistant structural units that may finally form a continuous sheet, known as surface crust (Nickling and McKenna Neuman, 2009). Early work by Gillette et al. (1980, 1982) 
demonstrated that even a weak crust (modulus of rupture, $M_{r} \geq 0.07 \mathrm{MPa}$ ) is able to protect the soil surface and increase the threshold friction velocity. Crust strength was shown to be dependent on soil clay content and $\mathrm{CaCO}_{3}$ strengthened the crust proportional to the soil's clay fraction. While the majority of $\mathrm{CaCO}_{3}$ is found mostly as inactive clasts or inert particles in the soil, it often acts as binding agent once some fractions of $\mathrm{CaCO}_{3}$ are solubilized, for instance following a precipitation event.

Wind tunnel tests performed on fine sand revealed that even low concentrations of soluble salts $(0-7 \mathrm{mg} \mathrm{NaCl}$ or $\mathrm{KCl} / \mathrm{g}$ soil) increases the fluid threshold shear velocity by the formation of cement-like bonds between individual grains (Nickling and Ecclestone, 1981). In a subsequent study, Nickling (1984) demonstrated that $\mathrm{CaCl}_{2}$ and $\mathrm{MgCl}_{2}$ are somewhat more effective in increasing the threshold friction velocity than $\mathrm{NaCl}$ and $\mathrm{KCl}$. For both the monoand divalent salts exponential relationships were found between salt concentration and $u_{*_{t}}$ At lower concentrations $(<\sim 2.5 \mathrm{mg})$, salt forms cement-like bonds at the solid to solid contacts, while at higher concentrations the precipitate begins to fill the pore space and encases the soil grains. The encased aggregates protrude into the air stream and finally they will be entrained at lower shear velocities as a result of increased fluid drag. This process may lead to an increasing supply of grains into the air stream and the destabilization of the crust.

Beyond clay- and salt crusts, biological crusts can also increase the threshold friction velocity. Polysaccharides extruded by cyanobacteria and microfungi entrap and bind soil particles together, and filamentous growths entangle loose particles together thereby creating soil aggregates (Belnap and Gardner, 1993; McKenna Neuman et al., 1996; Belnap, 2003). As shown by Belnap and Gillette (1998), even a thin cyanobacterial crust on a sandy surface is able to more than double the threshold friction velocity (from 0.3 to $0.7-0.8 \mathrm{~m} \mathrm{~s}^{-1}$ ), while $u_{*}$ for sandy soils covered with either a thick cyanobacterial or a well-developed lichen crust is $\sim 8-15$ times higher than a sandy soil with no crust. Obviously, the sediment transport rate and 
also dust emissions from a soil is strongly dependent on the presence or absence of surface crust and its destruction as affected by particle impact (Zobeck, 1991; Rice et al., 1996, 1997; Rice and McEwan, 2001; Houser and Nickling, 2001; Eldridge and Leys, 2003; Rajot et al., 2003; Goossens, 2004; McKenna Neuman et al., 2005; Langston and McKenna Neuman, 2005; O’Brien and McKenna Neuman, 2012). The presence of a soil crust does not only influence mineral particle emissions from aeolian surfaces in potential loess source areas, but biological crusts are assumed to be central to loess formation by acting as dust traps and preventing erosion (Svircev et al., 2013).

\subsubsection{Roughness elements and the fluid threshold}

While the inertial sublayer of the atmospheric boundary layer can be described by the logarithmic wind profile (Eq. 3.5) where the flow is fully developed and turbulent with neutral stability, this profile is altered over surfaces covered by tall and/or dense vegetation or other large roughness elements like boulders (Nickling and McKenna Neuman, 2009; King et al., 2005). In such cases, the wind velocity profile is displaced upwards and given by

$$
\bar{U}(z)=\frac{u_{*}}{\kappa} \ln \left(\frac{z-d}{z_{0}}\right)
$$

, where $d$ is the zero plane displacement height representing the upward displacement of the mean momentum sink (Jackson, 1981). Both the surface roughness $\left(z_{0}\right)$ and $d$ are functions of height, density, shape and flexibility of roughness elements (Thom, 1971). The layer below the mean momentum sink is called the roughness sublayer having a spatially uniform flow characteristic if roughness is dense and an increasingly heterogeneous flow as the roughness becomes sparser. A measure of the effect of roughness elements on the flow regime is the roughness density, $\lambda$

$$
\lambda=\frac{n_{r} b_{r} h_{r}}{S}
$$



and findings above, Raupach (1992) and Raupach et al. (1993) obtained an expression for $R_{t}$

$$
R_{t}=\frac{u_{* t}}{u_{* t r}}=\sqrt{\frac{1}{(1-m \sigma \lambda)(1+m \beta \lambda)}}
$$

495 , where $\sigma$ is the basal to frontal area ratio of the roughness element, $\beta=C_{R} / C_{S}$ is the ratio of 496 drag coefficient of a roughness element $\left(C_{R}\right)$ and the bare soil $\left(C_{S}\right)$, and $m$ is a parameter that 
accounts for the spatial non-uniformity of surface shear stress distribution. Subsequent tests and evaluations of the Raupach et al. (1993) model further refined values of the $\beta$ and $m$ parameters (Musick et al., 1996; Wolfe and Nickling, 1996; Crawley and Nickling, 2003), and revealed its good predictive capacity for wind tunnel experiments using solid objects, but less favorable performance in field environments (King et al., 2005). Extensions of the model for high roughness densities $(\lambda>1)$ and an improvement in model formulation were presented in Shao and Yang (2008) and Walter et al. (2012).

A major cause of the discrepancies between model predictions and field measurements of the threshold friction velocity ratio or the horizontal sediment flux is that the effects of the spatial distribution (Okin and Gillette, 2001), porosity, complex geometry and flexibility of vegetation on the drag partition are not captured by roughness density, $\lambda$. For instance, Gillies et al. (2002) demonstrated that vegetation has greater potential to absorb momentum than solid elements because of its porous and flexible nature. Air flow through the vegetation creates different wake characteristics than does air flow through solid objects, and the shear stress increases from a small value immediately downwind of a plant and asymptotically approaches the surface shear stress further downwind, thereby creating an area of reduced, but not zero shear stress (Okin, 2008). Using the data of Bradley and Mulhearn (1983), Okin (2008) defines a 90\% shear stress recovery within a downwind distance of 10 times the plant height in broad agreement with observations of Minvielle et al. (2003). The new model for shear stress partitioning on vegetated surfaces by Okin (2008) utilizes knowledge of the unvegetated gap size to characterize the spatial variability of shear stress on the surface and is able to simulate significant horizontal particle flux at high lateral cover, which is consistent with observations.

The role of vegetation as a dust trap in loess formation was recognized early (Pye, 1995), but its influence on loess particle mobilization and horizontal dust transport is less well 
understood. Loess landscapes during the last glacial period were mainly characterized by boreal forest steppe to open steppe/grassland with mosaic-like shrub vegetation (Willis et al., 2000; Rudner and Sümegi, 2001; Sümegi and Krolopp, 2002; Willis and Andel, 2004; Jiang and Ding, 2005; Sümegi et al., 2013; Feurdean et al., 2014; Magyari et al., 2014). Grasslands are significant dust sources (Shinoda et al., 2011), and the horizontal dust mass flux for grasslands was found to be an order of magnitude higher than for forest ecosystems (Breshears et al., 2003). At the same time, the spatial patterns of sediment erosion and deposition around grassy vegetation were found to be mosaic-like and different for various canopy densities depending on the different flow regimes created by the vegetation elements (Suter-Burri et al., 2013). This implies that the spatial patterns of grassy vegetation may also have had a profound influence on the grain size distributions of loess sediments during the wind-driven erosion-deposition events.

\subsubsection{Modes of transport}

Loess particle diameters fall within a size range of 0.1 to $~ 500-700$ micron. From the point of view of transport properties particles with diameters of $>0.2 \mu \mathrm{m}$ are considered to be in the continuum regime with Knudsen number, defined as

$$
K n=2 \lambda_{a} / D_{p}
$$

, lower than 1. In this regime the gas appears to the particle as a continuum because the particle diameters greatly exceeds $\lambda_{a}$, the mean free path of air molecules $\left(0.0639 \mu \mathrm{m}\right.$ at $15^{\circ} \mathrm{C}$ and $50 \% \mathrm{RH}$; Jennings, 1988), so the usual equations of continuum mechanics, and not those of statistical mechanics, apply (Flagan and Seinfeld, 1988).

Once airborne, the extent to which the wind affects particle trajectories is determined by particle inertia, drift/gravity and drag forces (Csanady, 1963; Raupach, 2002). Gravity gives heavy particles a settling velocity relative to the fluid causing them to continually change their 

number

$$
R e_{p t}=w_{t} D_{p} / v_{a}
$$

562 (Malcolm and Raupach, 1991; Chen and Fryrear, 2001; Durán et al., 2011). An explicit

fluid environment (Raupach, 2002). Greater inertia of heavy particles causes them to respond more slowly to accelerations than the fluid and the velocity history of a particle will differ from a gas particle (Csanady, 1963). In a given turbulent wind field, smaller particles follow the motions of air more closely than the larger ones because the characteristic time required for the particle to respond to a change in wind speed, defined as (Anderson, 1987; Flagan and Seinfeld, 1988),

$$
t_{p}=\frac{\rho_{p}-\rho_{a}}{\rho_{a}} \frac{D_{p}^{2} C_{c}}{18 v_{a}}
$$

, where $C_{c}$ is the Cunningham slip correction factor which accounts for non-continuum effects Rader (1990), decreases with decreasing particle size.

In the absence of turbulence, the particle vertical velocity will approach its settling, or terminal velocity, $w_{t}$, which is the highest velocity attainable by an object in free fall. It occurs once the sum of the drag force $\left(F_{D}\right)$ and buoyancy equals the downward force of gravity $\left(F_{G}\right)$ acting on the object. Since the net force on the object is zero it experiences zero acceleration $\left(d \overline{w_{p}} / d t=0 ;\right.$ where $\overline{w_{p}}$ is the average vertical velocity of the particle; Anderson, 1987;

Malcolm and Raupach, 1991; Shao, 2008), and $w_{t}$ is

$$
w_{t}=\sqrt{\frac{\rho_{p}-\rho_{a}}{\rho_{a}} \frac{4 g D_{p}}{3 C_{d}\left(R e_{p t}\right)}}
$$

, where $C_{d}$ is the drag coefficient, which depends on the particle terminal velocity Reynolds analytical solution of Eq. 3.24 valid in the Stokes regime $\left(R e_{p t}<1=D_{p}<\sim 25 \mu \mathrm{m}\right.$, with $\left.C_{d}=24 / R e_{p t}\right)$ is given by 


$$
w_{t}=g t_{p}=\frac{\rho_{p}-\rho_{a}}{\rho_{a}} \frac{g D_{p}^{2} C_{c}}{18 v_{a}}
$$

, which is the Stokes Law equation (Malcolm and Raupach, 1991; Durán et al., 2011). Since $C_{d}$ depends on $w_{t}$ through $R e_{p t}$, Eq. 3.24 must be solved numerically for $R e_{p t}>1$. By finding an empirical expression of $C_{d}\left(R e_{p t}\right)$ appropriate for $R e_{p t}<2 \times 10^{5}$, such as the Schiller-Naumann drag expression (Loth, 2008)

$$
C_{d}=\frac{24}{R e_{p t}}\left(1+0.15 R e_{p t}^{0.687}\right)
$$

and using that (Flagan and Seinfeld, 1988)

$$
C_{d} R e_{p t}^{2}=\frac{4}{3} \frac{D_{p}^{3} \rho_{a}\left(\rho_{p}-\rho_{a}\right) g}{v_{a}^{2}}
$$

,$w_{t}$ can be calculated numerically for the whole range of particle sizes in loess. Such a solution together with other expressions for $w_{t}$ and measured values of natural sands are shown in Fig. 7. As can be seen from this figure and demonstrated by Eqs. 3.24 and $3.26 w_{t}$ is proportional to $D_{p}{ }^{2}$ for small particles $\left(R e_{p t}<1\right)$ and $D_{p}{ }^{1 / 2}$ for larger (Shao, 2008). In fact, the fall velocity is influenced by both the aerodynamic properties of particles (surface area, shape, density) and the fluid properties (density and viscosity; Malcolm and Raupach, 1991; Chen and Fryrear, 2001; Farrell and Sherman, 2015). For two particles having the same size and shape, but different density the heavier (more dense) will settle faster, while for two particles with the same mass and density, the one with a larger surface area will settle slower (Farrell and Sherman, 2015).

Transport modes of particles are determined by the balance between the terminal velocity and the mean Lagrangian vertical velocity at which air parcels are dispersed upward by turbulence (Shao, 2008). Under neutral atmospheric conditions the latter is approximately $\kappa u_{*}$ (Raupach and Lu, 2004, Shao, 2008) and particles tend to move dispersively, i.e. in suspension, if $w_{t}<<$ $\kappa u *$. Pure suspension, in which particles essentially move with the fluid, occurs when the 
particle's terminal velocity is small compared to the friction velocity (Tsoar and Pye, 1987). Gillette et al. (1974) have found that the upper limit of pure suspension is $w_{t} / u * \approx 0.12$ to 0.7 , while Tsoar and Pye (1987) further subdivided this for short-term $\left(0.1<w_{t} / u_{*}<0.7\right)$ and longterm suspension regimes $\left(w_{t} / u *<0.1\right.$; Fig. 8$)$. The residence time of long-term suspended dust $(<\sim 20 \mu \mathrm{m})$ particles may be days or weeks and they can be transported thousands of kilometers from source regions (Tsoar any Pye, 1987, Pye, 1987). Pure saltation, when the particle trajectories are not affected by the vertical turbulent velocity fluctuations, occurs from $w_{\downarrow} / u *>\sim 1-2$ (Tsoar and Pye, 1987; Shao, 2008; Nickling and McKenna Neuman, 2009), and these larger particles saltate following ballistic trajectories (Ungar and Haff, 1987; Anderson and Haff, 1988). A sharp boundary between saltation and pure suspension does not exist and particles having semi-random trajectories ( 70-150 $\mu$ m; Anderson, 1987; Kok et al., 2012) influenced by both inertia and terminal velocity are considered to be transported in modified saltation $\left(0.7<w_{t} / u *<1\right.$; Hunt and Nalpanis, 1985; Nalpanis, 1985). As seen in Fig. 8, the transport modes of particles having different size are strongly dependent on the friction velocity, i.e. the intensity of atmospheric turbulence. For instance, a quartz particle with a diameter of $70 \mu \mathrm{m}$ may be transported in saltation or modified saltation in flows with weak wind shear and turbulence, as well as transported in short-term suspension in airflows with strong friction and turbulence.

\subsubsection{Saltation under transport- and supply-limited conditions}

Once the wind shear stress reaches a critical value, called the fluid threshold (Bagnold, 1941), a small number of particles are aerodynamically lifted into the air stream. Over flat, bare, dry sand surfaces the very fine and fine sand population $(\sim 70-250 \mu \mathrm{m})$ is the first to be moved by wind. After lifting, these particles are accelerated by the airflow into ballistic trajectories and bounce along the surface in a series of hops (Bagnold, 1941; Greeley and Iversen, 1985; 
Anderson and Haff, 1988; Nalpanis et al., 1993). After a few hops, some of these particles gain sufficient kinetic energy to eject or splash other particles from the soil to the air, with high-energy rebounds forming the saltation population and low-energy recoils the creeping or reptating population (Ungar and Haff, 1987). The newly ejected grains with high kinetic energy move downwind, impact the surface and eject an even larger number of stationary particles, causing an exponential increase in the number of grains in motion during the early stage of the saltation process (Bagnold, 1941; Ungar and Haff, 1987; Anderson and Haff, 1988, 1991; McEwan and Willets, 1991; Sorensen, 1991; Shao and Raupach, 1992). As more and more particles are entrained into the air, saltating particles extract momentum from the airflow and transfer this acquired momentum to the surface, thereby reducing the mean wind speed and increasing the surface roughness (Owen, 1964; Raupach, 1991; Shao and Raupach, 1992; McEwan and Willets, 1993; McKenna Neuman and Nickling, 1994; Shao and Li, 1999; Pähtz et al., 2012). The loss of fluid momentum limits the entrainment capacity of the flow and the particle ejection rate leading to an equilibrium state, called steady state saltation (Anderson and Haff, 1988), during which the particle concentration stays constant. Consequently, on average, each impacting grain produces a single outgoing grain during a collision with the bed, either by rebound or ejection (Ungar and Haff, 1987; Anderson and Haff, 1991, Kok and Renno, 2009; Durán et al., 2011). The properties of steady state saltation are largely determined by the splash process (Kok et al., 2012). Furthermore, since particle ejections through the splash process is more efficient than through aerodynamic drag (Owen, 1964; Mitha et al., 1986; Ungar and Haff, 1987; Raupach, 1991), saltation can be maintained at friction velocities $15-20 \%$ below the fluid threshold; this minimum shear velocity to sustain saltation is termed the impact threshold (Bagnold, 1941; Nickling and McKenna Neuman, 2009; Kok, 2010; Durán et al., 2011). 
While it is beyond the scope of this paper to provide an overview on the details of grain-bed interactions or the role of electrostatic forces and mid-air collisions in saltation (the interested reader is referred to reviews by Nickling and McKenna Neuman, 2009 and Kok et al., 2012 and references therein), some other aspects such as particle speed, saltation grain size and streamwise saltation flux under transport- and supply-limited conditions must be discussed. An aeolian transport system is considered transport-limited if the saltation flux is controlled only by the availability of wind momentum; that is, the surface can supply an unlimited amount of sediment. By contrast, in a supply-limited situation the amount of saltation flux is not controlled by the availability of wind momentum, but rather by the ability of the surface to supply grains to the airstream (Shao, 2008; Nickling and McKenna Neuman, 2009; Kok et al., 2012). In a transport-limited system and for steady state saltation, the speed of energetic particles moving higher up in the saltation layer increases with higher friction velocities, while the mean particle impact speed $\left(\overline{v_{l p}}\right)$ at the surface is independent of $u *$ (Rasmussen and Sorensen, 2008; Creyssels et al., 2009, Kok and Renno, 2009; Ho et al., 2011; Durán et al., 2011; Kok et al., 2012). At the same time, as shown explicitly by the simulations of Kok et al. (2014), the probability distribution of particle speeds at the surface broadens with increasing friction velocity and therefore an increasing fraction of impacting particles has very large impact speeds. Since larger particles require greater impact speeds to be splashed into saltation, the number of large particles entering saltation increases with friction velocity, causing a size shift of the saltation size distribution towards larger particle sizes (Kok and Renno, 2009), although in general the saltation size distribution in the range of 100-500 $\mu \mathrm{m}$ roughly matches the parent soil size distribution (Williams, 1964; Namikas, 2006; Kok and Renno, 2009; Kok et al., 2012). In contrast to transport-limited saltation where the mean impact speed of saltators remains constant with $u_{*}, \overline{v_{l p}}$ does increase with $u *$ for supplylimited conditions (Houser and Nickling, 2001; Ho et al., 2011), more likely resulting in a size 
659

660

661

662

663

664

665

666

667

668

669

670

671

67

67

674

675

shift of the saltation size distribution towards larger particle sizes with increasing friction velocities.

A basic measure of saltation is the vertically integrated streamwise saltation flux, $Q_{s}$ (in $\mathrm{kg}$ $\mathrm{m}^{-1} \mathrm{~s}^{-1}$; e.g. Shao, 2008), which is the integral over height $z$ of the streamwise sand flux density, $q(z)$ (in $\mathrm{kg} \mathrm{m}^{-2} \mathrm{~s}^{-1}$; Raupach and $\mathrm{Lu}, 2004$ )

$$
Q_{s}=\int_{0}^{\infty} q(z) d z
$$

On experimental and theoretical grounds, Bagnold (1941) proposed that $Q_{s}$ is proportional to the cube of the wind speed, and that

$$
Q_{s}=C_{B} \sqrt{\frac{D_{p}}{D_{250}}} \frac{\rho_{a}}{g} u_{*}^{3}
$$

, with $C_{B}=1.8$ for naturally graded sand and where $D_{250}$ is a reference diameter of $250 \mu \mathrm{m}$. The subsequent models of Kawamura (1951)

$$
Q_{s}=C_{K} \frac{\rho_{a}}{g} u_{*}^{3}\left(1-\frac{u_{* t}}{u_{*}}\right)\left(1-\frac{u_{* t}}{u_{*}}\right)^{2}
$$

, where $C_{K}=2.78$, and Owen (1964) or Lettau and Lettau (1978), just to mention some, all assumed that particle speed scales with $u *$ and $Q_{s}$ with $u *{ }^{3}$. The latest model by Durán et al. (2011) and Kok et al. (2012) for transport-limited saltation proposed that

$$
Q_{s}=C_{D K} \frac{\rho_{a}}{g} u_{* t} u_{*}^{2}\left(1-\frac{u_{* t}^{2}}{u_{*}^{2}}\right)
$$

, where $C_{D K} \approx 5$, based on the observation that mean particle speed is independent of $u *$ (Ungar and Haff, 1987; Durán et al., 2011; Ho et al., 2011). While Kawamura's model predicts the highest, this latest model predicts the lowest mass fluxes in relatively good accordance with observations (Fig. 9, for more details the reader is referred to Kok et al., 2012 and Sherman et al., 2013). 
In supply-limited situations, however, $Q_{s}$ is linearly proportional to the wind speed rather than to the cube as suggested e.g. by Raupach and Lu (2004). A recent study by de Vries et al. (2014) confirms the linear relationship between $Q_{s}$ and the wind speed, and in general the streamwise saltation flux is much lower in supply-limited situations as demonstrated by the data of Macpherson et al. (2008) (Fig. 10). Such a dependency implies that sediment transport is primarily governed by the supply and it is much less dependent on the variability of wind speed. This is important as most natural surfaces are supply-limited, including loess source regions and loess-covered surfaces themselves (Sweeney and Mason, 2013), owing to surface moisture and crust development (Nickling and McKenna Neuman, 2009).

This and other factors like temporal fluctuations of the instantaneous wind speed and direction cause the saltation to be intermittent (see Stout and Zobeck, 1997 and references therein).

Saltation intermittency can be quantified by the relative wind strength index, defined as

$$
s_{w}=\bar{U}-u_{* t} / \sigma_{U}
$$

, with $\bar{U}$ and $\sigma_{U}$ being the mean wind speed and its standard deviation (Stout and Zobeck, 1997). For $s_{w}<0$, the mean wind speed is below the threshold shear velocity $\left(\bar{U}<u *_{t}\right)$ and only occasional gusts may exceed $u_{* t}$ thereby initiating and sustaining saltation for a short period of time. If $s_{w}>0$ (i.e. $\bar{U}>u *_{t}$ ), saltation is maintained for longer periods interrupted by short events of no transport. For situations where $s_{w}=0\left(\bar{U}=u *_{t}\right)$, wind fluctuations exceed both the mean wind speed and the threshold at the same time and saltation begins. Clearly, natural surfaces possess a range of thresholds varying over short time scales in response to temporal and spatial variability of surface conditions and soil grain size, as well as the fluctuating wind speed (Nickling, 1988; Wiggs et al., 2004). Saltation over loess surfaces was found to be intermittent to non-existent and the threshold friction velocity of sand exceeded that of silt particles (Sweeney and Mason, 2013). This implies that saltation may have played a subordinate role in particle transport over loess landscapes. However, saltation transport may 
have been dominant over floodplains adjacent to sites of loess accumulation and over desert surfaces, both of which acted as major suppliers of sand-sized particles to loess sediments (floodplain: Stevens et al., 2010, 2013b; Újvári et al., 2012, 2014; Újvári and Klötzli, 2015; desert: Sun, 2002; Yang and Ding, 2008; Lu et al., 2011).

\subsubsection{Dust emission and resuspension mechanisms}

Dust particles that are generally $<10-20 \mu \mathrm{m}$ in diameter can be picked up by wind and transported hundreds to thousands of kilometers from their source regions (Pye, 1987). In general, three dust emission mechanisms are distinguished (Shao, 2008): direct aerodynamic entrainment/resuspension (Chepil, 1951, 1965; Loosemore and Hunt, 2000), saltation bombardment/sandblasting (Chepil, 1965; Gillette et al., 1974; Shao et al., 1993; Alfaro et al., 1997; Eames and Dalziel, 2000) and disaggregation/auto-abrasion (Shao, 2008). Dust emission rate, $F_{d}$, which is the vertical mass flux of airborne dust in the atmospheric surface layer, arises from these three mechanisms as (Shao, 2008)

$$
F_{d}=F_{d, a}+F_{d, s}+F_{d, d}
$$

As shown in section 3.1.1.2., a minimum of fluid threshold occurs at a grain size of $70-80 \mu \mathrm{m}$ and it is thought in general that increasing cohesive forces prevent dust particles from being directly lifted by wind. There is a growing body of evidence, however, that dust aerosols are often emitted at shear velocities well below the fluid threshold values observed for saltation, purely as a consequence of aerodynamic resuspension (Loosemore and Hunt, 2000; Kjelgaard et al., 2004; Roney and White, 2004; Macpherson et al., 2008; Klose and Shao, 2012;

Sweeney and Mason, 2013). In wind-tunnel experiments using a smoothed dust bed, Loosemore and Hunt (2000) found that a long-term steady dust flux occurs in the absence of saltation that can be given by

$$
F_{d, a}=3.6 u_{*}^{3}
$$


723

724

725

726

727

, where $F_{d, a}$ is in $\mu \mathrm{g} \mathrm{m}^{-2} \mathrm{~s}^{-1}$ and $u *$ is in $\mathrm{m} \mathrm{s}^{-1}$. As shown in Fig. 10a, this long-term dust flux is relatively small compared to dust emission rates from undisturbed and disturbed supplylimited desert and loess surfaces involving aerodynamic resuspension of loose surface dust (Macpherson et al., 2008; Sweeney and Mason, 2013). Using a portable wind tunnel over supply-limited desert surfaces, Macpherson et al. (2008) found that dust release through aerodynamic lifting is dependent on surface disturbance and the availability of fine, loose surface material. This latter finding is consistent with observations made by Nickling and Gillies (1993) and Sweeney and Mason (2013, see their Fig 7). Furthermore, Macpherson et al. (2008) recognized that supply-limited environments have the potential for multiple resuspension events and their active emission behavior is dependent on surface disturbance and wind speed fluctuations. While dust emissions are dominated by saltation impact during dust storms that are high-magnitude, low frequency events, emissions from supply-limited surfaces during low-magnitude, high-frequency events are often controlled by direct aerodynamic entrainment (Macpherson et al., 2008).

Although aerodynamic lifting can often produce considerable dust emissions from arid/semiarid regions (undisturbed surfaces: $F_{d, a} \sim 10-200 \mu \mathrm{g} \mathrm{m}^{-2} \mathrm{~s}^{-1}$, Fig. 10a), saltation bombardment is able to induce an order of magnitude higher dust production $\left(F_{d, s} \sim 100-3000 \mu \mathrm{g} \mathrm{m}^{-2} \mathrm{~s}^{-1}\right.$, Fig. 10b; Shao et al., 1993; Shao, 2008; Kok et al., 2012, 2014a). In this latter process, dust aerosols are emitted through the transfer of kinetic energy of impacting particles onto soil aggregates, and dust emissions are mainly dependent on saltation intensity (saltator flux and kinetic energy) and dust binding strength (Shao, 2008; Kok et al., 2012, 2014). Since dust production requires saltation as an intermediate process, the vertical dust flux is often considered to be proportional to the streamwise saltation flux as

$$
\alpha=\frac{F_{d, s}}{Q_{s}}
$$


, where $\alpha$ is the abrasion or sandblasting efficiency (Gillette, 1977; Shao et al., 1993). Abrasion efficiency was found to be positively correlated with saltator/soil aggregate size (Shao et al., 1993; Alfaro et al., 2004), the velocity of saltating grains (kinetic energy: Zobeck, 1991; Rice et al., 1996; Rice and McEwan, 2001; or momentum: Houser and Nickling, 2001), and the availability of $<10 \mu \mathrm{m}$ particulate material (Marticorena and Bergametti, 1995; Alfaro et al., 1997; Houser and Nickling, 2001; Alfaro, 2008), while inversely correlated with surface crusting (Rice et al., 1997; Houser and Nickling, 2001) and surface disturbance (Houser and Nickling, 2001). Experiments by Rice et al. (1996) and Gordon and McKenna Neuman (2009) reveal that particles retain 80 percent of their impact velocity during collisions with crusted surfaces, but only 40 to 65 percent on loose, unconsolidated beds, demonstrating that the loose bed absorbs more momentum and energy from the impacting sand particles, which is one of the contributing factors to why surface disturbance decreases the susceptibility of the surface to abrasion.

Several models have been proposed to relate the vertical dust flux to surface friction velocity, and in these models the dust emission rate is usually proportional to $u_{*}{ }^{n}$ with $n=\sim 3-4$ (Borrmann and Jaenicke, 1987; Gillette and Passi 1988; Shao et al., 1993; Nickling and Gillies, 1993; Marticorena and Bergametti, 1995; Kok et al., 2014a). For instance, the model of Gillette and Passi (1988), and Shao et al. (1993) predict, respectively,

$$
\begin{gathered}
F_{d, s}=\alpha_{G P} u_{*}^{4}\left(1-u_{* t} / u_{*}\right) \\
F_{d, s}=\alpha_{S} u_{*}^{3}\left(1-u_{* t}^{2} / u_{*}^{2}\right)
\end{gathered}
$$

, where $\alpha_{\mathrm{GP}}$ and $\alpha_{\mathrm{s}}$ are dimensional constants.

More recently, Kok et al. (2014b) developed a new dust emission scheme (referred to as K14) that, in contrast to previous models, accounts for the decrease in dust production per saltator impact that occurs as the soil becomes less erodible. Indeed, K14 shows better agreement against a compilation of dust flux measurements than the previous schemes of Gillette and 
Passi (1988) and Marticorena and Bergametti (1995), both of which are widely used in climate models (Huneeus et al., 2011). Furthermore, the implementation of K14 into the Community Earth System Model produces an improved simulation of the dust cycle (Kok et al. 2014b). As shown in Fig. 10b, large variability exists in the saltation-induced vertical dust flux, which can mostly be attributed to variations in soil erodibility and saltation fluid threshold (Marticorena and Bergametti, 1995; Shao, 2008; Kok et al., 2012, 2014a). Central in this discussion is the size distribution of dust aerosols released by the three mechanisms mentioned above, so we briefly touch upon this issue. The dust production model (DPM) by Alfaro et al. (1997) assumes that sandblasting results in the vertical flux of fine $\left(<20 \mu \mathrm{m}, \mathrm{PM}_{20}\right)$ mineral particles being a mixture, in various proportions, of three separate lognormally distributed populations with median diameters of 1.5, 6.7 and $14.2 \mu \mathrm{m}$ (Alfaro et al., 1998). Both the size characteristics of these three $\mathrm{PM}_{20}$ populations and the binding energies of $\mathrm{PM}_{20}$ particles within soil aggregates were found to be independent of the soil texture and mineral composition (Alfaro et al., 1998; Alfaro, 2008). While the largest population of $\mathrm{PM}_{20}$ particles could be released even at low wind speeds, it took increasingly larger energies to produce the finer populations. This was interpreted by considering that the binding energy of the fine particle populations within the soil aggregates was a decreasing function of their size (Alfaro et al., 1997, 1998; Alfaro and Gomes, 2001). Since the rupturing of inter-particle bonds between finer particles requires higher energies than those between coarser, the DPM predicts that larger saltating particle impact energies produce more disaggregated and thus smaller dust aerosols. As DPM assumes that saltator impact speed is proportional to wind speed, it predicts a shift to smaller aerosol sizes with increasing wind speed. Such an assumption is likely to be valid for supply-limited environments, but seems invalid for transport-limited systems (Kok, 2011b). 
Another theory for the size distribution of emitted dust aerosol is that of Shao $(2001,2004)$, which integrates both saltation bombardment and aggregates disintegration into the model as major dust emission mechanisms. In this scheme, both the dust emission rate and the emitted dust size distribution are constrained by two extreme soil size distributions $\left(p_{s}\left(D_{p}\right)\right)$ : the minimally- $\left(p_{m}\left(D_{p}\right)\right)$ and fully-disturbed $\left(p_{f}\left(D_{p}\right)\right)$ soil size distributions (Shao, 2001). For weak erosion events $p_{s}\left(D_{p}\right) \rightarrow p_{m}\left(D_{p}\right)$, while for strong events $p_{s}\left(D_{p}\right) \rightarrow p_{f}\left(D_{p}\right)$, and $p_{s}\left(D_{p}\right)$ can be written as

$$
p_{s}\left(D_{p}\right)=\gamma_{S} p_{m}\left(D_{p}\right)+\left(1-\gamma_{S}\right) p_{f}\left(D_{p}\right)
$$

, with

$$
\gamma_{S}=e^{-k_{S}\left(u_{*}-u_{*}\right)^{n_{S}}}
$$

, where $\gamma_{S}$ approaches 1 for weak erosion events, while it approaches zero for strong events $\left(k_{S}\right.$ and $n_{S}$ are empirical coefficients; Shao, 2001). This model predicts that airborne dust particles sampled during wind erosion events of different intensities will have different particle size distributions, as a consequence of breaking up of soil aggregates into finer particles at larger wind speed (Shao, 2001, 2004). In contrast to this, neither Gillette et al. (1974) nor Shao et al. (2011) found a clear dependence of airborne dust PSD on wind speed (also see Kok, 2011b). It is recognized in soil science that dry soil aggregates fail as brittle materials (Braunack et al., 1979; Perfect and Kay, 1995) and using this observation Kok (2011a) recently developed the brittle fragmentation theory (BFT) of dust emission. When a saltating particle impacts a dust aggregate, the resulting PSD of fragments will fall into either the elastic, damage or fragmentation regimes (Kun and Herrmann, 1999; Aström, 2006), depending on the impacting energy and dust aggregate cohesiveness. Kok (2011a) hypothesized that dust emission is predominantly due to fragmenting impacts and PSDs in this regime follow a power law, i.e. they are scale-invariant (Oddershede et al., 1993; Aström, 2006). This power law appears to describe the size distribution of emitted dust aerosols in the size range of 
$\sim 2-10 \mu \mathrm{m}$, while it is invalid for 1) dust directly lifted aerodynamically, 2) dust emitted by impacts in the damage regime (for soils where most of the $\mathrm{PM}_{20}$ dust exists as coatings on larger grains), and 3) large ( $>20 \mu \mathrm{m})$ dust particles that are likely to be ejected directly from soils rather than bound in aggregates (Kok, 2011a). The BFT theory predicts that the emitted dust PSD is not dependent on the wind speed at emission in agreement with field measurements (Kok, 2011b). Indeed, measurements by Maring et al. (2003) and Reid et al. (2008) also indicate that the dust size distribution of dust events are not substantially impacted by wind speed. Furthermore, recent aeroplane-based observations over various Sahara source regions found that the size distributions of emitted dust are highly similar for particle diameters below about $\sim 40 \mu \mathrm{m}$ (Rosenberg et al., 2014).

As noted by Kok (2011b), the brittle fragmentation theory of dust emission applies only to transport-limited situations where the saltator impact speed is independent of $u *$. It is thus possible that the PSD of dust aerosols generated during saltation under supply-limited conditions (i.e. when the saltator impact speed increases with $u *$; Houser and Nickling, 2001; Ho et al., 2011), does depend on the wind speed (Kok, 2011b). There are currently no measurements available to test this hypothesis.

\subsubsection{Deposition of air-borne mineral particles}

\subsubsection{Dry deposition}

Dry deposition is the transport of particulate species from the atmosphere to the surface in the absence of precipitation (Seinfeld and Pandis, 2006). Factors that govern the rate at which particles are delivered to the surface include 1) the level of atmospheric turbulence, 2) particle characteristics, and 3) the nature of the depositional surface itself. In dry deposition formulations the dry deposition flux, $F_{\text {dep }}\left(z_{r}\right)$, is assumed to be directly proportional to the local concentration of particles, $C_{p}$, at some reference height, $z_{r}$, as 


$$
F_{d e p}\left(z_{r}\right)=-w_{d} C_{p}
$$

841 , with $w_{d}$ being the dry deposition velocity (Chamberlain, 1967; Sehmel, 1980; Davidson et

842 al., 1982; Ferrandino and Aylor, 1985; Wesely and Hicks, 2000). During dry deposition,

843 particles are transported from the atmosphere to the surface through the atmospheric surface

844 layer by the combined actions of gravitational settling and turbulent diffusion, and through the

845 laminar sublayer by gravitational settling and Brownian diffusion (Seinfeld and Pandis, 2006;

846 Shao, 2008). Over vegetated surfaces, turbulent transfer carries the mineral particles from air

847 above the canopy to air within the canopy close to individual elements such as stems, leaves

848 and the ground surface. Particles are then carried through the laminar sublayer surrounding

849 these elements by Brownian diffusion and finally absorbed on the surface (Shao, 2008).

850 Particle removal and deposition on vegetation elements occurs in the laminar sublayer by

851 Brownian diffusion, interception and impaction (Slinn, 1982; Seinfeld and Pandis, 2006;

852 Shao, 2008). Brownian diffusion affects very fine particles, typically smaller than $0.1 \mu \mathrm{m}$

853 (Raupach and Lu, 2004; Petroff et al., 2008), which are subordinate and often absent in loess

854 and even in paleosoils (see Fig. 1). Interception occurs when small inertia particles, which

855 perfectly follow the mean air motion, pass close to an obstacle and collide with it as the

856 distance between the particle center and the surface is smaller than half the diameter (Fuchs,

857 1964; Petroff et al., 2008). Interception is effective for particles with a diameter of around 1

$858 \mu \mathrm{m}$ (see Fig. 11a and Shao, 2008), which is therefore an important depositional mechanism of

859 clay-sized and very fine silt particles in loess. Moving towards a vegetation element, a particle

860 with large inertia cannot follow the flow deviation around the obstacle, leaves its air

861 streamline and finally collides with the obstacle's surface in a process called impaction

862 (Seinfeld and Pandis, 2006; Petroff et al., 2008). Impaction dominates for particles in the size

863 range of $D_{p}=\sim 3-5$ to $50 \mu \mathrm{m}$ (Raupach and Lu, 2004), while above $50 \mu \mathrm{m}$ gravitational settling

864 is the dominant dry deposition mechanism (Fig. 11a and b). During impaction some particles 

the dry deposition velocity can be expressed as

$$
w_{d}=w_{t}+\frac{1}{r_{a}+r_{s}}
$$
, where $w_{t}$ is the gravitational settling velocity (defined above, Eq. 3.26), while $r_{a}$ and $r_{s}$ are

877 aerodynamic and surfaces resistances, respectively. For a neutral atmosphere the aerodynamic 878 resistance is calculated as

$$
r_{a}=\frac{\ln \left(z_{r} / z_{0}\right)}{\kappa u_{*}}
$$

879 , where $z_{r}$ is the reference height at which the dry deposition velocity is evaluated (Zhang et 880 881

$$
\text { al., 2001). Surface resistance is controlled by factors like surface collection efficiency, }
$$
particle size, atmospheric conditions, and surface properties, and can be expressed as

$$
r_{s}=\frac{1}{\varepsilon_{0} u_{*} \varepsilon R_{1}}
$$

882 , where $\varepsilon_{0}=3$ is an empirical constant, $\varepsilon$ is the total collection efficiency and $R_{1}$ is a correction 883 factor given as

$$
R_{1}=\exp \left(-S t^{1 / 2}\right)
$$


For Brownian diffusion $E_{B}$ is a function of the Schmidt number, $S c$, as

$$
E_{B}=S c^{-\gamma_{Z}}
$$

889 , where $S c=v_{a} / D_{B}$ with $D_{B}=k T C_{c} / 3 \pi \mu_{a} D_{p}$ being the Brownian diffusivity of particles 890 (here $k$ is the Boltzmann constant and $T$ is temperature in Kelvin) and $\gamma_{Z}$ is a parameter for 891 892 $E_{I N}$ the formula of

$$
E_{I N}=\frac{1}{2}\left(\frac{D_{p}}{R_{c}}\right)^{2}
$$

is used in both the Slinn (1982) and the Zhang et al. (2001) models. The parameters governing 894 the impaction process is the Stokes number and Zhang et al. (2001) suggest

$$
E_{I M}=\left(\frac{S t}{\alpha_{Z}+S t}\right)^{2}
$$

895 based on the work by Peters and Eiden (1992). The parameter $\alpha_{Z}$ depends on land use 896 category and ranges mainly from 0.6 to 2.

897 As pointed out by Venkatram and Pleim (1999) gravitational settling is not driven by a 898 concentration gradient and the usual treatment of gravitational settling as a parallel resistance 899 in dry deposition models (e.g. those of Slinn, 1982 and Zhang et al., 2001; Seinfeld and 900 Pandis, 2006) does not satisfy the particle mass conservation requirement. The correct 901 expression for $w_{d}$ is

$$
w_{d}=\frac{w_{t}}{1-e^{-r w_{t}}}
$$


, where $r$ is the total resistance. At the same time, Venkatram and Pleim (1999) admit that, in practice, the difference in magnitude of dry deposition velocity estimated by Eq. 3.42 and 3.50 is little. Based on this work, Zhang and Shao (2014) recently proposed a new parametrization in which the effects of gravitational settling and also surface collectors over a rough surface are adequately dealt with. By comparing the models of Slinn (1982), Zhang et al. (2001) and Zhang and Shao (2014) it is seen that the position of the deposition velocity minimum varies between the different parametrizations (Fig. 11b). While the Slinn (1982) scheme predicts its position in the accumulation mode at $0.1-0.3 \mu \mathrm{m}$, the Zhang et al. (2001) model predicts it for coarser $(0.5-2 \mu \mathrm{m})$, the Zhang and Shao (2014) model for finer particles $(0.01-1 \mu \mathrm{m})$. It must be noted here, however, that in an evaluation of model predicted and measured dry deposition fluxes the inferential method performed well in comparison with the gradient method, but it still overestimated the total deposition flux and large differences became apparent when individual grain size classes were investigated (Goossens, 2005). In our review of dry deposition, important results of a wind tunnel experiment of Goossens (2008) must be invoked here to gain a better understanding on the influence this process has on particle size distributions. Goossens's (2008) wind tunnel data demonstrate that at low $(\sim<0.3-0.35)$ shear velocities the settling dust is coarser than the horizontally transported dust for a narrow layer $(60 \mathrm{~cm})$ over the surface, while for $u *$ larger than this threshold the median grain diameter of settling dust does not differ from that of the parent dust. At constant horizontal transport flux the vertical deposition flux decreases with increasing wind speed up to $u *=0.34 \mathrm{~m} \mathrm{~s}^{-1}$, then remains constant. For particles $<50 \mu \mathrm{m}$, the rate of decrease is much greater for coarser grains, while for particles $>50 \mu \mathrm{m}$ this rate remains constant with changing $u *$. These observations indicate that the deposition of atmospheric dust particles is strongly affected by vertical mixing created by the turbulent nature of the airflow (Nielsen, 1993) and mixing significantly hampers deposition of grains up to $\sim 50 \mu \mathrm{m}$. For coarser grains the 
deposition is predominantly determined by gravity and no longer by turbulence (Goossens, 2008). Clearly, the coarser dust particles are transported near the ground and preferentially deposited relative to the dust cloud as a whole and closer to the source (see Fig. 9 in Goossens, 2008). Thus, loess becomes finer with distance from sources as demonstrated in field studies such as those of the Peoria loess in the US (Mason et al., 1994; 2003).

\subsubsection{Wet deposition}

During wet deposition air-borne particles are removed from the atmosphere by hydrometeors and subsequently delivered to the Earth's surface. This process is called wet or precipitation scavenging and includes in-cloud scavenging (rainout) and below-cloud scavenging (washout)

(Seinfeld and Pandis, 2006). Particles entrained into clouds are subject to nucleation scavenging and in this process some dust particles initiate drop formation and act as cloud condensation nuclei (CCN) and/or ice nuclei (IN) (Pruppacher and Klett, 1997). In-cloud scavenging is the main removal mechanism for sub-micron particles from the atmosphere (Feng, 2007). Particles located below the base of a precipitating cloud are collected by falling hydrometeors and this process of impaction scavenging depends on the net action of various forces influencing the relative motion of particles and hydrometeors (Andronache, 2003; Feng, 2007). Considering the size distribution of loess mineral particles, it seems logical to focus our review on the second process of wet scavenging: below-cloud scavenging. In its fall through air, a raindrop will collide with and collect some of the mineral dust particles present in the swept out volume. Whether a collision will occur depends on the sizes of the raindrop and the particle and their relative locations (Seinfeld and Pandis, 2006). The capture of aerosol particles by falling hydrometeors is controlled by microphysical processes such as Brownian diffusion, interception, inertial impaction, diffusiophoresis, thermophoresis and electric effects (Greenfield, 1957; Davenport and Peters, 1978; Wang et al., 1978; Slinn, 
952

953

954

955

956

2010)

$$
\frac{d N\left(D_{p}\right)}{d t}=-\Lambda\left(D_{p}\right) N\left(D_{p}\right)
$$

957

958

959

$$
\Lambda\left(D_{p}\right)=\int_{0}^{\infty} \frac{\pi}{4} D_{r d}^{2} w_{t}\left(D_{r d}\right) \varepsilon_{w}\left(D_{r d}, D_{p}\right) N\left(D_{r d}\right) d D_{r d}
$$

, where $w_{t}\left(D_{r d}\right)$ is the terminal velocity of raindrops, $N\left(D_{r d}\right)$ is the raindrop number size

distribution and $\varepsilon_{w}\left(D_{r d}, D_{p}\right)$ is the total raindrop-particle collection efficiency, which is

962

assumed to be equal to the collision efficiency (Slinn, 1983; Seinfeld and Pandis, 2006). The

963

above expression can further be simplified by assuming that all raindrops have the same

964

diameter (the representative raindrop diameter, $\left.D_{r d-r}\right)$ and a number concentration $N\left(D_{r d-r}\right)$

965

(Seinfeld and Pandis, 2006). For a monodisperse raindrop distribution Eq. 3.52 simplifies to

$$
\Lambda\left(D_{p}\right)=\frac{\pi}{4} D_{r d-r}^{2} w_{t}\left(D_{r d-r}\right) \varepsilon_{w}\left(D_{r d-r}, D_{p}\right) N\left(D_{r d-r}\right)
$$

966 For a monodisperse raindrop number size spectrum, the rainfall intensity $J\left(\mathrm{~mm} \mathrm{hr}^{-1}\right)$ can be 967 expressed as

$$
\mathrm{J}=\frac{\pi}{6} D_{r d-r}^{3} w_{t}\left(D_{r d-r}\right) N\left(D_{r d-r}\right)
$$

, and combining Eq. 3.53 and 3.54

$$
\Lambda\left(D_{p}\right)=\frac{3}{2} \frac{\varepsilon_{w}\left(D_{r d-r}, D_{p}\right) J}{D_{r d-r}}
$$


969

970

971

972

973 geometric volume swept out by a falling drop will be collected (Seinfeld and Pandis, 2006).

974 For particles $<\sim 0.2 \mu \mathrm{m}$ Brownian diffusion is the dominant mechanism leading to the

975 collection of dust by falling raindrops, while for larger particles interception and inertial

976 impaction become dominant (Fig. 12a). Based on dimensional analysis and experimental data,

977 Slinn (1983) proposed that

$$
\varepsilon_{w}\left(D_{r d}, D_{p}\right)=E_{B w}+E_{I N w}+E_{I M w}
$$

978 , with

$$
\begin{gathered}
E_{B w}=\frac{4}{R e_{r d} S c}\left[1+0.4 R e_{r d}^{1 / 2} S c^{1 / 3}+0.16 R e_{r d}^{1 / 2} S c^{1 / 2}\right] \\
E_{I N w}=4 \frac{D_{p}}{D_{r d}}\left[\frac{\mu_{a}}{\mu_{w}}+\left(1+2 R e_{r d}^{1 / 2}\right) \frac{D_{p}}{D_{r d}}\right] \\
E_{I M w}=\left(\frac{S t-S t^{*}}{S t-S t^{*}+2 / 3}\right)^{3 / 2}\left(\frac{\rho_{p}}{\rho_{w}}\right)^{1 / 2}
\end{gathered}
$$

979 , where the raindrop Reynolds number is given by

$$
R e_{r d}=\frac{D_{r d} w_{t}\left(D_{r d}\right) \rho_{a}}{2 \mu_{a}}
$$

980 , the Stokes number as

$$
S t=\frac{2 t_{p}\left[w_{t}\left(D_{r d}\right)-w_{t}\left(D_{p}\right)\right]}{D_{r d}}
$$

981 , and the critical Stokes number is

$$
S t^{*}=\frac{1.2+1 / 12 \ln \left(1+R e_{r d}\right)}{1+\ln \left(1+R e_{r d}\right)}
$$

982 The particle Schmidt number $(S c)$ and particle relaxation time $\left(t_{p}\right)$ are defined in sections above, and $w_{t}\left(D_{r d}\right)$ is the raindrop terminal velocity. 


$$
E_{T P w}=\frac{4 \alpha_{T P}\left(2+0.6 R e_{r d}^{1 / 2} P r_{a}^{1 / 3}\right)\left(T_{a}-T_{s}\right)}{w_{t}\left(D_{r d}\right) D_{r d}}
$$

999 , and

$$
E_{D P w}=\frac{4 \beta_{D P}\left(2+0.6 R e_{r d}^{1 / 2} S c_{w}^{1 / 3}\right)\left(p_{s}^{0} / T_{s}-p_{a}^{0} R H / T_{a}\right)}{w_{t}\left(D_{r d}\right) D_{r d}}
$$

1000 , with

$$
\begin{gathered}
\alpha_{T P}=\frac{2 C_{c}\left(k_{a}+5 \lambda_{a} / D_{r d} k_{p}\right) k_{a}}{5 P_{a}\left(1+6 \lambda_{a} / D_{r d}\right)\left(2 k_{a}+k_{p}+10 \lambda_{a} / D_{r d} k_{p}\right)} \\
\beta_{D P}=\frac{T_{a} D_{w}}{P_{a}}\left(\frac{M_{w}}{M_{a}}\right)^{1 / 2}
\end{gathered}
$$




$$
\operatorname{Pr}_{a}=\frac{c_{a} \mu_{a}}{k_{a}}
$$

1001

, and

$$
S c_{w}=\frac{\mu_{a}}{\rho_{a} D_{w}}
$$

1002 In the above equations $T_{a}$ and $T_{s}$ are air and raindrop surface temperatures (in Kelvin), $p_{a}{ }^{0}$ and $1003 p_{s}{ }^{0}$ are water vapor pressures at temperatures $T_{a}$ and $T_{s}, k_{a}$ and $k_{p}$ are thermal conductivity of 1004 air and particle, $P_{a}$ is atmospheric pressure, $C_{c}$ and $\lambda_{a}$ are the Cunningham slip correction 1005 factor and the mean free path of air molecules, $D_{w}$ is the water vapor diffusivity in air, $M_{a}$ and $M_{w}$ are molecular weights of air and water, and $c_{a}$ is heat capacity of air. When a particle moves along the streamlines of air close to the raindrop surface it can be captured due to attraction originating from opposite charges of the raindrop $\left(Q_{r d}\right)$ and the particle $\left(q_{p}\right)$. The electrostatic contribution to $\varepsilon_{w}\left(D_{r d}, D_{p}\right)$ is given as (Andronache, 2004; Andronache et al., 2006)

$$
E_{E S w}=\frac{16 K_{E S} C_{c} Q_{r d} q_{p}}{3 \pi \mu_{a} w_{t}\left(D_{r d}\right) D_{r d}^{2} D_{p}}
$$

1011 , where $K=9 \times 10^{9} \mathrm{~N} \mathrm{~m}^{2} \mathrm{C}^{-2}$. The mean raindrop and particle charges can be expressed as a 1012 function of size as

$$
Q_{r d}=a \alpha_{E S} D_{r d}^{2}
$$

1013 , and

$$
q_{p}=a \alpha_{E S} D_{p}^{2}
$$

1014 , where $a=0.83 \times 10^{-6}$ and $\alpha_{E S}\left(\mathrm{C} \mathrm{m}^{-2}\right)$ is an empirical parameter varying between 0 and 7 , but 2 1015 can be used for average conditions of strongly electrified clouds (Pruppacher and Klett, 1997; 1016 Andronache, 2004).

1017 Considering all the mechanisms detailed above, the raindrop-particle collision efficiency (Eq. 1018 3.56) can be re-written as 


$$
\varepsilon_{w}\left(D_{r d}, D_{p}\right)=E_{B w}+E_{I N w}+E_{I M w}+E_{T P w}+E_{D P w}+E_{E S w}
$$

1019

1020

1021

1022

1023

1024

1025

1026

1027

1028

1029

1030

1031

1032

1033

1034

1035

1036

1037

1038

1039

As can be seen in Fig. 12a, Brownian diffusion is the dominant collection mechanism for particles $<0.1-0.2 \mu \mathrm{m}$ and thermophoresis makes a comparable contribution to Brownian diffusion in the $0.1-1 \mu \mathrm{m}$ size range. These mechanisms are therefore largely irrelevant for loess/paleosols, while inertial impaction and interception are the most important, since these are the most effective collection mechanisms for large particles $(>\sim 3.5 \mu \mathrm{m})$. The contribution from electric charges increases with particle size and becomes dominant for particles in the 0.2-3.5 $\mu \mathrm{m}$ size range. At the same time, diffusiophoresis has a constant, but relatively low contribution to the total collection efficiency (Fig. 12a; Seinfeld and Pandis, 2006). It is also visible in Fig. 12b that the total collision efficiency decreases with the increase of the size of rain droplets up to 5-8 $\mu \mathrm{m}$, affecting the clay and very fine silt fractions in loess/paleosols. Figure 13 displays the size-resolved wet scavenging coefficient for different rain rates. For these calculations and also for the collection efficiency calculations a monodispersed raindrop size distribution is assumed and parameterized as (Willis, 1984, Loosmore and Cederwall, 2004)

$$
D_{r d-r}=0.97 J^{0.158}
$$

The raindrop terminal velocity is calculated after Willis (1984) as

$$
w_{t}\left(D_{r d-r}\right)=4854 D_{r d-r} e^{-1.95 D_{r d-r}}
$$

, which seems to be an appropriate choice for raindrops of 0.1 to $10 \mathrm{~mm}$ (Wang et al., 2010). As shown in Fig. 13, the wet scavenging coefficients calculated with Eq. 3.72 (full model), i.e. considering all the microphysical mechanisms mentioned above, are in good agreement with the controlled experiments of Sparmacher et al. (1993). Although it is not shown in Fig. 13, the Slinn (1983) parameterization underestimates $\Lambda\left(D_{p}\right)$, especially for particles having a diameter of $0.1-1 \mu \mathrm{m}$. As the full model predicts, the wet scavenging rate varies significantly 
with the rain rate and the aerosol size. When the rain rate increases the corresponding scavenging rate increases, too (Fig. 13).

After a shorter-longer transport in suspension loess particles are accumulated on the surface due to dry or wet deposition. The effect of rain events and associated below-cloud scavenging on wind-blown loess/dust particle size distributions can be demonstrated by calculating the depletion of volume of a model aerosol distribution due to wet scavenging. At some time $t$ during a scavenging event, the concentration of particles is related to the initial concentration by the scavenging rate by integrating Eq. 3.51, yielding

$$
N\left(D_{p}\right)_{t}=N\left(D_{p}\right)_{0} e^{-\Lambda\left(D_{p}\right) t}
$$

, where $N\left(D_{p}\right)_{0}$ is the initial number concentration of particles. For an initial number concentration, the remote continental aerosol distribution parameters of Jaenicke (1993) are used. Assuming a unit density of particles, the mass size distribution is equal to the volume size distribution (Pruppacher and Klett, 1997; Seinfeld and Pandis, 2006; Feng, 2007) and the wet scavenging of particle mass can be illustrated using the volume size distribution. Fig. 14 shows the volume size distribution of the remote continental model aerosol after rain events of different durations $\left(t_{r}\right)$ at a rain rate $(J)$ of $10 \mathrm{~mm} \mathrm{hr}^{-1}$. It is clearly visible that coarse particles $(>5 \mu \mathrm{m})$ are efficiently removed from the air after only a short duration of rainfall, while the mass washed out in the accumulation mode $(0.1$ to $2 \mu \mathrm{m})$ is negligible even after 10 hr of wet scavenging. This implies that, similar to dry deposition, the removal of clay-sized and very fine silt particles (up to $\sim 5 \mu \mathrm{m}$ ) by wet deposition is much less efficient than the removal of larger grains by the same process, which again may have an effect on loess PSDs.

\subsection{Loess grain size proxies}

Loess grain size proxies are widely used in Quaternary paleoenviromental studies, mainly to reconstruct wind speed and dust source distance variations, as well as changes of the dust 
cycle on glacial/interglacial to millennial timescales, involving changes in vegetation cover and the precipitation regime. In the following overview we followed the phrasing given in the cited studies for explaining the background and interpretation of proxies, although in some cases these are considered inadequate and imprecise. Further discussion on the physical background of proxies and improved interpretations are given in section 4 .

\subsection{1. $U$ - and Twin Peak ratios}

As proposed by Vandenberghe et al. (1985, 1997) and Vandenberghe and Nugteren (2001), the $U$-ratio $(16-44 \mu \mathrm{m} / 5.5-16 \mu \mathrm{m})$, which is the ratio of the coarse silt and the medium to fine silt fractions (Fig. 1), can be applied as a proxy for discriminating cold periods (high $U$-ratio), characterized by a dynamic aeolian environment (strong winds), from warm periods (low $U$ ratio), with weak winds. As revealed by Vandenberghe et al. (1997) and Nugteren et al. (2004) in the Luochuan sequence, aeolian sedimentation is dominated by the $<16 \mu \mathrm{m}$ fraction during warm, interglacial climatic periods and the $>16 \mu \mathrm{m}$ fraction during cold, glacial periods. For this reason, the fraction $>16 \mu \mathrm{m}$ was interpreted by these authors as being a good indicator of the climate signal in loess. By eliminating both the clay $(<5.5 \mu \mathrm{m}$ in laser particle analysis; Konert and Vandenberghe, 1997) and the $>44 \mu \mathrm{m}$ fractions, this parameter disregards the secondary formed, pedogenic clay minerals and fine sand particles likely transported in saltation (Fig. 8; Vandenberghe et al., 1997; Vandenberghe, 2013).

An index resembling the $U$-ratio, introduced by Machalett et al. (2008) for loess deposits in Kazakhstan, establishes quantitative comparison between very coarse silt and medium to coarse silt fractions $(T P$-ratio $=$ Twin Peak ratio: 30.1-63.4/11.8-27.4 $\mu \mathrm{m})$. Varying heights of peaks within the bimodal silt distributions and proportions of the 30.1-63.4 and 11.8-27.4 $\mu \mathrm{m}$ fractions are believed to reflect changing aeolian dust transport activities and wind strength on the local/regional scale. High TP-ratios indicate cold periods with stronger winds that carry 
coarser particles, while low TP values refer to warm conditions and weaker winds (Machalett et al., 2008).

\subsubsection{Grain size index (GSI)}

The grain size index (GSI: $20-50 \mu \mathrm{m} /<20 \mu \mathrm{m}$ ), as introduced by Rousseau et al. (2002), is considered to be a 'reliable index of wind dynamics' and a 'suitable indicator for atmospheric dust'. Whether this definition means the dust deposition rate or dust concentration at the proxy site, or otherwise, is not defined by Rousseau et al. (2002). Similar indices $(<2 \mu \mathrm{m} / 10$ $50 \mu \mathrm{m}$ and $<2 \mu \mathrm{m} />10 \mu \mathrm{m}$ ) have previously been proposed by Liu et al. (1989) and Ding et al. (1992) for reconstructing wind intensity variations. In subsequent studies, the GSI has been calculated from laser particle sizer datasets as the ratio of the $26-52.6 \mu \mathrm{m}$ and $<26 \mu \mathrm{m}$ fractions (Rousseau et al., 2007a; Antoine et al., 2009a). The GSI appears to be similar to the $U$-ratio, but it includes the clay fraction too (Fig. 1). GSI generally reflects changes in the efficiency of entrainment, transport and deposition of coarse versus fine dust grains, due to wind speed variations (Rousseau et al., 2007a), and high GSI values indicate increased frequency and strength of dust storms and correspondingly high sedimentation rates. A slightly modified version of GSI has been introduced in a follow-up paper dealing with US loess in the Eustis sequence, in which $G S I$ (here: $20.7-63.4 \mu \mathrm{m} /<20.7 \mu \mathrm{m}$ ) variations were interpreted in terms of varying atmospheric circulation, i.e. westerly versus southeasterly circulation (Rousseau et al., 2007b). Although recent studies of late glacial loess in Serbia (Surduk), the Czech Republic (Dolni Vestonice) and Ukraine (Stayky) (Antoine et al., 2009b, 2013; Rousseau et al., 2011) used this latter form of GSI for revealing variations in aeolian dynamics (first of all wind strength: Antoine et al., 2013), some new elements in the interpretation of GSI emerged too. As recognized and proposed by Rousseau et al. (2011), loess PSDs are related to a combination of changes in the wind and precipitation regimes, 
both on local and larger spatial scales. Such variations affect the dust cycle directly through their effect on the efficiency of dust entrainment, dust transport and deposition, and indirectly by changing the distribution, characteristics and vegetation of the dust source areas (Rousseau et al., 2011). Thus, GSI appears to be an integrative proxy and likely reflects the combined effects of all the above environmental factors on loess sedimentation and not just wind strength.

\subsubsection{Mean and median grain size $\left(M_{s}, M_{d}\right)$, and various fractions of loess}

Since loess grain size is thought to be a function of wind speed (see e.g. section 3.1.1.8.), the mean and median grain sizes $\left(M_{s}, M_{d}\right)$ are considered to be indices of wind strength (Liu, 1985; An et al., 1991; Derbyshire et al., 1995, Chen et al., 1997). As proposed by An et al. (1991), the indices may reflect the degree of aridity in the source area and the frequency of dust storms too. Subsequently, some argued that $M_{d}$ of Chinese loess is not just a proxy of Asian winter monsoon intensity, but reflect the advance and retreat of desert sources, or in other words source distance (Ding et al., 1999, 2001, 2002, 2005). While Shi et al. (2003) consider $M_{d}$ as a measure of the airflow intensity, Qin et al. (2005) interpret the $M_{d}$ of bulk loess as a proxy of source distance and the $M_{d}$ of the coarse mode (>10 $\left.\mu \mathrm{m}\right)$ as an index of the 'average intensity of the aerodynamic force'. Whether this applies to the aerodynamic force at lifting or during transport is not specified by Qin et al. (2005). Likewise, the $M_{d}$ of the coarse dust fraction has been interpreted by Prins et al. (2007) as reflecting the 'average dynamic conditions' of the East Asian winter monsoon circulation system on the Chinese Loess Plateau, which is again a rather vague interpretation. More recently Sun et al. (2010a, 2012) argues that the loess particle size variations are coupled to changes in the winter monsoon strength and $M_{s}$ is a proxy which is influenced by wind intensity in the first place, and by source-to-sink distance and the aridity/extent of dust sources in the second. 
Different grain size fractions of loess have been applied as paleoclimate indicators for atmospheric circulation (wind strength, aridity) in the past. For instance, the $>63 \mu \mathrm{m}$ and/or fine sand fractions of loess have been interpreted as indicators of wind intensity and dust storm variability, i.e. aeolian dynamics (e.g. Lu et al., 2004; Antoine et al., 2013). The >63 $\mu \mathrm{m}$ grain size fraction has also been used for identifying loess events (phases of coarse loess sedimentation) in Serbia (Antoine et al., 2009b). Others (Ding et al., 1999, 2005) argued that source distance is another important factor to be considered (at least in China) and the variability of the $>63 \mu \mathrm{m}$ fraction of loess reflects advance and retreat of the desert margins. A further control on grain size is certainly sediment availability, as proposed by Stevens et al. (2011).

\subsubsection{Quartz mean, median and maximum diameters $\left(Q_{M s}, Q_{M d}, Q_{M a x}\right)$, and quartz $>40 \mu m$} fraction $(Q>40)$

The quartz mean, median and maximum diameters $\left(Q_{M s}, Q_{M d}, Q_{M a x}\right)$, and the quartz $>40 \mu \mathrm{m}$ fraction $(Q>40)$ have been introduced as winter monsoon proxies for the Chinese loess (Porter and An, 1995; Xiao et al., 1995; An and Porter, 1997; An, 2000; Sun et al., 2010a). While $Q_{M d}$ is regarded as a proxy measure of average wind strength, $Q_{M a x}$ is considered as a proxy index of maximum wind strength, i.e. the competency and capacity of the transporting medium (Xiao et al., 1995). In the study of Porter and An (1995), both the $Q_{M d}$ and $Q_{>40}$ are interpreted as reliable measures of dust flux, assuming correlations between the coarsegrained fractions of atmospheric dust and the total dry deposition flux. Later on, Porter (2001) argued that high $Q_{M d}$ values also may record increased frequency and intensity of dust storms. More recently, Sun et al. (2006) interpreted mean grain size of quartz $\left(Q_{M s}\right)$ as a proxy of the 'average energy of wind systems', which can provide information on changes of 'dust transport dynamics'. 
One of the major advantages of using the quartz fraction instead of bulk sample grain size distributions is that quartz particles are resistant to any chemical/physical alteration during transport, sedimentation and weathering processes in low-temperature environments (Clayton et al., 1978). Furthermore, bulk samples include pedogenic clays deflated from the dust source regions and argillic clay produced by post-depositional pedogenesis (Xiao et al., 1995; An, 2000; Sun et al., 2000) and these components can effectively be disregarded using only the quartz particle size distributions and calculated proxies.

\section{Results and discussion}

\subsection{Down-profile MS/grain size variations and inter-relations of proxies}

Low-field mass-specific susceptibility, $\chi_{L F}$, varies between 13.2 and $1.2 \times 10^{-7} \mathrm{~m}^{3} \mathrm{~kg}^{-1}$ in the profile from the MIS 5 pedocomplex at the base of the Dunaszekcső sequence to the less weathered loess layers (Fig. 4). The degree of pedogenesis, as indicated by $\chi_{P}$, reaches two maxima in the MIS 5e soil, shows a sharp drop towards the loess units and remains low throughout including MIS 3 (Fig. 15). In contrast to the GS measures and proxies, magnetic susceptibility does not exhibit significant millennial scale variations either in the MIS5e paleosol or above in the MIS 4, 3 and 2 loess/weathered loess layers. Indeed, high-frequency environmental variations lasting no more than a few thousand years are expected to cause minimal MS variations and the $\chi_{L F}$ record serves as a low-pass filter on climatic/environmental variables (Anderson and Hallett, 1996). Our observations of minimal high-frequency MS variations are consistent with those of e.g. Porter and An (1995) in China and Markovic et al. (2009), Bradák et al., (2011), Novothny et al. (2011), Rolf et al. (2014) and Fitzsimmons and Hambach (2014) in East Central Europe. It is worth noting, however, that Stevens et al. (2011), Sümegi et al. (2012) and Terhorst et al. (2014) reported many 
notable millennial MS peaks from the last glacial loess records of Crvenka, Madaras and Krems-Wachtberg in Serbia, Hungary and Austria, respectively.

As with the MS record, two climate modes (glacial/interglacial) can be distinguished in the bulk GS record. While the $M_{s}, M_{d} / D_{50}$ and $D_{90}$ parameters vary in the MIS 5e-c paleosol (unit 2) around mean values of 15,17 and $55 \mu \mathrm{m}$, respectively, with one standard deviation (SD) of 2-3 and $8 \mu \mathrm{m}$, much higher values $(25.5,32$ and $84 \mu \mathrm{m})$ are seen in the loess units with increased variability (SD of 5-7 and $10 \mu \mathrm{m}$ ). All of the bulk GS proxies show coarsening in grain size both within the last interglacial soil (unit 2) and the overlying loess units from MIS 4 to 2 (Fig. 15). While high-frequency grain size variations are present throughout the record, the magnitude of such variations are rather suppressed in the MIS 5e-c paleosol compared to the MIS 4-2 loess units. Such high-frequency fluctuations and bulk GS trends have been recognized in numerous loess records in Europe (Rousseau et al., 2002; Shi et al., 2003; Markovic et al., 2008; Antoine et al., 2009a; Bokhorst et al., 2011; Novothny et al., 2011; Rousseau et al., 2011) and China (Porter and An, 1995; Nugteren et al., 2004; Sun et al., 2006, 2012; Prins et al., 2007). As can be seen in Figs. 15 and 16, the bulk GS proxies are well-correlated and exhibit similar variations despite the arguments above (section 3.2) on the advantages of each proxies. The $M_{d} / D_{50}$ correlates very well with $G S I$ and shows slightly less strong correlation with the $U$-ratio (Fig. 16a), not surprisingly because the $<5.5$ and $>44 \mu \mathrm{m}$ fractions of the grain size distributions are disregarded in calculations of the $U$-ratio, while these distributions tails affect the final value of $M_{d} / D_{50}$. At the same time, an almost perfect correlation was found between the $U$-ratio and GSI for all sediment types (Fig. 16b), likely because of the minor differences in the coarse silt and fine/medium silt fractions used in their calculations $(16-44 / 5.5-16$ versus $20-50 /<20)$ and the relatively low proportions of the $<5.5$ $\mathrm{m}$ fractions omitted in the $U$-ratio calculations. Consequently, the various bulk loess grain size 
indices do not really provide different information on past environmental conditions, so we do not see clear advantages of using one over the other.

What regards the quartz GS, all of the proxy $\left(Q_{M s}, Q_{M d}, Q_{D 90}\right)$ values are shifted towards coarser grain sizes by $\sim 5-15 \mu \mathrm{m}$ compared to the bulk loess grain size proxies and a highfrequency variability is clearly visible in quartz proxies throughout the studied sequence (Fig. 15). Although the fluctuations in the MIS 5e-c paleosol are significant, they are less pronounced compared to those recorded in loess units. Interestingly, the gradual quartz grain size coarsening is restricted only to the interglacial soil and completely absent in the loess layers (from unit 3 upwards). Further, while some in-phase coarse GS events are observed in the bulk and quartz GS records (marked by black arrows in Fig. 15), many coarse GS events in the bulk GS record have no counterparts in the quartz record and vice versa. As demonstrated in Fig. 17, no correlation exist between the bulk and quartz GS proxies and this holds true for all sediment types, i.e. from paleosol to loess. While both the bulk $M_{d}$ and $D_{90}$ values become gradually coarser from paleosols to loess/weathered loess (17/55 vs. 32/84 $\mu \mathrm{m}), Q_{M d}$ and $Q_{D 90}$ show limited change between sediment types (47.8/92 vs. 48.3/99 $\mu \mathrm{m}$; Figs. 15 and 17). The observations that bulk and quartz GS are uncorrelated in the studied profile are somewhat inconsistent with those made by Sun et al. (2006), who found no or only very weak covariance for the Chinese red clays, while relatively high correlations for loess and paleosols. The bulk and quartz GS datasets presented here reveal that applying the bulk or the quartz proxies would lead to different environmental interpretations and reconstructions of the main characteristics of aeolian sedimentation in the past for some intervals of loess formation. Thus, it seems to be a crucial issue to better understand which processes and factors exert control on the bulk/quartz PSDs and how they influence the GS proxies and related climatic/environmental interpretations. 
Bulk loess PSDs are complex functions of many variables such as wind strength, source distance, sediment availability, etc. (Vandenberghe, 2013) and are mixtures of sediment populations derived from different sources and/or transported to the site of deposition by different mechanisms (Sun et al., 2002; Prins et al., 2007; Weltje and Prins, 2007). End member PSDs determined by End Member Modeling Algorithms (EMMA) are dynamic populations of grains responding similarly to the dynamics of sediment dispersal within a system (Prins and Vriend, 2007). The different end members (EM) in the cited works are associated with distinct atmospheric transport mechanisms, modes and travel distances. As such, one or two of the EMs (mostly $\mathrm{EM}_{1-2}$ ) represent an assemblage of grains transported in saltation or short-term suspension during major dust outbreaks, in low suspension clouds from local sources like floodplains/alluvial fans (e.g. Prins et al., 2007; Bokhorst et al., 2011; Vandenberghe, 2013; Nottebaum et al., 2015). At the other end of the grain size spectrum, another end member (mostly $\mathrm{EM}_{3}$ ) represents the continuous background dust load of the atmosphere, and this fine dust is thought to be transported at high elevation $(3-8 \mathrm{~km})$ from distant sources (Sun et al., 2002; Prins et al., 2007; Bokhorst et al., 2011; Varga et al., 2012; Vandenberghe, 2013). However, this interpretation has recently been questioned based on dust storm deposits in China (Qiang et al., 2010). That study concluded that the $<20 \mu \mathrm{m}$ fractions of dust storm deposits are most probably settled by forming aggregates and/or adhering to larger grains, therefore, the fine-grained components of loess in China were most probably transported by dust-producing windstorms from the proximal desert regions and less likely to be transported by high-level flows. Although wind transport modes are thought to have the most profound effect on loess PSDs, grain mobilization and deposition processes seems equally important in shaping PSDs and must be considered in grain size proxy 
interpretations. As will be shown in the following the fine fractions (clay to medium silt) are likely affected in a more complex manner by these mechanisms than the coarse fractions. Wind velocity and grain size records of recent dust storms on the Qinghai-Tibetan Plateau, China reveal moderate positive correlation between $10 \mathrm{~m}$ mean wind speed and the $>63 \mu \mathrm{m}$ fraction and negative for the 63-2, $<10$ and $<2 \mu \mathrm{m}$ fractions (Qiang et al., 2007). The same covariance, however, cannot be seen in more recent data published by Qiang et al. (2010). Early formulations of both the $U$-ratio and GSI were based on the idea that stronger winds result in coarser grain size of settled dust and higher $U$-ratio/GSI values can be interpreted as 'higher energy deposition' (Vandenberghe et al., 1997) or 'stronger wind dynamics' (Rousseau et al., 2002). Such an interpretation would assume a simple negative linear relationship between coarse $(16-44,20-50 \mu \mathrm{m})$ and fine silt to clay $(5.5-16,<20 \mu \mathrm{m})$ fractions appearing in these proxies, but more complicated patterns are seen when the appropriate fractions from our dataset are plotted (Fig. 18). This is no surprise as the final proportion of these fractions, foremost of all the fine silt and clay fractions, within a PSD is affected by numerous stochastic processes as surmised by Wang et al. (2006) and Qiang et al. (2010), too. So, focusing on these fractions and particle mobilization processes, it is well-known that high amounts of dust are released in dust storms through sandblasting (Shao et al., 1993; Alfaro et al., 1997), as discussed in section 3.1.1.9. Alfaro et al. (1997) argued that larger saltating particle impact energies produce smaller dust aerosol particles, thus higher wind speeds would result in finer PSDs of dust, on contrary to the expectations and assumptions made in developing the above bulk loess GS proxies. The models of Shao $(2001,2004)$ predict the same, but the brittle fragmentation theory of dust emission (Kok, 2011a) predict little or no dependence of the dust PSD on wind speed. And indeed, an analysis of published measurements of the emitted dust PSD by Kok (2011b) indicates that the PSD of dust up to $10 \mu \mathrm{m}$ is actually independent of wind speed for transport-limited conditions. In a study of 
dust storm deposits of 17 events in the Qaidam basin Qiang et al. (2010) found no correlation between the volume percentages of fine particles (clay/fine silt) and the wind strength. Furthermore, recent airplane-based measurements of the size-resolved dust flux in the boundary layer show little or no dependence on source region or wind speed for dust sizes up to $\sim 40 \mu \mathrm{m}$ (Rosenberg et al., 2014). Nonetheless, it remains possible that the PSD of dust aerosols generated during saltation under supply-limited conditions depends on the wind speed at emission, but this has yet not been tested in field studies, which have been focused on dust emission from transport-limited environments that are more productive dust sources (Gillette et al., 1974; Maring et al., 2003; Reid et al., 2008; Shao et al., 2011). Since most productive dust sources are transport-limited, these results indicate that the fine silt fraction in loess is independent of the wind speed at emission. However, a possible complicating factor is that fine dust can also be emitted through direct aerodynamic resuspension (Macpherson et al., 2008; Klose and Shao, 2012; Sweeney and Mason, 2013) and, to our knowledge, no information is available on wind speed and PSD relations under this process.

So far we have analyzed the mobilization of grains and it is supposed that after atmospheric transport dust is deposited on the surface via dry or wet deposition. Coarse grains $(>\sim 50 \mu \mathrm{m})$ will settle relatively fast as a result of gravitational settling (Fig. 11b; section 3.1.2.1), so these particles almost always represent a local signal (not considering extreme examples of long atmospheric transport of large, 75-250 $\mu \mathrm{m}$ quartz crystals; Betzer et al., 1988). At the same time, the dry deposition of $<40-50 \mu \mathrm{m}$ particles is profoundly affected by vertical mixing caused by the turbulence of the flow (Goossens, 2008), which is proportional to $u *$ (Nielsen and Teakle, 2004). Higher wind speeds (and friction velocities) will thus hamper deposition of these fine particles, and also may lead to the re-suspension of already deposited particles (Sweeney and Mason, 2013). Also, the dry deposition velocities become lower with decreasing grain size and are influenced by impaction and interception on vegetation elements 
(Fig. 11) and precipitation scavenging is also less efficient towards the fine grains (clay fraction; Figs. 12, 13 and 14), although wet deposition is considered subordinate during glaciations. All these processes allow a long-distance transport for fine dust, and one of the major problems in interpreting loess PSDs is that the source of fine particles is normally not known. These sources can be both proximal and distant, thus, the bulk loess PSDs cannot uniquely be interpreted as resulting from the variance of one specific variable (e.g. wind speed) of a given locale, but the distributions contain local and regional-scale elements and processes having a stochastic nature. Along with this, it seems possible that the moderate correlation between the coarse silt and fine silt/clay fractions in the $U$-ratio or the GSI (Fig. 18) can be explained by the fact that stronger winds (higher $u *$ ) would keep the larger/heavier grains suspended for a longer period of time, while the settling of fine dust is inhibited by higher wind speeds, or if settled, the particles are effectively re-suspended and eroded from the surface. Since both the mobilization and deposition of particles are influenced by many factors (transport/supply-limited conditions, vegetation cover, surface conditions, etc.) as discussed above, a significant scatter and only a moderate correlation in the coarse versus fine silt/clay data is expected, as is the case in our dataset in Fig. 18.

Beyond the above discussed difficulties, three other complicating factors must also be considered. First, a proportion of fine particles in loess is likely to be transported as silt- or sand-sized aggregates (Pye, 1995; Derbyshire et al., 1998; Falkovich et al., 2001; Mason et al., 2003, 2011; Qiang et al., 2010). Minimally and fully dispersed PSDs of three analyzed loess samples clearly demonstrate that the $\sim 1-20 \mu \mathrm{m}$ fractions are affected by aggregation (Fig. 19), which may explain some of the temporal variations in clay and fine silt fractions (Mason et al., 2003). The second factor to be considered is chemical weathering which may produce very fine silt and clay minerals during post-depositional pedogenesis thereby influencing PSDs mainly during interglacial intervals (Xiao et al, 1995; Wang et al., 2006; 
Hao et al., 2008). The third factor is the potential underestimation of the clay $(<2 \mu \mathrm{m})$ fraction by laser diffraction (see above in section 2.2 and e.g. Mason et al., 2003, 2011), which is a methodological issue affecting the fine tail of PSDs.

Obviously, the bulk loess GS proxies $\left(M_{s}, M_{d}, U\right.$-ratio, $\left.G S I\right)$ reflect all the above discussed processes to some extent, so they are integrative and can be interpreted as being the result of a combined local/regional signal of atmospheric properties (wind strength and its variations, vertical mixing) and environmental settings such as topography (Mason et al., 1999; Goossens, 2006; Nottebaum et al., 2014), source distance (Ding et al., 2005; Yang and Ding, 2008), aridity of the source and sink, and vegetation cover (Pye, 1995; Lehmkuhl, 1997). Such an explanation deduced from the above argumentations and discussions agrees well with the latest interpretation of GSI by Rousseau et al. (2011) who stressed the combined effect of local to regional scale wind and precipitation regimes on the dust cycle. One possible way to identify local effects on grain size may be to sample multiple loess profiles or drilling cores to identify spatial patterns of loess thickness and grain size (Muhs et al., 1999, 2008; Mason, 2001; Mason et al., 2003). Thickness and grain size trends may provide insight into sediment transport pathways, source distance, as well as sorting processes, and can help to pick out features in the bulk GS records that are strictly local versus those that are consistently present over a larger area, provided that the sections are ${ }^{14} \mathrm{C}$ or OSL/IRSL-dated in high resolution (Stevens et al., 2013a). This way the local effects of topography, sediment availability and dust source changes can be filtered out. Obviously, all of these arguments imply that the interpretation of the bulk GS record of a single loess section in isolation is always more problematic. 


\subsection{Factors influencing the quartz proxies}

Interpretations of the quartz GS proxies appear to be less compromised compared to bulk loess proxies. First, quartz grains are resistant to alteration in low-temperature environments and their main physical characteristics (dimensions and shape) are unaffected by transport and weathering processes (Xiao et al., 1995), although their surface microtextures preserve information on the mode of entrainment (Vos et al., 2014). Quartz GS is thus not expected to be influenced by pedogenic processes even under the effect of interglacial soil formation. Second, quartz grains are concentrated in coarser fractions (short-term suspension and saltation populations, see Figs. 8, 15, 17 and section 4.1), although they are also present in the finer fractions down to 1-2 $\mu \mathrm{m}$, but in very low proportions (Fig. 1).

Once quartz grains are mobilized by direct aerodynamic lifting or particle impacts, most of them are entrained in saltation, modified saltation or short-term suspension depending on the particle size and the turbulent intensity of the flow, i.e. the friction velocity (Fig. 8; sections 3.1.1.7. and 3.1.1.8.). Over supply-limited surfaces that were likely dominant in periglacial steppe environments (Svircev et al., 2013), the mean impact speed of saltators increases with $u_{*}$ (Houser and Nickling, 2001; Ho et al., 2011) resulting in a size shift of the saltation size distribution towards larger particle sizes with increasing friction velocities. During subsequent dry deposition, larger quartz grains that dominate quartz PSDs settle rapidly due to gravity (Fig. 11b), and their settling is much less affected by turbulence than settling of fine quartz grains (Goossens, 2008) that are present in much lower proportions (Fig. 1). However, a dust storm will be much more rapidly depleted in coarser grains with increasing transport distance than in finer ones, but this again strongly depends on turbulent intensity (Goossens, 2008), at what height the dust is injected into the atmosphere and whether it is above the boundary layer. If the friction velocity is higher, a dust cloud will be less depleted in coarser grains, so quartz grain size is again strongly linked to the flow properties (turbulence/friction velocity, 
wind speed). Upon wet deposition (e.g. during the wet seasons and most likely under interglacial conditions), grains are rapidly removed from the air down to $5 \mu \mathrm{m}$, and coarser grains will be scavenged faster (Figs. 13 and 14, section 3.1.2.2). Based on all of these, the quartz grain size is primarily controlled by transport distance, wind speed and convective conditions during emissions, as this latter will determine the height at which dust is injected into the flow. Thus, the quartz grain size is thought to be a local signal. This is confirmed by single-grain provenance studies using heavy minerals of zircon and rutiles, which also point to more local sources (Stevens et al., 2010, 2013b; Újvári et al., 2012, 2014; Újvári and Klötzli, 2015). Obviously, quartz PSDs are also influenced by the local vegetation as a dust trap and sediment availability (Pye, 1995; Stevens et al., 2011; Vandenberghe, 2013). It is well known that mid-latitude loess landscapes were dominated by forest steppe to open grassland vegetation during the last glaciation (see above in section 3.1.1.6; Willis et al., 2000; Jiang and Ding, 2005; Feurdean et al., 2014; Magyari et al., 2014) and even a grassy vegetation cover can have a profound influence on sediment redistribution patterns (e.g. Suter-Burri et al., 2013) and therefore the resulting loess/quartz grain size, depending on the spatial patterns of vegetation and canopy densities. Although the vegetation effects on quartz PSDs cannot be quantified at the present level of knowledge, some constraints can be placed on sediment availability. If sufficient quartz grains of all size were available in a close source region (e.g. a floodplain some hundreds of meters away from the loess site), the loess quartz GS would be primarily dependent on the magnitude and frequency of dust storms, i.e. the flow characteristics. If intense dust storms were active over the source and depositional region, but the quartz supply would have been limited (also in size), these events would not be recorded by quartz GS in loess sequences. Nevertheless, it can be reasonably assumed that distinct peaks of $Q_{M d}$ and even more $Q_{D 90}$ (or $Q_{M a x}$ of Xiao et al., 1995) mark intense dust storm conditions in the loess record, provided that an abrupt shift to another local source of 
coarse sediments, including quartz grains, can be ruled out. However, the activation of another nearby source and its contribution to the quartz assemblage of a loess sequence may occur, as demonstrated by Stevens et al. (2013a). In conclusion, the $Q_{M d}$ and $Q_{M a x} / Q_{D 90}$ proxies are likely to be indicative of mean and maximum wind strength, or more specifically the magnitude of vertical velocity fluctuations in the first place, provided that a constant and stable local source $(<\sim 1-10 \mathrm{~km})$ of quartz such as very near alluvial fans/floodplains could be assumed. This requirement may be valid for some European loess sites and for shorter timescales, but does not appear to be met for the majority of loess records for example on the Chinese Loess Plateau. Since other factors such as vegetation cover and surface conditions (wetness, surface crust) also influence the quartz PSDs, they cannot be interpreted as unique proxies of wind speed. Still we argue that quartz PSD interpretations are compromised by a more limited set of complicating factors than bulk PSDs and related proxies.

\subsection{Integrative assessment of bulk and quartz grain size proxies}

We suggest here that a combined evaluation of bulk and quartz GS proxies may provide a better insight into environmental changes affecting the dust cycle on local versus regional scales. In the studied Hungarian loess record a coarsening trend can be seen in both the bulk and quartz GS proxies for the lowermost paleosol (unit 2, MIS 5e-c; Fig. 15), as mentioned above. In contrast to this, the same trend is only traceable in the bulk proxies in loess units (from unit 3 upwards), while the quartz proxies vary around a constant mean value. The amplitude of high-frequency variability of the bulk loess grain size proxies in the MIS 5e-c paleosol are much lower than in loess, while the quartz proxy fluctuations are less suppressed in the lowermost soil compared to those in the loess units. Also, a coarsening trend in bulk loess proxies can be seen from MIS 5c, when pedogenesis $\left(\chi_{P}\right)$ started to significantly decrease (Fig. 15), while the quartz proxies exhibit a coarsening trend throughout the MIS 5e- 
c period without showing obvious signs of pedogenic influence. These observations suggest that the bulk loess grain size proxies are weathering-dominated during soil formation periods, while the quartz proxies are not. This agrees well with the findings of Sun et al. (2010b) who observed the attenuation of rapid monsoon signals in paleosols, recorded by bulk grain size proxies, as a function of pedogenic intensity along a transect across the Chinese Loess Plateau. In fact, the major trends in the lowermost paleosol in the studied profile can be explained either by an increase in wind strength from MIS 5e to 5c, a general climate cooling, and/or an increase in source aridity associated with decreasing vegetation cover and increasing sediment supply. Clearly, these factors co-vary and cannot easily be distinguished from each other. Nevertheless, the degree of pedogenesis (and likely precipitation amounts) reached two absolute maxima in the MIS 5e-c soil as revealed by $\chi_{P}$, and exhibit a gradual decrease in the upper part of the paleosol (from MIS 5c to b) thereby broadly supporting the inference on source aridity increase. However, decreasing rainfall would have an effect on the Danube's sediment load and, through the flow dynamics, the grain size of sediments available for transport from this potential source to the loess site, thereby indirectly affecting the loess grain size. Finally, Zhang et al. (1999) proposed that the regional-scale transport of Asian dust during interglacial stages is mainly attributable to non-dust storm processes. As for this hypothesis, the low-amplitude fluctuations in bulk loess proxies in the studied paleosol are likely to be due to post-depositional overprinting, and thus the bulk loess grain size proxies does not provide much information on aeolian activity, while the quartz proxies show highfrequency fluctuations and so do not really fit in the proposed model. Nevertheless, both proxies indicate a different climate state during MIS 5e-c compared to MIS 4-2. As opposed to the interglacial, increasing wind strength during the last glacial is only supported by bulk grain size proxies in loess units. The absence of the coarsening trend in quartz proxies and their large, high-frequency variabilities imply that only the amplitude of 
vertical velocity fluctuations (i.e. turbulence as shown by $Q_{D 90}$ and $Q_{M d}-Q_{D 90}$ ) may have increased towards MIS 2 and the Last Glacial Maximum, while the mean wind speed remained broadly constant as revealed, at least in a qualitative sense, by the $Q_{M d}$ values. A gradual cooling and increasing aridity from MIS 4 to MIS 2 could have resulted in coarsening, but this should be reflected in the quartz proxies, too. Based on the patterns of both GS records considerable changes occurred in the dust cycle when the interglacial climate state switched to glacial conditions at the transition of MIS $5 \mathrm{c}$ to $\mathrm{b}$ as a threshold was passed by the climate system through gradual cooling, source aridity increase and opening of vegetation. The magnitude and perhaps the frequency of dust outbreaks may have increased during MIS 4 and MIS 2 as shown by distinct peaks in bulk (e.g. $\left.M_{d}, D_{90}\right)$ and quartz $\left(Q_{M d}\right.$ and $Q_{D 90}$ ) proxies, while relatively calm periods are seen in early MIS 3 which was a mild interval in the last glaciation (van Andel, 2002). However, any inference on dust storm frequency/magnitude increase remains hypothetical using grain size proxies alone and needs validation from mass accumulation rate (MAR) calculations based on high-resolution absolute age data.

\section{Summary and concluding remarks}

This focused review of dust mobilization, transport and deposition mechanisms attempts to provide a more comprehensive understanding on the influence and control these environmental processes may have on loess PSD variations with the final aim to improve loess bulk and quartz proxy interpretations. Clearly, many if not all of these processes have a stochastic nature and therefore proxy evaluations tend to be difficult. Nevertheless, major trends and patterns are identifiable and knowing the factors actively shaping loess PSDs, some important and valid inferences can be made thereby contributing to the general 
understanding of Late Pleistocene environmental changes that mid-latitude semi-arid regions experienced.

As demonstrated above, quartz proxies seem to be easier interpretable than bulk GS proxies due to a more limited set of environmental factors influencing quartz PSDs. Together with this, we argue that quartz (or bulk) proxies cannot be used to quantitatively reconstruct wind speed values and their variations in the past as did e.g. Wang and Lai (2014), although such models can help in putting constraints on dust source distance variations. With careful site selections (e.g. in Europe), the effect of topography and source distance on PSDs may be eliminated or at least minimized, thereby obtaining a better record of GS variations dominated by other influential factors, such as wind speed at emission and during transport, turbulent intensity, presence of convection, source aridity and sediment availability. By the combined interpretation of bulk and quartz GS proxies temporal changes of the dust cycle from local to regional scales could be better understood. Use of the bulk proxies alone is justified in studies focusing on paleoenvironmental reconstructions on glacial/interglacial timescales and possibly useful to track short-term oscillations of the dust cycle on regional scales. Although mass accumulation rates (MARs) are not reviewed and discussed in this paper, such data, if obtained from high-resolution and high-precision absolute dating of loess (Stevens et al., 2007, 2008; Pigati et al., 2013; Újvári et al., 2014), should be used along with grain size datasets to reach more robust inferences on dust cycle changes. In addition, MAR data would be extremely useful to gain more insight into the supposed link between abrupt climatic shifts in the North Atlantic and mid-latitude loess regions (e.g. Rousseau et al., 2002; 2011; Sun et al., 2012). This is because both bulk GS and MAR are influenced by greatly overlapping environmental factors (Stevens et al., 2006, 2007, 2008), although the influences on both proxies do not consistently co-vary on short, sub-orbital timescales (Stevens and Lu, 2009). 


\section{Acknowledgements}

1512 This work has been funded by a post doc project from the Hungarian Scientific Research 1513 Fund to GÚ (OTKA PD-108639). Additional financial support provided by the Bolyai János 1514 Research Scholarship of the Hungarian Academy of Sciences (GÚ, GV) is gratefully 1515 acknowledged. Constructive and insightful comments by Joe Mason and Thomas Stevens 1516 improved this paper substantially. Editorial handling and comments by Ian Candy is 1517 appreciated.

\section{Author contributions}

1522 GÚ designed the study, performed the field work and sampling with JK. JK did the quartz 1523 separations and all the laser-diffraction grain size analyses, while GÚ performed the MS 1524 measurements. GV analyzed the grain size data. GÚ wrote the paper with the active 1525 participation of JFK. All authors contributed to the interpretation of results. 


\section{References}

Alfaro, S.C., 2008. Influence of soil texture on the binding energies of fine mineral dust particles potentially released by wind erosion. Geomorphology 93, 157-167.

Alfaro, S.C., Gomes, L., 2001. Modeling mineral aerosol production by wind erosion: emission intensities and aerosol distributions in source areas. Journal of Geophysical Research 106, 18075-18084.

Alfaro, S.C., Gaudichet, A., Gomes, L., Maillé, M., 1997. Modeling the size distribution of soil aerosol produced by sandblasting. Journal of Geophysical Research 102, D10, $11239-11249$.

Alfaro, S.C., Gaudichet, A., Gomes, L., Maillé, M., 1998. Mineral aerosol production by wind erosion: aerosol particle sizes and binding energies. Geophysical Research Letters 25, 991-994.

Alfaro, S.C., Rajot, J.L., Nickling, W., 2004. Estimation of PM20 emissions by wind erosion: main sources of uncertainties. Geomorphology 59, 63-74.

An, Z.S., 2000. The history and variability of the East Asian paleomonsoon climate. Quaternary Science Reviews 19, 171-187.

An, Z.S., Porter, S.C., 1997. Millennial-scale climatic oscillations during the last interglaciation in central China. Geology 25, 603-606.

An, Z.S., Kukla, G., Porter, S.C., Xiao, J.L., 1991. Late Quaternary dust flow on the Chinese Loess Plateau. Catena 18, 125-132.

Anderson, R.S., 1987. Eolian sediment transport as a stochastic process: The effects of a fluctuating wind on particle trajectories. Journal of Geology 95, 497-512.

Anderson, R.S., Haff, P.K., 1988. Simulation of eolian saltation. Science 241 820-823. 
Anderson, R.S., Haff, P.K., 1991. Wind modification and bed response during saltation of sand in air, in: Barndorff-Nielsen, O.E., Willets, B.B. (Eds.), Aeolian Grain Transport 1, Acta Mechanica Supplementum 1, pp. 21-51.

Anderson, R.S., Hallet, B., 1996. Simulating magnetic susceptibility profiles in loess as an aid in quantifying rates of dust deposition and pedogenic development. Quaternary Research 45, 1-16.

Andronache, C., 2003. Estimated variability of below-cloud aerosol removal by rainfall for observed aerosol size distributions, Atmospheric Chemistry and Physics 3, 131-143, doi:10.5194/acp-3-131-2003, 2003.

Andronache, C., 2004. Diffusion and electric charge contributions to below-cloud wet removal of atmospheric ultra-fine aerosol particles. Journal of Aerosol Science 35, $1467-1482$.

Andronache, C., Grönholm, T., Laakso, L., Phillips, V., Venäläinen, A., 2006. Scavenging of ultrafine particles by rainfall at a boreal site: observations and model estimations. Atmospheric Chemistry and Physics 6, 4739-4754, doi:10.5194/acp-6-4739-2006.

Antoine, P., Rousseau, D.-D., Moine, O., Kunesch, S., Hatté, C., Lang, A., Tissoux, H., Zöller, L., 2009a. Rapid and cyclic aeolian deposition during the Last Glacial in European loess: a high-resolution record from Nussloch, Germany. Quaternary Science Reviews 28, 2955-2973.

Antoine, P., Rousseau, D.-D., Fuchs, M., Hatté, C., Gauthier, C., Markovic, S.B., Jovanovic, M., Gaudenyi, T., Moine, O., Rossignol, J., 2009b. High resolution record of the last climatic cycle in the southern Carpathian basin at Surduk (Vojvodina, Serbia). Quaternary International 198, 19-36.

Antoine, P., Rousseau, D.-D., Degeai, J-P., Moine, O., Lagroix, F., Kreutzer, S., Fuchs, M., Hatté, C., Gauthier, C., Svoboda, J., Lisá, L., 2013. High-resolution record of the 
environmental response to climatic variations during the Last InterglacialeGlacial cycle in Central Europe: the loess-palaeosol sequence of Dolní Vestonice (Czech Republic). Quaternary Science Reviews 67, 17-38.

Assallay, A.M., Rodgers, C.D.F., Smalley, I.J., Jefferson, I.F., 1998. Silt: 2 - 62 ㅆm, 9-4ø. Earth-Science Reviews 45, 61-88.

Aström, J.A., 2006. Statistical models of brittle fragmentation. Advances in Physics 55, 247 78.

Bagnold, R.A., 1941. The Physics of Blown Sand and Desert Dunes. Chapman and Hall, New York, $265 \mathrm{p}$.

Bartlein, P.J., Harrison, S.P., Brewer, S., Connor, S., Davis, B.A.S., Gajewski, K., Guiot, J., Harrison-Prentice, T.I., Henderson, A., Peyron, O., Prentice, I.C., Scholze, M., Seppä, H., Shuman, B., Sugita, S., Thompson, R.S., Viau, A., Williams, J., Wu, H., 2011. Pollen-based continental climate reconstructions at 6 and 21 ka: a global synthesis. Climate Dynamics 37, 775-802.

Belly, P.Y., 1964. Sand Movement by Wind. Technical Memorandum No. 1. U.S. Army Coastal Engineering Research Center, Washington, D.C.

Belnap, J., 2003. Biological soil crusts and wind erosion, in: Belnap, J., Lange, O.L. (Eds.), Biological Soil Crusts: Structure, Function and Management. Springer, Berlin, pp. 339347.

Belnap, J., Gardner, J.S., 1993. Soil microstructure in soils of the Colorado Plateau: the role of the cyanobacterium Microcoleus vaginatus. Great Basin Naturalist 53, 40-47.

Belnap, J., Gillette, D.A., 1998. Vulnerability of desert biological soil crusts to wind erosion: the influences of crust development, soil texture, and disturbance. Journal of Arid Environments 39, 133-142. 
Betzer, P.R., Carder, K.L., Duce, R.A., Merrill, J.T., Tindale, N.W., Uematsu, M., Costello, D.K., Young, R.W., Feely, R.A., Breland, J.A., Bernstein, R.E., Greco, A.M., 1988. Long-range transport of giant mineral aerosol particles. Nature 336, 568-571.

Blott, S.J., Pye, K., 2001. GRADISTAT: a grain size distribution and statistics package for the analysis of unconsolidated sediments. Earth Surface Processes and Landforms 26, $1237-1248$.

Bokhorst, M.P., Vandenberghe, J., Sümegi, P., Lanczont, M., Gerasimenko, N.P., Matviishina, Z., Markovic, S.B., Frechen, M., 2011. Atmospheric circulation patterns in central and eastern Europe during the Weichselian Pleniglacial inferred from loess grain-size records. Quaternary International 234, 62-74.

Borrmann, S., Jaenicke, R., 1987. Wind tunnel experiments on the resuspension of submicrometer particles from a sand surface. Atmospheric Environment 21, 1891-1898.

Bradák, B., Thamó-Bozsó, E., Kovács, J., Márton, E., Csillag, G., Horváth, E., 2011. Characteristics of Pleistocene climate cycles identified in Cérna Valley loess-paleosol section (Vértesacsa, Hungary). Quaternary International 234, 86-97.

Bradley, E.F., Mulhearn, P.J., 1983. Development of velocity and shear-stress distributions in the wake of a porous shelter fence. Journal of Wind Engineering and Industrial Aerodynamics 15, 145-156.

Braunack, M.V., Hewitt, J.S., Dexter, A.R., 1979. Brittle-fracture of soil aggregates and the compaction of aggregate beds. Journal of Soil Science 30, 653-667.

Breshears, D.D., Whicker, J.J., Johansen, M.P., Pinder III, J.E., 2003. Wind and water erosion and transport in semi-arid shrubland, grassland, and forest ecosystems: quantifying dominance of horizontal wind-driven transport. Earth Surface Processes and Landforms $28,1189-1209$. 
Buggle, B., Hambach, U., Müller, K., Zöller, L., Markovic, S.B., Glaser, B., 2014. Iron mineralogical proxies and Quaternary climate change in SE European loess-paleosol sequences. Catena 117, 4-22.

Chamberlain, A.C., 1967. Transport of lycopodium spores and other small particles to rough surfaces. Proceedings of the Royal Society London 296, 45-70.

Chate, D.M., 2005. Study of scavenging of submicron-sized aerosol particles by thunderstorm rain events. Atmospheric Environment 39, 6608-6619.

Chate, D.M., Rao, P.S.P., Naik, M.S., Momin, G.A., Safai, P.D., Ali, K., 2003. Scavenging of aerosols and their chemical species by rain. Atmospheric Environment 37, 2477-2484.

Chen, F.H., Bloemendal, J., Wang, J.M., Li, J.J., Oldfield, F., 1997. High-resolution multiproxy climate records from Chinese loess; evidence for rapid climatic changes over the last 75 ka. Palaeogeography, Palaeoclimatology, Palaeoecology 130, 323-335.

Chen, W., Fryrear, D.W., 2001. Aerodynamic and geometric diameters of airborne particles. Journal of Sedimentary Research 71, 365-371.

Chepil, W.S., 1951. Properties of soil which influence wind erosion: IV. State of dry aggregate structure. Soil Science, 72 387-401.

Chepil, W.S., 1956. Influence of moisture on erodibility of soil by wind. Soil Science Society of America Proceedings 20, 288-292.

Chepil, W.S., 1965. Transport of soil and snow by wind. Meteorological Monographs 6, $123-132$.

Clayton R.N., Jackson M.L., Sridhar K., 1978. Resistance of quartz silt to isotopic exchange under burial and intense weathering conditions. Geochimica et Cosmochimica Acta 42, $1517-1522$.

Coles, D., 1956. The law of the wake in the turbulent boundary layer. Journal of Fluid Mechanics 1, 191-226. 
Cornelis, W.M., Gabriels, D., 2003. The effect of surface moisture on the entrainment of dune sand by wind: an evaluation of selected models. Sedimentology 50, 771- 790 .

Cornelis, W.M., Gabriels, D., Hartmann, R., 2003. Parameterisation for the threshold shear velocity to initiate deflation of dry and wet sediment. Geomorphology, 59, 43-51.

Cornelis, W.M., Gabriels, D., Hartmann, R., 2004a. A conceptual model to predict the deflation threshold shear velocity as affected by near-surface soil water: I. Theory. Soil Science Society of America Journal 68, 1154-1161.

Cornelis, W.M., Gabriels, D., Hartmann, R., 2004b. A conceptual model to predict the deflation threshold shear velocity as affected by near-surface soil water: II. Calibration and verification. Soil Science Society of America Journal 68, 1162-1168.

Crawley, D., Nickling, W.G., 2003. Drag partition for regularly-arrayed rough surfaces. Boundary-Layer Meteorology 107, 445-468.

Creyssels, M., Dupont, P., El Moctar, A.O., Valance, A., Cantat, I., Jenkins, J.T., Pasini, J.M., Rasmussen, K.R., 2009. Saltating particles in a turbulent boundary layer: experiment and theory. Journal of Fluid Mechanics 625, 47-74.

Csanady, G.T., 1963. Turbulent diffusion of heavy particles in the atmosphere. Journal of Atmospheric Science 20, 201-208.

Cui, B., Komar, P.D., Baba, J., 1983. Settling velocities of natural sand grains in air. Journal of Sedimentary Petrology 53, 1205-1211.

Davenport, H.M., Peters, L.K., 1978. Field studies of atmospheric particulate concentration changes during precipitation, Atmospheric Environment 12, 997-1008.

Davidson, C.I., Miller, J.M., Pleskow, M.A., 1982. The influence of surface structure on predicted particle dry deposition to natural grass canopies. Water, Air and Soil Pollution $18,25-44$. 
Dearing, J.A., Dann, R.J.L., Hay, K., Lees, J.A., Loveland, P.J., Maher, B.A., Ogrady, K., 1996. Frequency-dependent susceptibility measurements of environmental materials. Geophysical Journal International 124, 228-240.

Derbyshire, E., Kemp, R., Meng, X., 1995. Variations in loess and palaeosol properties as indicators of palaeoclimatic gradients across the Loess Plateau of North China. Quaternary Science Reviews 14, 681-697.

Derbyshire, E., Meng, X.M., Kemp, R.A., 1998. Provenance, transport and characteristics of modern Aeolian dust in western Gansu Province, China, and interpretation of the Quaternary loess record. Journal of Arid Environments 39, 497-516.

de Vries, S., van Thiel de Vries, J.S.M., van Rijn, L.C., Arens, S.M., Ranasinghe, R., 2014. Aeolian sediment transport in supply limited situations. Aeolian Research 12, 75-85.

Ding, Z.L., Rutter, N.W., Han, J.T., Liu, T.S., 1992. A coupled environmental system formed at about 2.5 Ma over eastern Asia. Palaeogeography, Palaeoclimatology, Palaeoecology 94, 223-242.

Ding, Z.L., Ren, J.Z., Yang, S.L., Liu, T.S., 1999. Climate instability during the penultimate glaciation: evidence from two high-resolution loess records, China, Journal of Geophysical Research 104, 20123-20132.

Ding, Z.L., Yu, Z.W., Yang, S.L., Sun, J.M., Xiong, S.F., Liu, T.S., 2001. Coeval changes in grain size and sedimentation rate of eolian loess, the Chinese Loess Plateau. Geophysical Research Letters 28, 2097-2100.

Ding, Z.L., Derbyshire, E., Yang, S. L., Yu, Z.W., Xiong, S.F., Liu, T.S., 2002. Stacked 2.6Ma grain size record from the Chinese loess based on five sections and correlation with the deep-sea $\delta^{18} \mathrm{O}$ record. Paleoceanography 17, doi:10.1029/2001PA000725. 
Ding, Z.L., Derbyshire, E., Yang, S.L., Sun, J.M., Liu, T.S., 2005. Stepwise expansion of desert environment across northern China in the past 3.5 Ma and implications for monsoon evolution. Earth and Planetary Science Letters 237, 45-55.

Durán, O., Claudin, P., Andreotti, B., 2011. On aeolian transport: grain-scale interactions, dynamical mechanisms and scaling laws. Aeolian Research 3, 243-270.

Eames, I., Dalziel, S.B., 2000. Dust resuspension by flow around an impacting sphere. Journal of Fluid Mechanics 403, 305-328.

Eldridge, D.J., Leys, J.F., 2003. Exploring some relationships between biological soil crusts, soil aggregation and wind erosion. Journal of Arid Environments 53, 457-466.

Falkovich, A.H., Ganor, E., Levin, Z., Formenti, P., Rudich, Y., 2001. Chemical and mineralogical analysis of individual mineral dust particles. Journal of Geophysical Research 106 (D16), 18029-18036.

Farrell, E.J., Sherman, D.J., 2015. A new relationship between grain size and fall (settling) velocity in air. Progress in Physical Geography, 0309133314562442, DOI: 10.1177/0309133314562442.

Ferguson, R.I., Church, M., 2004. A simple universal equation for grain settling velocity. Journal of Sedimentary Research 74, 933-937.

Ferrandino, F.J., Aylor, D.E., 1985. An explicit equation for deposition velocity. BoundaryLayer Meteorology 31, 197-201.

Feurdean, A., Persoiu, A., Tantau, I., Stevens, T., Magyari, E.K., Onac, B.B., Markovic. S., Andric, M., Connor, S., Galka, M., Hoek, W.S., Lamentowicz, M., Sümegi, P., Persoiu, I., Kolaczek, P., Kuneš, P., Marinova, E., Slowinski, M., Michczyńska, D., Stancikaite, M., Svensson, A., Veski, S., Fărcaş, S., Tămaş, T., Zernitskaya, V., Timar, A., Tonkov, S., Toth, M., Willis, K.J., Płóciennik, M., Gaudeny, T., 2014. Climate variability and 
associated vegetation response throughout Central and Eastern Europe (CEE) between 60 and 8 ka. Quaternary Science Reviews 106, 206-224.

1721

1722

Fécan, F., Marticorena, B., Bergametti, G., 1999. Parametrization of the increase of the aeolian erosion threshold wind friction velocity due to soil moisture for arid and semiarid areas. Annales Geophysicae 17, 149-157.

Fitzsimmons, K.E., Hambach, U., 2014. Loess accumulation during the last glacial maximum: Evidence from Urluia, southeastern Romania. Quaternary International 334-335, 74-85.

Flagan, R.C., Seinfeld, J.H., 1988. Fundamentals of air pollution engineering. Prentice-Hall Inc., Englewood Cliffs, New Jersey. ISBN 0-13-332537-7.

Fletcher, B., 1976. Incipient motion of granular materials. Journal of Physics D: Applied Physics 9, 2471-2478.

Forster, T., Evans, M.E., Heller, F., 1994. The frequency dependence of low field susceptibility in loess sediments. Geophysical Journal International 118, 636-642.

Gillette, D.A., 1977. Fine particulate emissions due to wind erosion. Transactions of the American Society of Agricultural and Biological Engineers 20, 890-897.

Gillette, D.A., Passi, R., 1988. Modeling dust emission caused by wind erosion. Journal of Geophysical Research 93, 14233-14242.

Gillette, D.A., Stockton, P.H., 1989. The effect of nonerodible particles on the wind erosion of erodible surfaces. Journal of Geophysical Research 94, 885-893.

Gillette D.A., Blifford, I.H., Fryrear, D.W., 1974. Influence of wind velocity on size distributions of aerosols generated by wind erosion of soils. Journal of Geophysical Research 79, 4068-4075.

Gillette, D.A., Adams, J., Endo, A., Smith, D., Kihl, R., 1980. Threshold velocities for input of soil particles into the air by desert soils. Journal of Geophysical Research 85, 56215630. 
Gillette, D.A., Adams, J., Kuhs, D., Kihl, R., 1982. Threshold friction velocities and rupture moduli for crusted desert soils for the input of soil particles into the air. Journal of Geophysical Research 87, 9003-9015.

Gillies, J.A., Nickling, W.G., King, J., 2002. Drag coefficient and plant form-response to wind speed in three plant species: Burning Bush (Euonymus alatus), Colorado Blue Spruce (Picea pungens glauca.), and Fountain Grass (Pennisetum setaceum). Journal of Geophysical Research 107, 4760, doi:10.1029/2001JD001259.

Greeley, R., Iversen, J.D., 1985. Wind as a Geological Process on Earth, Mars, Venus, and Titan. New York, Cambridge University Press.

Greenfield, S., 1957. Rain scavenging of radioactive particulate matter from the atmosphere. Journal of Meteorology 14, 115-125.

Gomes, L., Rajot, J.L., Alfaro, S.C., Gaudichet, A., 2003. Validation of a dust production model from measurements performed in semi-arid agricultural areas of Spain and Niger. Catena 52, 257-271.

Goossens, D., 2004. Effect of soil crusting on the emission and transport of wind-eroded sediment: field measurements on loamy sandy soil. Geomorphology 58, 145-160.

Goossens, D., 2005. Quantification of the dry aeolian deposition of dust on horizontal surfaces: an experimental comparison of theory and measurements. Sedimentology 52, 859-873.

Goossens, D., 2006. Aeolian deposition of dust over hills: the effect of dust grain size on the deposition pattern. Earth Surface Processes and Landforms 31, 762-776.

Goossens, D., 2008. Relationships between horizontal transport flux and vertical deposition flux during dry deposition of atmospheric dust particles. Journal of Geophysical Research 113, F02S13, doi:10.1029/2007JF000775. 
Gordon, M., McKenna Neuman, C., 2009. A comparison of collisions of saltating grains with loose and consolidated silt surfaces. Journal of Geophysical Research 114, F04015, doi:10.1029/2009JF001330.

Grover, S.N., Pruppacher, H.R., Hamielec, A.E., 1977. A numerical determination of the efficiency with which spherical aerosol particles collide with spherical water drops due to inertial impaction and phoretic and electric forces. Journal of Atmospheric Science 34, 1655-1663.

Guo, Z.T., Ruddiman, W.F., Hao, Q.Z., Wu, H.B., Qiao, Y.S., Zhu, R.X., Peng, S.Z., Wei, J.J., Yuan, B.Y., Liu, T.S., 2002. Onset of Asian desertification by 22 Myr ago inferred from loess deposits in China. Nature 416, 159-163

Hao, Q., Oldfield, F., Bloemendal, J., Guo, Z., 2008. Particle size separation and evidence for pedogenesis in samples from the Chinese Loess Plateau spanning the past 22 m.y. Geology 36, 727-730.

Heller, F., Liu, X.M., Liu, T.S., Xu, T.C., 1991. Magnetic susceptibility of loess in China. Earth and Planetary Science Letters 103, 301-310.

Heller, F., Shen, C.D., Beer, J., Liu, X.M., Liu, T.S., Bronger, A., Suter, M., Bonani, G., 1993. Quantitative estimations of pedogenic ferrimagnetic formation in Chinese loess and palaeoclimatic implications. Earth and Planetary Science Letters 114, 385-390.

Herbert, F., Beheng, K.D., 1986. Scavenging of airborne particles by collision with water drops--Model studies on the combined effect of essential microdynamic mechanisms. Meteorology and Atmospheric Physics 35, 201-211.

Houser, C.A., Nickling, W.G., 2001. The factors influencing the abrasion efficiency of saltating grains on a clay-crusted playa. Earth Surface Processes and Landforms 26, 491- 505 . 
Ho, T.D., Valance, A., Dupont, P., El Moctar, A.O., 2011. Scaling laws in aeolian sand transport. Physical Review Letters 106, 094501.

Huneeus, N., Schulz, M., Balkanski, Y., Griesfeller, J., Prospero, J., Kinne, S., Bauer, S., Boucher, O., Chin, M., Dentener, F., Diehl, T., Easter, R., Fillmore, D., Ghan, S., Ginoux, P., Grini, A., Horowitz, L., Koch, D., Krol, M.C., Landing, W., Liu, X., Mahowald, N., Miller, R., Morcrette, J.J., Myhre, G., Penner, J., Perlwitz, J., Stier, P., Takemura, T., Zender, C.S., 2011. Global dust model intercomparison in AeroCom phase I, Atmospheric Chemistry and Physics 11, 7781-7816, doi:10.5194/acp-11-77812011, 2011.

Hunt, J.C.R., Nalpanis, P., 1985. Saltating and suspended particles over flat and sloping surfaces, I. Modelling concepts, in: Barndorff-Nielson, O.E., Møller, J.T., Rasmussen, K.R. Willetts, B.B. (Eds.), Proceedings of International Workshop on the Physics of Blown Sand. Aarhus, University of Aarhus, pp. 9-36.

Iversen, J.D., White, B.R., 1982. Saltation threshold on Earth, Mars, and Venus. Sedimentology 29, 111-119.

Iversen, J.D., Rasmussen, K.R., 1999. The effect of wind speed and bed slope on sand transport. Sedimentology 46, 723- 731.

Iversen, J.D., Pollack, J.B., Greeley, R., White, B.R., 1976. Saltation threshold on Mars: The effect of interparticle force, surface roughness, and low atmospheric density. Icarus 29 , $381-393$.

Jackson, P.S., 1981. On the displacement height in the logarithmic profile. Journal of Fluid Mechanics 111, 15-25.

Jaenicke, R., 1993. Tropospheric aerosols, in: Hobbs, P.V. (Ed.), Aerosol-Cloud-Climate Interactions. Academic Press, San Diego, CA, pp. 1-31. 
Jaworek, A., Adamiak, K., Balachandran, W., Krupa, A., Castle, P., Machowski, W., 2002. Numerical simulation of scavenging of small particles by charged droplets. Aerosol Science and Technology 36, 913-924.

Jennings, S.G., 1988. The mean free path in air. Journal of Aerosol Science 19, 159-166.

Jiang, H., Ding. Z.L., 2005. Temporal and spatial changes of vegetation cover on the Chinese Loess Plateau through the last glacial cycle: evidence from spore-pollen records. Review of Palaeobotany and Palynology 133, 23-37.

Kageyama, M., Lainé, A., Abe-Ouchi, A., Braconnot, P., Cortijo, E., Crucifix, M., de Vernal, A., Guiot, J., Hewitt, C. D., Kitoh, A., Kucera, M., Marti, O., Ohgaito, R., OttoBliesner, B., Peltier, W. R., Rosell-Mel'e, A., Vettoretti, G., Weber, S. L., Yu, Y., and MARGO Project members, 2006. Last Glacial Maximum temperatures over the North Atlantic, Europe and western Siberia: a comparison between PMIP models, MARGO sea-surface temperatures and pollen-based reconstructions, Quaternary Science Reviews $25,2082-2102$.

Kawamura, R., 1951. Study of sand movement by wind. Institute of Science and Technology, Tokyo, Report 5, Tokyo, Japan, pp. 95-112.

Kemp, R.A., 2001. Pedogenic modification of loess: significance for palaeoclimatic reconstructions. Earth-Science Reviews 54, 145-156.

King, J., Nickling, W.G., Gillies, J.A., 2005. Representation of vegetation and other nonerodible elements in aeolian shear stress partitioning models for predicting transport threshold. Journal of Geophysical Research 110, F04015, doi:10.1029/2004JF000281.

Kjelgaard, J.F., Chandler, D.G., Saxton, K.E., 2004. Evidence for direct suspension of loessial soils on the Columbia Plateau. Earth Surface Processes and Landforms 29, 221-236. 
Klose, M., Shao, Y., 2012. Stochastic parameterization of dust emission and application to convective atmospheric conditions. Atmospheric Chemistry and Physics 12, 73097320, doi:10.5194/acp-12-7309-2012.

Klose, M., Shao, Y., 2014. Stochastic parameterization of dust emission and application to convective atmospheric conditions. Atmospheric Chemistry and Physics 12, 73097320, doi:10.5194/acp-12-7309-2012.

Kok, J.F., 2010. Difference in the wind speeds required for initiation versus continuation of sand transport on Mars: implications for dunes and dust storms. Physical Review Letters 104, 074502 .

Kok, J.F., 2011a. A scaling theory for the size distribution of emitted dust aerosols suggests climate models underestimate the size of the global dust cycle. Proceedings of the National Academy of Sciences USA 108, 1016-1021.

Kok, J.F., 2011b. Does the size distribution of mineral dust aerosols depend on the wind speed at emission? Atmospheric Chemistry and Physics 11, 10149-10156.

Kok. J.F., Renno, N.O., 2006. Enhancement of the emission of mineral dust aerosols by electric forces Geophysical Research Letters 33 L19s10.

Kok, J.F., Renno, N.O., 2009. A comprehensive numerical model of steady state saltation (COMSALT). Journal of Geophysical Research 114, D17204.

Kok, J.F., Parteli, E.J.R., Michaels, T.I., Karam, B.D., 2012. The physics of wind-blown sand and dust. Reports on Progress in Physics 75, 106901.

Kok, J.F., Mahowald, N.M., Fratini, G., Gillies, J.A., Ishizuka, M., Leys, J., Mikami, M., Park, M.-S., Park, S.-U., Van Pelt, R.S., Zobeck, T.M., 2014a. An improved dust emission model - Part 1: Model description and comparison against measurements. Atmospheric Chemistry and Physics 14, 13023-13041. 
Kok, J.F., Albani, S., Mahowald, N.M., Ward, D.S., 2014b. An improved dust emission model - Part 2: Evaluation in the Community Earth System Model, with implications for the use of dust source functions. Atmospheric Chemistry and Physics 14, 13043-13061.

Konert, M., Vandenberghe, J., 1997. Comparison of laser grain size analysis with pipette and sieve analysis: a solution for the underestimation of the clay fraction. Sedimentology 44, $523-535$.

Kun, F., Herrmann, H.J., 1999. Transition from damage to fragmentation in collision of solids Physical Review E 59, 2623-2632.

Langston, G., McKenna Neuman, C., 2005. An experimental study on the susceptibility of crusted surfaces to wind erosion: a comparison of the strength properties of biotic and salt crusts. Geomorphology 72, 40-53.

Lee, B.E., Soliman, B.F., 1977. An investigation of the forces on three-dimensional bluff bodies in rough wall turbulent boundary layers. Journal of Fluids Engineering 99, 503510.

Lehmkuhl, F., 1997. The spatial distribution of loess and loess-like sediments in the mountain areas of Central and High Asia. Zeitschrift fur Geomorphologie Supplementband 111, $97-116$.

Leong, K.H., 1984. Thermophoresis and diffusiophoresis of large aerosol particles of different shapes. Journal of Aerosol Science 15, 511-517.

Lettau, K., Lettau, H. H., 1978. Experimental and micro-meteorological field studies of dune migration, in: Lettau, K., Lettau, H.H., (Eds.), Exploring the World's Driest Climate, Institute for Environmental Studies, University of Wisconsin Madison, pp. 110-147. 
Li, X., Zhang, H., 2011. Research on threshold friction velocities during dust events over the Gobi Desert in northwest China. Journal of Geophysical Research 116, D20210, doi:10.1029/2010JD015572.

Licht, A., van Cappelle, M., Abels, H.A., Ladant, J.-B., Trabucho-Alexandre, J., FranceLanord, C., Donnadieu, Y., Vandenberghe, J., Rigaudier, T., Lécuyer, C., Terry Jr, D., Adriaens, R., Boura, A., Guo, Z., Naing Soe, A., Quade, J., Dupont-Nivet, G., Jaeger, J.-J., 2014. Asian monsoons in a late Eocene greenhouse world. Nature 513, 501-506.

Liu, T.S., 1985. Loess and the Environment. China Ocean Press, Beljing, 251 p.

Liu, T.S., Ding, Z.L., 1998. Chinese loess and the paleomonsoon. Annual Reviews of Earth and Planetary Sciences 26, 111-145.

Liu, T.S., Ding, Z.L., Chen, M.Y., An, Z.S., 1989. The global surface energy system and the geological role of wind stress. Quaternary International 2, 43-54.

Liu, Q.S., Deng, C.L., Torrent, J., Zhu, R.X., 2007. Review of recent developments in mineral magnetism of the Chinese loess. Quaternary Science Reviews 26, 368-385.

Liu, Q.S., Roberts, A.P., Larrasoana, J.C., Banerjee, S.K., Guyodo, Y., Tauxe, L., Oldfield, F., 2012. Environmental magnetism: principles and applications. Reviews of Geophysics 50, RG4002.

Loosmore, G.A., Hunt, J.R., 2000. Dust resuspension without saltation. Journal of Geophysical Research 105(D16), 20663-20671.

Loosmore, G.A., Cederwall, R.T., 2004. Precipitation scavenging of atmospheric aerosols for emergency response applications: testing an updated model with new real-time data. Atmospheric Environment 38, 993-1003.

Loth, E., 2008. Drag of non-spherical solid particles of regular and irregular shape. Powder Technology 182, 342-353. 
Lu, H., Mason, J.A., Stevens, T., Zhou, Y., Yi, S., Miao, X., 2011. Response of surface processes to climatic change in the dunefields and Loess Plateau of North China during the late Quaternary. Earth Surface Processes and Landforms 36, 1590-1603.

Lu, H., Zhang, F., Liu, X., Duce, R.A., 2004. Periodicities of palaeoclimatic variations recorded by loess-paleosol sequences in China. Quaternary Science Reviews 23, 18911900.

Machalett, B., Oches, E.A., Frechen, M., Zöller, L., Hambach, U., Mavlyanova, N.G., Markovic, S.B., Endlicher, W., 2008. Aeolian dust dynamics in Central Asia during the Pleistocene e driven by the long-term migration, seasonality and permanency of the Asiatic polar front. Geophysics, Geochemistry and Geosystems 8, Q08Q09. doi:10.1029/2007GC001938.

Macpherson, T., Nickling, W.G., Gillies, J.A., Etyemezian, V., 2008. Dust emissions from undisturbed and disturbed supply-limited desert surfaces. Journal of Geophysical Research 113, F02S04, doi:10.1029/2007JF000800.

Magyari, E.K., Kunes, P., Jakab, G., Sümegi, P., Pelánková, B., Schäbitz, F., Braun, M., Chytry, M., 2014. Late Pleniglacial vegetation in eastern-central Europe: are there modern analogues in Siberia. Quaternary Science Reviews 95, 60-79.

Maher, B.A., 1986. Characterisation of soils by mineral magnetic measurements. Physics of the Earth and Planetary Interiors 42, 76-92.

Maher, B.A., Taylor, R.M., 1988. Formation of ultrafine-grained magnetite in soils. Nature $336,368-370$.

Maher, B.A., Thompson, R., 1995. Paleorainfall reconstructions from pedogenic magnetic susceptibility variations in the Chinese loess and paleosols. Quaternary Research 44, $383-391$. 
Malcolm, L.P., Raupach, M.R., 1991. Measurements in an air settling tube of the terminal velocity distribution of soil material. Journal of Geophysical Research 96, 1527515286.

Maring, H., Savoie, D.L., Izaguirre, M.A., Custals, L., Reid, J.S., 2003. Mineral dust aerosol size distribution change during atmospheric transport. Journal of Geophysical Research 108, 8592, doi:10.1029/2002JD002536.

Markovic, S.B., Bokhorst, M., Vandenberghe, J., Oches, E.A., Zöller, L., McCoy, W.D., Gaudenyi, T., Jovanovic, M., Hambach, U., Machalett, B., 2008. Late Pleistocene loesspaleosol sequences in the Vojvodina region, North Serbia. Journal of Quaternary Science $23,73-84$.

Markovic, S.B., Hambach, U., Catto, N., Jovanovic, M., Buggle, B., Machalett, B., Zöller, L., Glaser, B., Frechen, M., 2009. Middle and Late Pleistocene loess sequences at Batajnica, Vojvodina, Serbia. Quaternary International 198, 255-266.

Marshall, J.K., 1971. Drag measurements in roughness arrays of varying density and distribution. Agricultural Meteorology 8, 269-292.

Marticorena, B., Bergametti, G., 1995, Modeling the atmospheric dust cycle: I. Design of a soil-derived emission scheme. Journal of Geophysical Research 100, 16415-16430.

Mason, J.A., 2001. Transport direction of Peoria Loess in Nebraska and implications for loess sources on the central Great Plains. Quaternary Research 56, 79- 86.

Mason, J.A., Jacobs, P.M., Greene, R.S.B., Nettleton, W.D., 2003. Sedimentary aggregates in the Peoria Loess of Nebraska, USA. Catena 53, 377-397.

Mason, J.A., Greene, R.S.B., Joeckel, R.M., 2011. Laser diffraction analysis of the disintegration of aeolian sedimentary aggregates in water. Catena $87,107-118$.

Mason, J.A., Nater, E.A., Hobbs, H.C., 1994. Transport direction of Wisconsinan loess in southeastern Minnesota. Quaternary Research 41, 44- 51. 
Mason, J.A., Nater, E.A., Zanner, C.W., Bell, J.C., 1999. A new model of topographic effects on the distribution of loess. Geomorphology 28, 223-236.

McEwan, I.K., Willetts, B.B., 1991. Numerical model of the saltation cloud, in: BarndorffNielsen, O.E., Willets, B.B. (Eds.), Aeolian Grain Transport 1, Acta Mechanica Supplementum 1, pp. 53-66.

McEwan, I.K., Willetts, B.B., 1993. Adaptation of the near-surface wind to the development of sand transport. Journal of Fluid Mechanics 252, 99-115.

McKenna Neuman, C., 2003. Effects of temperature and humidity upon the entrainment of sedimentary particles by wind. Boundary-Layer Meteorology 108, 61-89.

McKenna Neuman, C., Nickling, W.G., 1989. A theoretical and wind tunnel investigation of the effect of capillary water on the entrainment of sediment by wind. Canadian Journal of Soil Science 69, 79-96.

McKenna Neuman, C., Nickling, W.G., 1994. Momentum extraction with saltation: Implications for experimental evaluation of wind profile parameters. Boundary-Layer Meteorology 68, 35-50.

McKenna Neuman, C., Maxwell, C.D., Boulton, J.W., 1996. Wind transport of sand surfaces crusted with photoautotrophic microorganisms. Catena 27, 229- 247.

McKenna Neuman, C., Maxwell, C., Rutledge, C., 2005. Spatial analysis of crust deterioration under particle impact. Journal of Arid Environments 60, 321-342.

Minvielle, F., Marticorena, B., Gillette, D.A., Lawson, R.E., Thompson, R., Bergametti, G., 2003. Relationship between the aerodynamic roughness length and the roughness density in cases of low roughness density. Environmental Fluid Mechanics 3, 249-267.

Mitha, S., Tran, M.Q., Werner, B.T., Haff, P.K., 1986. The grain-bed impact process in aeolian saltation. Acta Mechanica 63, 267-278.

Muhs, D.R., 2013. The geologic records of dust in the Quaternary. Aeolian Research 9, 3-48. 
Muhs, D.R., Aleinikoff, J.N., Stafford, T.W., Jr., Kihl, R., Been, J., Mahan, S.A., Cowherd, S., 1999. Late Quaternary loess in northeastern Colorado: Part I-Age and paleoclimatic significance. Geological Society of America Bulletin 111, 1861-1875.

Muhs, D.R., Bettis, E.A., Aleinikoff, J.N., McGeehin, J.P., Beann, J., Skipp, G., Marshall, B.D., 2008. Origin and paleoclimatic significance of Quaternary loess in Nebraska: evidence from stratigraphy, chronology, sedimentology, and geochemistry. Geological Society of America Bulletin 120, 1378-1407.

Musick, H.B., Trujillo, S.M., Truman, C.R., 1996. Wind-tunnel modelling of the influence of vegetation structure on saltation threshold. Earth Surface Processes and Landforms 21, $589-605$.

Nalpanis, P., 1985. Saltating and suspended particles over flat and sloping surfaces, II. Experiments and numerical simulations, in: Barndorff-Nielsen, O.E., Møller, J.T., Rasmussen, K.R., Willetts, B.B. (Eds.), Proceedings of International Workshop on the Physics of Blown Sand. Aarhus, University of Aarhus, pp. 37-66.

Nalpanis, P., Hunt, J.C.R., Barrett, C.F., 1993. Saltating particles over flat beds. Journal of Fluid Mechanics 251, 661-685.

Namikas, S.L., 2006. A conceptual model of energy partitioning in the collision of saltating grains with an unconsolidated sediment bed. Journal of Coastal Research 22, 1250 1259.

Nickling, W.G., 1984. The stabilizing role of bonding agents on the entrainment of sediment by wind. Sedimentology $31,111-117$.

Nickling, W.G., 1988. The initiation of particle movement by wind. Sedimentology 35, 499512.

Nickling, W.G., Ecclestone, M., 1981. The effects of soluble salts on the threshold shear velocity of fine sand. Sedimentology $28,1-6$. 
Nickling, W.G., Gillies, J.A., 1993. Dust emission and transport in Mali, West Africa. Sedimentology 40, 859-868.

Nickling, W.G., McKenna Neuman, C., 2009. Aeolian sediment transport, in: Parsons, A., Abrahams, A.D. (Eds.), Geomorphology of Desert Environments. New York, Springer, pp. 517-555.

Nielsen, P., 1993. Turbulence effects on the settling of suspended particles. Journal of Sedimentary Petrology 63, 835-838.

Nielsen, P., Teakle, I.A.L., 2004. Turbulent diffusion of momentum and suspended particles: A finite-mixing-length theory. Physics of Fluids 16, 2342-2348.

Nikuradse, J., 1933. Laws of flow in rough pipes. (1950 translation) National Advisory Committee on Aeronautics, Technical Memorandum No 1292, Washington, DC.

Nottebaum, V., Lehmkuhl, F., Stauch, G., Hartmann, K., Wünnemann, B., Schimpf, S., Lu, H., 2014. Regional grain size variations in aeolian sediments along the transition between Tibetan highlands and north-western Chinese deserts: the influence of geomorphological settings on aeolian transport pathways. Earth Surface Processes and Landforms 39, 1960-1978.

Nottebaum, V., Stauch, G., Hartmann, K., Zhang, J., Lehmkuhl, F., 2015. Unmixed loess grain size populations along the northern Qilian Shan (China): Relationships between geomorphologic, sedimentologic and climatic controls. Quaternary International 372, $151-166$.

Novothny, Á., Frechen, M., Horváth, E., Wacha, L., Rolf, C., 2011. Investigating the penultimate and last glacial cycles of the Sütto loess section (Hungary) using luminescence dating, high-resolution grain size, and magnetic susceptibility data. Quaternary International 234, 75-85. 
Nugteren, G., Vandenberghe, J., 2004. Spatial climatic variability on the Central Loess Plateau (China) as recorded by grain size for the last $250 \mathrm{kyr}$. Global and Planetary Change 41, 185-206.

Nugteren, G., Vandenberghe, J., van Huissteden, J., An, Z.S., 2004. A Quaternary climate record based on grain size analysis from the Luochuan loess section on the Central Loess Plateau, China. Global and Planetary Change 41, 167-183.

O’Brien, P., McKenna Neuman C., 2012. A wind tunnel study of particle kinematics during crust rupture and erosion. Geomorphology 173-174, 149-160.

Oddershede, L., Dimon, P., Bohr, J., 1993. Self-organized criticality in fragmenting. Physical Review Letters 71, 3107-3110.

Okin, G.S., 2008. A new model of wind erosion in the presence of vegetation. Journal of Geophysical Research 113, F02S10, doi:10.1029/2007JF000758.

Okin, G.S., Gillette, D.A. 2001. Distribution of vegetation in wind-dominated landscapes: Implications for wind erosion modeling and landscape processes. Journal of Geophysical Research, 106 (D9), 9673-9683, doi:10.1029/2001JD900052,.

Owen, P.R., 1964. Saltation of uniform grains in air. Journal of Fluid Mechanics 20, 225-242.

Pähtz, T., Kok, J.F., Herrmann, H.J., 2012. The apparent surface roughness of a sand surface blown by wind from an analytical model of saltation. New Journal of Physics 14, 043035 .

Perfect, E., Kay, B.D., 1995. Brittle fracture of fractal cubic aggregates. Soil Science Society of America Journal 59, 969-974.

Peters, K., Eiden, R., 1992. Modelling the dry deposition velocity of aerosol particles to a spruce forest. Atmospheric Environment 26, 2555-2564. 
Petroff, A., Mailliat, A., Amielh, M., Anselmet, F., 2008. Aerosol dry deposition on vegetative canopies. Part I: Review of present knowledge. Atmospheric Environment $42,3625-3653$.

Pigati, J.S., McGeehin, J.P., Muhs, D.R., Bettis III, E.A., 2013. Radiocarbon dating late Quaternary loess deposits using small terrestrial gastropod shells. Quaternary Science Reviews 76, 114-128.

Polakowski, C., Ryzak, M., Bieganowski, A., Sochan, A., Bartminski, P., Debicki, R., Stelmach, W., 2014. The reasons for incorrect measurements of the mass fraction ratios of fine and coarse material by laser diffraction. Soil Science Society of America Journal $79,30-36$.

Porter, S.C., 2001. Chinese loess record of monsoon climate during the last glacialinterglacial cycle. Earth-Science Reviews 54, 115-128.

Porter, S.C., An, Z.S., 1995. Correlation between climate events in the North Atlantic and China during the last glaciation. Nature 375, 305-308.

Prandtl, L., 1935. The mechanics of viscous flows, in: Durand, W.F. (Ed.), Aerodynamic Theory, vol III. Berlin, Springer, pp. 34-208.

Prins, M.A., Vriend, M., 2007. Glacial and interglacial eolian dust dispersal patterns across the Chinese Loess Plateau inferred from decomposed loess grain-size records. Geochemistry, Geophysics, Geosystems 8, Q07Q05, doi:10.1029/2006GC001563.

Prins, M.A., Vriend, M., Nugteren, G., Vandenberghe, J., Lu, H., Zheng, H., Weltje, G.J., 2007. Late Quaternary aeolian dust input variability on the Chinese Loess Plateau: inferences from unmixing of loess grain-size records. Quaternary Science Reviews 26, $230-242$.

Pruppacher, H.R., Klett, J.D., 1997. Microphysics of Clouds and Precipitation. Kluwer Academic Publishers, Dordrecht. 
Pye, K., 1987. Aeolian Dust and Dust Deposits. London, Academic Press Inc.

Pye, K., 1995. The nature, origin and accumulation of loess. Quaternary Science Reviews 14, $653-667$.

Pye, K., Tsoar, H., 1987. The mechanics and geological implications of dust transport and deposition in desert with particular reference to loess formation and dune sand diagenesis in the northern Negev, Israel, in: Frostick, L., Reid, I. (Eds.), Desert Sediments: Ancient and Modern. Geological Society Special Publication 35, pp. $139-156$.

Qiang, M.R., Chen, F.H., Zhou, A.F., Xiao, S., Zhang, J.W., Wang, Z.T., 2007. Impacts of wind velocity on sand and dust deposition during dust storm as inferred from a series of observations in the northeastern Qinghai-Tibetan Plateau, China. Powder Technology $175,82-89$.

Qiang, M., Lang, L., Wang, Z., 2010. Do fine-grained components of loess indicate westerlies: Insights from observations of dust storm deposits at Lenghu (Qaidam Basin, China). Journal of Arid Environments 74, 1232-1239.

Qiao, Y.S., Guo, Z.T., Hao, Q.Z., Yin, Q.Z., Yuan, B.Y., Liu, T.S., 2006. Grain-size features of a Miocene loess-soil sequence at Qinan: Implications on its origin. Science in China: Series D Earth Sciences 49, 731-738.

Qin, X., Cai, B., Liu, T.S., 2005. Loess record of the aerodynamic environment in the east Asia monsoon area since 60,000 years before present. Journal of Geophysical Research 110, B01204, doi:10.1029/2004JB003131.

Rader, D.J., 1990. Momentum slip correction factor for small particles in nine common gases. Journal of Aerosol Science 21, 161-168.

Rajot, J.L., Alfaro, S.C., Gomes, L., Gaudichet, A., 2003. Soil crusting on sandy soils and its influence on wind erosion. Catena 53, 1-16. 
Ramstein, G., Kageyama, M., Guiot, J., Wu, H., Hély, C., Krinner, G., Brewer, S., 2007. How cold was Europe at the Last Glacial Maximum? A synthesis of the progress achieved since the first PMIP model-data comparison. Climate of the Past 3, 331-339.

Rasmussen, K.R., Sorensen, M., 2008. Vertical variation of particle speed and flux density in aeolian saltation: measurement and modeling. Journal of Geophysical Research 113, F02s12.

Raupach, M.R., 1991. Saltation layers, vegetation canopies and roughness lengths, in: Barndorff-Nielsen, O.E., Willets, B.B. (Eds.), Aeolian Grain Transport 1, Acta Mechanica Supplementum 1, pp. 83-96.

Raupach, M.R., 1992. Drag and drag partition on rough surfaces. Boundary-Layer Meteorology 60, 375-395.

Raupach, M.R., 2002. Diffusion of heavy particles in a turbulent flow, in: Raats, P.A.C., Smiles, D.E., Warrick, A.W. (Eds.), Environmental Mechanics: Water, Mass and Energy Transfer in the Biosphere (The Philip Volume). AGU Geophysical Monograph 129 (American Geophysical Union, Washington, DC), pp. 301-316.

Raupach, M.R., Lu, H., 2004. Representation of land-surface processes in Aeolian transport models. Environmental Modelling and Software 19, 93-112.

Raupach, M.R., Gillette, D.A., Leys, J.F., 1993. The effect of roughness elements on wind erosion threshold. Journal of Geophysical Research 98, 3023-3029.

Ravi, S., D’Odorico, P., Over, T.M., Zobeck, T.M., 2004. On the effect of air humidity on soil susceptibility to wind erosion: the case, 1999 of air-dry soils. Geophysical Research Letters 31, L09501, doi:10.1029/2004GL019485.

Ravi, S., Zobeck, T.M., Over, T.M., Okin, G.S., D’Odorico, P., 2006. On the effect of moisture bonding forces in air-dry soils on threshold friction velocity of wind erosion. Sedimentology 53, 597-609. 
Reid, J.S., Reid, E.A., Walker, A., Piketh, S., Cliff, S., Al Mandoos, A., Tsay, S.C., Eck, T.F., 2008. Dynamics of southwest Asian dust particle size characteristics with implications for global dust research. Journal of Geophysical Research 113, D14212, doi:10.1029/2007JD009752.

Rice, M.A., McEwan, I.K., 2001. Crust strength: a wind tunnel study of the effect of impact by saltating particles on cohesive soil surfaces. Earth Surface Processes and Landforms 26, 721-733.

Rice, M.A., Willetts, B.B., McEwan, I.K., 1996. Wind erosion of crusted soil sediments. Earth Surface Processes and Landforms 21, 279-293.

Rice, M.A., Mullins, C.E., McEwan, I.K., 1997. An analysis of soil strength in relation to potential abrasion by saltating particles. Earth Surface Processes and Landforms 22, 869-883.

Rolf, C., Hambach, U., Novothny, Á., Horváth, E., Schnepp, E., 2014. Dating of a Last Glacial loess sequence by relative geomagnetic palaeointensity: A case study from the Middle Danube Basin (Süttő, Hungary). Quaternary International 319, 99-108.

Roney, J.A., White, B.R., 2004. Definition and measurement of dust aeolian threshold. Journal of Geophysical Research 109, F01013, doi:10.1029/2003JF000061.

Rosenberg, P. D., Parker, D. J., Ryder, C. L., Marsham, J. H., Garcia-Carreras, L., Dorsey, J. R., Brooks, I. M., Dean, A. R., Crosier, J., McQuaid, J. B., Washington, R. (2014). Quantifying particle size and turbulent scale dependence of dust flux in the Sahara using aircraft measurements. Journal of Geophysical Research 119, 7577-7598.

Rousseau, D.-D., Antoine, P., Hatté, C., Lang, A., Zöller, L., Fontugne, M., Ben Othman, D., Luck, J.-M., Moine, O., Labonne, M., Bentaleb, I., Jolly, D., 2002. Abrupt millennial climatic changes from Nussloch (Germany) Upper Weichselian eolian records during the last glaciation. Quaternary Science Reviews 21, 1577-1582. 
Rousseau, D.-D., Sima, A., Antoine, P., Hatté, C., Lang, A., Zöller, L., 2007a. Link between European and North-Atlantic abrupt climate changes over the last glaciation. Geophysical Research Letters 34, L22713. 1029/2007/GL031716.

Rousseau, D.-D., Antoine, P., Kunesch, S., Hatté, C., Rossignol, J., Lang, A., Packman, S., 2007b. Evidence of cyclic dust deposition in the US Great plains during the last deglaciation from the high-resolution analysis of the Peoria loess in the Eustis sequence (Nebraska, USA). Earth and Planetary Science Letters 262, 159-174.

Rousseau, D.-D., Antoine, P., Gerasimenko, N., Sima, A., Fuchs, M., Hatté, C., Moine, O., Zöller, L., 2011. North Atlantic abrupt climatic events of the last glacial period recorded in Ukrainian loess deposits. Climate of the Past 7, 221-234.

Rudner, Z.E., Sümegi, P., 2001. Recurring taiga forest-steppe habitats in the Carpathian Basin in the Upper Weichselian. Quaternary International 76/77, 177-189.

Schlichting, H. 1936. Experimentle untersuchungen zum Rauhigkeitsproblem. IngenieurArchiv 7, 1-34. (English Translation: NACA Technical Memorandum 823, 1936).

Sehmel, G.A., 1980. Particle and gas dry deposition: a review. Atmospheric Environment 14, 983-1011.

Seinfeld, J.H., Pandis, S., 2006. Atmospheric Chemistry and Physics: From Air Pollution to Climate Change. 2nd edition, Wiley, New York.

Selah, A., Fryrear, D.W., 1995. Threshold wind velocities of wet soils as affected by wind blown sand. Soil Science 160, 304-309.

Shao, Y.P., 2001. A model for mineral dust emission. Journal of Geophysical Research 106, 20239-20254.

Shao, Y.P., 2004. Simplification of a dust emission scheme and comparison with data. Journal of Geophysical Research 109, D10202, doi:10.1029/2003JD004372.

Shao, Y.P., 2008. Physics and Modelling of Wind Erosion, 2nd ed. Heidelberg, Springer. 
Shao, Y.P., Li, A., 1999. Numerical modelling of saltation in the atmospheric surface layer. Boundary-Layer Meteorology 91, 199-225.

Shao, Y.P., Lu, H., 2000. A simple expression for wind erosion threshold friction velocity. Journal of Geophysical Research 105, 22437-22443.

Shao, Y.P., Raupach, M.R., 1992. The overshoot and equilibration of saltation. Journal of Geophysical Research 97 20559-20564.

Shao, Y.P., Yang, Y., 2008. A theory for drag partition over rough surfaces. Journal of Geophysical Research 113, F02S05, doi:10.1029/2007JF000791.

Shao, Y.P., Raupach, M.R., Findlater, P.A., 1993. Effect of saltation bombardment on the entrainment of dust by wind. Journal of Geophysical Research 98, 12719-12726.

Shao, Y.P., Ishizuka, M., Mikami, M., Leys, J.F., 2011. Parameterization of size-resolved dust emission and validation with measurements. Journal of Geophysical Research 116, D08203, doi:10.1029/2010JD014527.

Sharratt, B.S., Vaddella, V.K., Feng, G., 2013. Threshold friction velocity influenced by wetness of soils within the Columbia Plateau. Aeolian Research 9, 175-182.

Sherman, D.J., Li, B., Ellis, J.T., Farrell, E.J., Maia, L.P., Granja, H., 2013. Recalibrating aeolian sand transport models. Earth Surface Processes and Landforms 38, 169-178.

Shi, C., Zhu, R., Glass, B.P., Liu, Q., Zeman, A., Suchy, V., 2003. Climate variations since the last interglacial recorded in Czech loess. Geophysical Research Letters 30, 1562, doi:10.1029/2003GL017251.

Shinoda, M., Gillies, J.A., Mikami, M., Shao, Y., 2011. Temperate grasslands as a dust source: Knowledge, uncertainties, and challenges. Aeolian Research 3, 271-293.

Slinn, W.G.N., 1982. Prediction for particle deposition to vegetative canopies. Atmospheric Environment 16, 1785-1794. 
Slinn, W.G.N., 1983. Precipitation scavenging, in: Raderson, D. (Ed.), Atmospheric Sciences and Power Production. Division of Biomedical Environmental Research, US Department of Energy (Chapter 11) Washington D.C.

Slinn, W.G.N., Hales, J.M., 1971. A reevaluation of the role of thermophoresis as a mechanism of in- and below-cloud scavenging. Journal of Atmospheric Science 28, $1465-1471$.

Smalley, I.J., 1970. Cohesion of soil particles and the intrinsic resistance of simple soil systems to wind erosion. Journal of Soil Science 21, 154-161.

Smalley, I.J., 1995. Making the material: the formation of silt-sized primary mineral particles for loess deposits. Quaternary Science Reviews 14, 645-651.

Smalley, I.J., Vita-Finzi, C., 1968. The formation of fine particles in sandy deserts and the nature of "desert" loess. Journal of Sedimentary Petrology 38, 766-774.

Smalley, I.J., Markovic, S.B., Svircev, Z., 2011. Loess is [almost totally formed by] the accumulation of dust. Quaternary International 240, 4-11.

Smith, B.J., Wright, J.S., Whalley, W.B., 2002. Sources of non-glacial, loess-size quartz silt and the origins of "desert loess". Earth-Science Reviews 59, 1-26.

Sorensen, M., 1991. An analytic model of wind-blown sand transport, in: Barndorff-Nielsen, O.E., Willets, B.B. (Eds.), Aeolian Grain Transport 1, Acta Mechanica Supplementum 1, pp. 67-81.

Sorensen, M., 2004. On the rate of aeolian sand transport. Geomorphology 59, 53-62.

Sow, M., Alfaro, S.C., Rajot, J.L., Marticorena, B., 2009. Size resolved dust emission fluxes measured in Niger during 3 dust storms of the AMMA experiment. Atmospheric Chemistry and Physics 9, 3881-3891.

Sparmacher, H., Fulber, K., Bonka, H., 1993. Below-cloud scavenging of aerosol particles: Particle-bound radionuclides - Experimental. Atmospheric Environment 27A, 605-618. 
Stevens, T., Lu, H., 2009. Optically stimulated luminescence dating as a tool for calculating sedimentation rates in Chinese loess: comparisons with grain-size records. Sedimentology 56, 911-934.

Stevens, T., Armitage, S.J., Lu, H., Thomas, D.S.G., 2006. Sedimentation and diagenesis of Chinese loess: implications for the preservation of continuous, high-resolution climate records. Geology 34, 849-852.

Stevens, T., Thomas, D.S.G., Armitage, S.J., Lunn, H.R., Lu, H., 2007. Reinterpreting climate proxy records from late Quaternary Chinese loess: a detailed OSL investigation. EarthScience Reviews 80, 111-136.

Stevens, T., Lu, H., Thomas, D.S.G., Armitage, S.J., 2008. Optical dating of abrupt shifts in the Late Pleistocene East Asian monsoon. Geology 36, 415-418.

Stevens, T., Palk, C., Carter, A., Lu, H., Clift, P.D., 2010. Assessing the provenance of loess and desert sediments in northern China using $\mathrm{U}-\mathrm{Pb}$ dating and morphology of detrital zircons. Geological Society of America Bulletin 122, 1331-1344.

Stevens, T., Markovic, S.B., Zech, M., Hambach, U., Sümegi, P., 2011. Dust deposition and climate in the Carpathian Basin over an independently dated last glacialeinterglacial cycle. Quaternary Science Reviews 30, 662-681.

Stevens, T, Adamiec, G., Bird, A.F., Lu, H., 2013a. An abrupt shift in dust source on the Chinese Loess Plateau revealed through high sampling resolution OSL dating. Quaternary Science Reviews 82, 121-132.

Stevens, T., Carter, A., Watson, T.P., Vermeesch, P., Andó, S., Bird, A.F., Lu, H., Garzanti, E., Cottam, M.A., Sevastjanova, I., 2013b. Genetic linkage between the Yellow River, the Mu Us desert and the Chinese Loess Plateau. Quaternary Science Reviews 78, 355368.

Stout, J.E., Zobeck, T.M., 1997. Intermittent saltation. Sedimentology 44, 959-970. 
Stull, R.B., 1988. An Introduction to Boundary Layer Meteorology. Dordrecht, Kluwer.

Sun, J.M., 2002. Provenance of loess material and formation of loess deposits on the Chinese Loess Plateau. Earth and Planetary Science Letters 203, 845-859.

Sun, D., Bloemendal, J., Rea, D.K., Vandenberghe, J., Jiang, F., An, Z., Su, R., 2002. Grainsize distribution function of polymodal sediments in hydraulic and aeolian environments, and numerical partitioning of the sedimentary components. Sedimentary Geology 152, 263-277.

Sun, Y.B., Lu, H.Y., An, Z.S., 2000. Grain size distribution of quartz isolated from Chinese loess/paleosol. Chinese Science Bulletin 45, 2296-2298.

Sun, Y.B., Lu, H.Y., An, Z.S., 2006. Grain size of loess, palaeosol and Red Clay deposits on the Chinese Loess Plateau: Significance for understanding pedogenic alteration and palaeomonsoon evolution. Palaeogeography, Palaeoclimatology, Palaeoecology 241, $129-138$.

Sun, Y.B., An, Z.S., Clemens, S.C., Bloemendal, J., Vandenberghe, J., 2010a. Seven million years of wind and precipitation variability on the Chinese Loess Plateau. Earth and Planetary Science Letters 297, 525-535.

Sun, Y.B., Wang, X., Liu.Q.S., Clemens, S.C., 2010b. Impacts of post-depositional processes on rapid monsoon signals recorded by the last glacial loess deposits of northern China. Earth and Planetary Science Letters 289, 171-179.

Sun, Y.B., Clemens, S.C., Morrill, C., Lin, X., Wang, X., An, Z.S., 2012. Influence of Atlantic meridional overturning circulation on the East Asian winter monsoon. Nature Geoscience 5, 46-49.

Suter-Burri, K., Gromke, C., Leonard, K.C., Graf, F., 2013. Spatial patterns of aeolian sediment deposition in vegetation canopies: Observations from wind tunnel experiments using colored sand. Aeolian Research 8, 65-73. 
Sümegi, P., Krolopp, E., 2002. Quatermalacological analysis for modeling the upper Weichselian palaeoenvironmental changes in the Carpathian Basin. Quaternray International 91, 53-63.

Sümegi, P., Gulyás, S., Csökmei, B., Molnár, D., Hambach, U., Stevens, T., Markovic, S.B., Almond, P.C., 2012. Climatic fluctuations inferred for the Middle and Late Pleniglacial (MIS 2) based on high-resolution ( ca. 20 y) preliminary environmental magnetic investigation of the loess section of the Madaras brickyard (Hungary). Central European Geology 55, 329-345.

Sümegi, P., Magyari, E., D_aniel, P., Moln_ar, M., Törőcsik, T., 2013. Responses of terrestrial ecosystems to Dansgaard-Oeshger cycles and Heinrich-events: a 28,000-year record of environmental changes from SE Hungary. Quaternary International 293, $34-50$.

Svircev, Z., Markovic, S.B., Stevens, T., Codd, G.A., Smalley, I., Simeunovic, J., Obreht, I., Dulic, T., Pantelic, D., Hambach, U., 2013. Importance of biological loess crusts for loess formation in semi-arid environments. Quaternary International 296, 206-215.

Sweeney, M.R., Mason, J.A., 2013. Mechanisms of dust emission from Pleistocene loess deposits, Nebraska, USA. Journal of Geophysical Research 118, 1460-1471.

Syers, J.K., Chapman, S.L., Jackson, M.L., 1968. Quartz isolation from rocks, sediments and soils for determination of oxygen isotopes composition. Geochimica et Cosmochimica Acta $32,1022-1025$.

Terhorst, B., Kühn, P., Damm, B., Hambach, U., Meyer-Heintze, S., Sedov, S., 2014. Paleoenvironmental fluctuations as recorded in the loess-paleosol sequence of the Upper Paleolithic site Krems-Wachtberg, Quaternary International, 351, 67-82.

Thom, A.S., 1971. Momentum absorption by vegetation. Quarterly Journal of the Royal Meteorological Society 97, 414-428. 
Tsoar, H., Pye, K., 1987. Dust transport and the question of desert loess formation. Sedimentology 34, 139-153.

Tuller, M., Or, D., 2005. Water films and scaling of soil characteristic curves at low water contents. Water Resources Research 41, W09403.

Újvári, G., Mentes, Gy., Bányai, L., Kraft, J., Gyimóthy, A., Kovács, J., 2009. Evolution of a bank failure along the River Danube at Dunaszekcső, Hungary. Geomorphology 109, 197-209.

Újvári, G., Varga, A., Ramos, F.C., Kovács, J., Németh, T., Stevens, T., 2012. Evaluating the use of clay mineralogy, $\mathrm{Sr}-\mathrm{Nd}$ isotopes and zircon $\mathrm{U}-\mathrm{Pb}$ ages in tracking dust provenance: an example from loess of the Carpathian Basin. Chem Geol 304-305, 8396.

Újvári, G., Klötzli, U., Kiraly, F., Ntaflos, T., 2013. Towards identifying the origin of metamorphic components in Austrian loess: insights from detrital rutile chemistry, thermometry and U-Pb geochronology. Quaternary Science Reviews 75, 132-142.

Újvári, G., Molnár, M., Novothny, Á., Páll-Gergely, B., Kovács, J., Várhegyi, A., 2014. AMS ${ }^{14} \mathrm{C}$ and OSL/IRSL dating of the Dunaszekcső loess sequence (Hungary): chronology for 20 to $150 \mathrm{ka}$ and implications for establishing reliable age-depth models for the last 40 ka. Quaternary Science Reviews 106, 140-154.

Újvári, G., Klötzli, U., 2015. U-Pb ages and Hf isotopic composition of zircons in Austrian last glacial loess: constraints on heavy mineral sources and sediment transport pathways. International Journal of Earth Sciences 104, 1365-1385.

Ungar, J.E., Haff, P.K., 1987. Steady state saltation in air. Sedimentology 34, 289-299.

Van Andel, T.H., 2002. Climate and landscape of the middle part of the Weichselian glaciation in Europe: the Stage 3 Project. Quaternary Research 57, 2-8. 
Vandenberghe, J., 2013. Grain size of fine-grained windblown sediment: A powerful proxy for process identification. Earth-Science Reviews 121, 18-30.

Vandenberghe, J., Nugteren, G., 2001. Rapid climatic changes recorded in loess successions, Global and Planetary Change 28, 1-9.

Vandenberghe, J., Mücher, H.J., Roebroeks, W., Gemke, D., 1985. Lithostratigraphy and palaeoenvironment of the Pleistocene deposits at Maastricht-Belvedere, Southern Limburg, The Netherlands. Meded. Rijks Geol. Dienst, Nieuwe Ser. (Neth.) 39, 7-18.

Vandenberghe, J., An, Z.S., Nugteren, G., Lu, H., van Huissteden, J., 1997. New absolute time scale for the Quaternary climate in the Chinese loess region by grain-size analysis. Geology 25, 35-38.

Varga, Gy., Kovács, J., Újvári, G., 2012. Late Pleistocene variations of the background aeolian dust concentration in the Carpathian Basin: an estimate using decomposition of grain-size distribution curves of loess deposits. Netherlands Journal of Geosciences Geologie en Mijnbouw 91, 159-171.

Varga, Gy., Újvári, G., Kovács, J., Szalai, Z., 2015. Effects of particle optical properties on grain size measurements of aeolian dust deposits. Geophysical Research Abstracts 17, EGU2015-9848-1.

Venkatram, A., Pleim, J., 1999. The electrical analogy does not apply to modeling dry deposition of particles. Atmospheric Environment 33, 3075-3076.

von Kármán, T., 1930. Mechanische Ähnlichkeit und Turbulenz. Nachrichten von der Gesellschaft der Wissenschaften zu Göttingen, Fachgruppe 1 (Mathematik) 5, 58-76.

Vos, K., Vandenberghe, N., Elsen, J., 2014. Surface textural analysis of quartz grains by scanning electron microscopy (SEM): From sample preparation to environmental interpretation. Earth-Science Reviews 128, 93-104. 
Walter, B., Gromke, C., Lehning, M., 2012. Shear-stress partitioning in live plant canopies and modifications to Raupach's model. Boundary-Layer Meteorology 144, 217-241.

Wang, T-Z., Lai, Z-P., 2014. A theoretical model on the relation between wind speed and grain size in dust transportation and its paleoclimatic implications. Aeolian Research 13, $105-108$.

Wang, P.K., Grover, S.N., Pruppacher, H.R., 1978. On the effect of electric charge on the scavenging of aerosol particles by clouds and small raindrops. Journal of Atmospheric Science 35, 1735-1743.

Wang, H., Mason, J.A., Balsam, W.L., 2006. The importance of both geological and pedological processes in control of grain size and sedimentation rates in Peoria Loess. Geoderma 136, 388-400.

Wang, X., Zhang, L., Moran, M.D., 2010. Uncertainty assessment of current size-resolved parameterizations for below-cloud particle scavenging by rain. Atmospheric Chemistry and Physics 10, 5685-5705.

Weltje, G.J., Prins, M.A., 2007. Genetically meaningful decomposition of grain size distributions. Sedimentary Geology 202, 409-424.

Wesely, M.L., Hicks, B.B., 2000. A review of the current status of knowledge on dry deposition. Atmospheric Environment 34, 2261-2282.

Whalley, W.B., Marshall, J.R., Smith, B.J., 1982. Origin of desert loess from some experimental observations. Nature 300, 433-435.

White, F.M., 2006. Viscous Fluid Flow. New York, McGraw-Hill.

Whitmore, P.J., 1981. Thermo- and diffusiophoresis for small aerosol particles. Journal of Aerosol Science 12, 1-9.

Whitmore, P.J., Meisen, A., 1976. The theory of diffusiophoresis for large aerosol particles. Journal of Aerosol Science 7, 297-310. 
Wiggs, G.F.S., Atherton, R.J., Baird, A.J., 2004. Thresholds of aeolian sand transport: establishing suitable values. Sedimentology 51, 95-108.

Williams, G., 1964. Some aspects of the eolian saltation load. Sedimentology, 3, 257- 287.

Willis, P.T., 1984. Functional fits to some observed drop size distributions and parameterization of rain. Journal of Atmospheric Science 41, 1648-1661.

Willis, K.J., Rudner, E., Sumegi, P., 2000. The full-glacial forests of central and southeastern Europe. Quaternary Research 53, 203-213.

Willis, K.J., van Andel, T.H., 2004. Trees or no trees? the environments of central and eastern Europe during the Last Glaciation. Quaternary Science Reviews 23, 2369-2387.

Wolfe, S.A., Nickling, W.G., 1996. Shear stress partitioning in sparsely vegetated desert canopies. Earth Surface Processes and Landforms 21, 607-619.

Worm, H.-U., 1998. On the superparamagnetic-stable single domain transition for magnetite, and frequency dependency of susceptibility. Geophysical Journal International 133, 201-206.

Wright, J.S., 1995. Glacial comminution of quartz sand grains and the production of loessic silt: a simulation study. Quaternary Science Reviews 14, 669-680.

Wright, J.S., 2001. "Desert" loess versus "glacial” loess; quartz silt formation, source areas and sediment pathways in the formation of loess deposits. Geomorphology 36, $231-256$.

Wright, J.S., 2007. An overview of the role of weathering in the production of quartz silt. Sedimentary Geology 202, 337-351.

Wright, J.S., Smith, B.J., 1993. Fluvial comminution and the production of loess-sized quartz silt: a simulation study. Geografiska Annaler 75A, 23-34. 
Wright, J.S., Smith, B.J., Whalley, W.B., 1998. Mechanisms of loess-sized quartz silt production and their relative effectiveness: laboratory simulations. Geomorphology 23, $15-34$.

Wu, H., Guiot, J., Brewer, S., Guo, Z., 2007. Climatic changes in Eurasia and Africa at the Last Glacial Maximum and mid-Holocene: reconstruction from pollen data using inverse vegetation modelling, Climate Dynamics 29, 211-229.

Wyngaard, J.C., 2010. Turbulence in the Atmosphere. Cambridge University Press.

Xiao, J.L., Porter, S.C., An, Z.S., Kumai, H., Yoshikawa, S., 1995. Grain size of quartz as an indicator of winter monsoon strength on the Loess Plateau of central China during the last 130,000 yr. Quaternary Research 43, 22-29.

Yang, S., Ding, Z.L., 2008. Advance-retreat history of the East-Asian summer monsoon rainfall belt over northern China during the last two glacial-interglacial cycles. Earth and Planetary Science Letters 274, 499-510.

Zender, C.S., Bian, H.S., Newman, D., 2003. Mineral Dust Entrainment and Deposition (DEAD) model: description and 1990s dust climatology. Journal of Geophysical Research 108, D14, 4416.

Zhang, X.Y., Arimoto, R., An, Z.S., 1999. Glacial and interglacial patterns for Asian dust transport. Quaternary Science Reviews 18, 811-819.

Zhang, L., Gong, S., Padro, J., Barrie, L., 2001. A size-segregated particle dry deposition scheme for an atmospheric aerosol module. Atmospheric Environment 35, 549-560.

Zhang, J., Shao, Y.P., 2014. A new parameterization of particle dry deposition over rough surfaces. Atmospheric Chemistry and Physics 14, 12429-12440.

Zhou, L.P., Oldfield, F., Wintle, A.G., Robinson, S.G., Wang, J.T., 1990. Partly pedogenic origin of magnetic variations in Chinese loess. Nature 346, 737-739. 
2425 Zobeck, T.M., 1991. Abrasion of crusted soils: influence of abrader flux and soil properties.

2426 Soil Science Society of America Journal 55, 1091-1097.

2427 


\section{Figure captions}

Figure 1. Typical loess/soil bulk and quartz particle size distributions from the studied profile at Dunaszekcső with the most widely used bulk loess grain size proxies. Samples shown are Dsz-GS-018 (loess, bulk/quartz: thin/bold black line), Dsz-GS-104 (loess, bulk/quartz: thin/bold red line) and Dsz-GS-290 (paleosol, bulk/quartz: thin/bold blue line). Abbreviations: M.sd. - medium sand, C.sd. - coarse sand, C.s. - coarse silt, Md grain size - median grain size, GSI - grain size index, PM - pipette method (based on Stokes sedimentation), LPS - laser particle sizer (based on forward scattering of monochromatic coherent light). Size limits of clay, silt and sand fractions determined by laser particle sizer are different from those given by the pipette method (e.g. clay $=<2 \mu \mathrm{m}$ for the PM, while it is $<4.6 / 5.5 \mu \mathrm{m}$ for LPS; Konert and Vandenberghe, 1997).

Figure 2. Location of the Dunaszekcsö loess sequence in the Carpathian Basin.

Figure 3. Scanning electron microscopy images of isolated quartz particles. a) Angular quartz grain from sample Dsz-GS-150, b) surface with v-shaped impact features of the same quartz particle from sample Dsz-GS-150, c) Quartz grain with conchoidal fractures and v-shaped percussion cracks from sample Dsz-GS-293, d) Blow-up of the quartz surface with v-shaped percussion cracks and breakage with sharp edges (sample Dsz-GS-293).

Figure 4. Relationship between $\chi_{\mathrm{FD}}\left(=\chi_{\mathrm{LF}}-\chi_{\mathrm{HF}}\right)$ and low field susceptibility $\left(\chi_{\mathrm{FD}}\right) \cdot \chi_{\mathrm{B}}$ is the background susceptibility.

Figure 5. Measurements and models of threshold friction velocities required to initiate particle motion on dry sand surfaces. Models were run for quartz spheres $\left(\rho_{p-Q}=2650 \mathrm{~kg}\right.$ $\mathrm{m}^{-3}$ ). Some of the measurements of the fluid threshold were done on materials other than sand and dust (Fletcher, 1976; Iversen et al., 1976; Iversen and White, 1982), and for these the effect of different densities were taken into account by calculating the equivalent particle diameter $\left(D_{p-e q v}=D_{p} \rho_{p} / \rho_{p-Q}\right.$, Chepil, 1951). The fluid threshold was calculated with air 
2453

2454

2455

2456

2457

2458

2459

2460

2461

2462

2463

2464

2465

2466

2467

2468

2469

2470

2471

2472

2473

2474

2475

2476

parameters of $\rho_{a}=1.225 \mathrm{~kg} \mathrm{~m}^{-3}$ and $v_{a}=1.47 \times 10^{-5} \mathrm{~m}^{2} \mathrm{~s}^{-1}$ (at $15^{\circ} \mathrm{C}$ ) in the Iversen and White (1982) model (for the equations the reader is referred to the original paper or Kok et al., 2012), while $\gamma=3 \times 10^{-4} \mathrm{~N} \mathrm{~m}^{-1}$ was used in the Shao and Lu (2000) model (Eq. 3.9). The Bagnold (1941) model is given by Eq. 3.7 in the text.

Figure 6. Measured and modeled 'wet' threshold friction velocity as a function of gravimetric soil moisture for a) loamy fine sand and sandy loam, and b) clay loam and clay soils.

Measurements for different soils are from Selah and Fryrear (1995). The empirical model, $u_{* t w}=0.305+0.022\left(\theta_{g} / \theta_{g 1.5}\right)+0.506\left(\theta_{g} / \theta_{g 1.5}\right)^{2}$, of Selah and Fryrear (1995) is compared with theoretical models of Fécan et al. (1999) (Eq. 3.13-3.14) and Cornelis et al. (2004a) (Eq. 3.153.16). For all model calculations $u_{*}=0.31 \mathrm{~m} \mathrm{~s}^{-1}$ has been used, as published by Selah and Fryrear (1995) for the oven-dried soils without abrasion. The CGH (2004a) model is only given for the loamy fine sand soil, with parameters of $D_{p}=130 \mu \mathrm{m}$ and surface tension of water at $15^{\circ} \mathrm{C}, \gamma_{s t}=0.0735 \mathrm{~N} \mathrm{~m}^{-1}$. The rest of the parameters $\left(A_{C o 1}, A_{C o 2}, A_{C o 3}\right)$ are as defined in the text.

Figure 7. Particle terminal velocity as a function of grain size. Settling tube experimental data originate from Cui et al. (1983) and Malcolm and Raupach (1991). Newton's Impact Law (Eq. 3.24), the Stokes Law (Eq. 3.26), and the Ferguson and Church (2004) and Farrell and Sherman (2015) models are also shown. For calculating $w_{t}$ using the Impact and Stokes Laws quartz density of $2650 \mathrm{~kg} \mathrm{~m}^{-3}$ and air density at $15^{\circ} \mathrm{C}$ of $1.2256 \mathrm{~kg} \mathrm{~m}^{-3}$ are used. $C_{d}$ has been derived for Eq. 3.24 by solving Eq. 3.27-3.28 numerically. For calculations using Eq. 3.26 a kinematic viscosity of air at $15^{\circ} \mathrm{C}$ of $1.455 \times 10^{-5} \mathrm{~m}^{2} \mathrm{~s}^{-1}$ has been used and $C_{c}$ is computed following Rader (1990). Fall velocity has been calculated using the Ferguson and Church (2004) expression (their Eq. 4) with parameters for natural sand of $C_{l}=18$ and $C_{2}=1$. Terminal velocity calculations based on the Farrell and Sherman (2015) model (their Eq. 18) are only 
2477

2478

2479

2480

2481

2482

2483

2484

2485

2486

2487

2488

2489

2490

2491

2492

2493

2494

2495

2496

2497

2498

2499

2500

2501

given for the very fine to medium sand fractions, since this expression is valid only for the sand fraction.

Figure 8. Transport modes of quartz grains as a function of friction velocity and particle diameter. The most widely used grain size proxies are also shown in this context. Terminal velocities are from Ferguson and Church (2004) with parameters as defined in Fig. 7.

Transport modes with different $w_{t} / u *$ values as limits are from Gillette et al. (1974), Hunt and Nalpanis (1985), Nalpanis (1985), Tsoar and Pye (1987) and Shao (2008). Typical friction velocities in dust storms originate from Tsoar and Pye (1987), Li and Zhang (2011), while typical $M_{d}$ grain size of loess are from Tsoar and Pye (1987), Derbyshire et al. (1995), Pye (1995), Shi et al. (2003), Ding et al. (2005), Prins et al. (2007), Yang and Ding (2008), Varga et al. (2012), and Vandenberghe (2013).

Figure 9. Measured and modeled streamwise saltation flux as a function of friction velocity. Wind tunnel data for the transport rate of 230 and $242 \mu \mathrm{m}$ diameter sands are from Iversen and Rasmussen (1999) and Sorensen (2004) (transport-limited situation), while for noncohesive, clay and salt crusted surfaces (all three undisturbed) are from Macpherson et al. (2008) (supply-limited situations). Saltation mass flux is calculated for sand with a diameter of $250 \mu \mathrm{m}$ and an air density of $1.2256 \mathrm{~kg} \mathrm{~m}^{-3}$ (at $15^{\circ} \mathrm{C}$ ) using model equations of 3.30-3.32 and parameters as defined in the text (section 3.1.1.8.). These theoretical models of Bagnold (1941), Kawamura (1951), Durán et al. (2011) and Kok et al. (2012) are proposed for transport-limited situations.

Figure 10. Vertical dust flux as a function of shear velocity due to a) direct aerodynamic entrainment and b) saltation bombardment. In panel a), long-term dust flux measurements and the best-fit model are from Loosemore and Hunt (2000) (=LH2000), while the rest of the data are from experiments of Macpherson et al. (2008) (=M2008) carried out on supply-limited non-cohesive, clay crusted and salt crusted surfaces. In panel b), field measurements during 
2502

2503

2504

2505

2506

2507

2508

2509

2510

2511

2512

2513

2514

2515

2516

2517

2518

2519

2520

2521

2522

2523

2524

2525

different erosion events are from Gomes et al. (2003) (=G2003) and Sow et al. (2009) (=S2009), while the bold lines are Eq. 3.37-38, and represents models of Gillette and Passi (1988) (=GP1988) and Shao et al. (1993) (=S1993). The model by Kok et al. (2012) $(=\mathrm{K} 2012)$ is given as $F_{d, s}=\alpha_{K} u_{* t}\left(u_{*}^{2}-u_{* t}^{2}\right)$, which uses $u_{* t}=0.20 \mathrm{~m} \mathrm{~s}^{-1}$ and is normalized to yield $10000 \mu \mathrm{g} \mathrm{m}^{-2} \mathrm{~s}^{-1}$ at $u_{*}=1 \mathrm{~m} \mathrm{~s}^{-1}$.

Figure 11. Collection efficiency a) and dry deposition velocity b) as a function of particle size. Total collection efficiency, $\varepsilon$, and collection efficiency from Brownian diffusion, $E_{B}$, interception, $E_{I N}$, as well as impaction, $E_{I M}$, are given for grass using the Slinn (1982) parameterization. For dry deposition calculations $u *=0.5 \mathrm{~m} \mathrm{~s}^{-1}$ and $\rho_{p}=2650 \mathrm{~kg} \mathrm{~m}^{-3}$ was used in all models. Parameters in the Slinn (1982) scheme: $c_{\vee} / c_{d}=0.33, f_{I N}=0.01, R^{\prime}=20 \mu \mathrm{m}, R^{\prime \prime}=1$ $\mathrm{mm}, b=2, z_{0}=40 \mathrm{~mm}, h_{c}=20 \mathrm{~cm}, \gamma_{S l}=4$. The model of Zhang et al. (2001) is applied to land use categories of 3 (deciduous, need leaf trees), 6 (grass) and 10 (shrub and interrupted woodland) with parameters of $z_{0}=0.6,0.05$ and $0.1, \alpha_{Z}=1.1,1.2$ and $1.3, \beta_{Z}=2, \gamma_{Z}=0.56,0.54$ and 0.54 , $R_{c}=2,2$ and $10 \mathrm{~mm}$. The most recent Zhang and Shao (2014) scheme is applied to two surface categories (sand and plant) with parameters of $z_{r}=250$ and $15 \mathrm{~mm}, z_{0}=2.877$ and $0.135 \mathrm{~mm}$, $d=200$ and $0 \mathrm{~mm}, h_{c r}=230$ and $0.1 \mathrm{~mm}, d_{c}=5$ and $0.2 \mathrm{~mm}, \lambda_{f}=0.4$ and $0.125, A_{\text {in }}=150$ and 1 , $b=1$.

Figure 12. a) Contributions to total collision efficiency between a raindrop $\left(D_{r d}=1 \mathrm{~mm}\right)$ and dust particles and b) total collision efficiency $\left(\varepsilon_{w}\right)$ for different rain droplet sizes. Collection efficiencies from Brownian diffusion $\left(E_{B w}\right)$, interception $\left(E_{I N w}\right)$ and inertial impaction $\left(E_{I M w}\right)$ are calculated based on the Slinn (1984) model with modifications to include thermophoresis $\left(E_{T P w}\right)$, diffusiophoresis $\left(E_{D P w}\right)$, and electrostatic mechanisms $\left(E_{E S w}\right)$ after Davenport and Peters (1978) and Andronache et al. (2004, 2006). Parameters $\left(15^{\circ} \mathrm{C}\right): \rho_{p}=1000 \mathrm{~kg} \mathrm{~m}^{-3}$, $\rho_{a}=1.225 \mathrm{~kg} \mathrm{~m}^{-3}, \mu_{a}=1.783 \times 10^{-5} \mathrm{~kg} \mathrm{~m}^{-1} \mathrm{~s}^{-1}, v_{a}=1.455 \times 10^{-5} \mathrm{~m}^{2} \mathrm{~s}^{-1}, \mu_{a}=1.139 \times 10^{-3} \mathrm{~kg} \mathrm{~m}^{-1} \mathrm{~s}^{-1}$, 
$c_{a}=1005 \mathrm{~J} \mathrm{~kg}^{-1} \mathrm{~K}^{-1}, k_{a}=0.02534 \mathrm{~J} \mathrm{~m}^{-1} \mathrm{~s}^{-1} \mathrm{~K}^{-1}, T_{a}-T_{r d s}=3{ }^{\circ} \mathrm{C}, D_{w v}=2.35 \times 10^{-5} \mathrm{~m}^{2} \mathrm{~s}^{-1}, \mathrm{RH}=80 \%$, $\alpha_{E S}=2$.

Figure 13. Measured and modeled wet scavenging coefficients as a function of particle size and rain rate $(J)$. The model is based on work by Slinn (1983), Loosemore and Cederwall (2004), Seinfeld and Pandis (2006), Davenport and Peters (1978), and Andronache et al. (2004, 2006). Parameters as defined in the caption of Fig. 12.

Figure 14. Calculated changes in the volume size distribution of the remote continental model aerosol after various rainfall durations $\left(t_{r}\right)$ at a rain rate $(J)$ of $10 \mathrm{~mm} \mathrm{hr}^{-1}$. The model aerosol distribution parameters are from Jaenicke (1993): $N_{l}=3200 \mathrm{~cm}^{-3}, N_{2}=2900 \mathrm{~cm}^{-3}, N_{3}=0.3$ $\mathrm{cm}^{-3}, D_{p l}=0.02 \mu \mathrm{m}, D_{p 2}=0.116 \mu \mathrm{m}, D_{p 3}=1.8 \mu \mathrm{m}, \log \sigma_{l}=0.161, \log \sigma_{l}=0.217, \log \sigma_{l}=0.380$.

Figure 14. Bulk and quartz grain size proxy variations as a function of depth in the Dunaszekcső sequence. Infra Red Stimulated Luminescence (IRSL) ages are pIR-IRSL 225 (first number) and pIR-IRSL 290 (second number) ages as published and defined in Újvári et al. (2014). Ages at depths of 10 and $14.9 \mathrm{~m}$ are yet unpublished age data, both are pIR-IRSL 290 ages. Legend: 1. loess, 2. recent soil, 3. weathered loess, 4. red-brown, well-developed pedocomplex, 5. IRSL sampling points. Black arrows denote in-phase coarse GS events between bulk and quartz grain size proxies.

Figure 16. Internal relationships of median diameter, U-ratio and grain size index in the Dunaszekcső sequence.

Figure 17. Relationships between bulk loess and quartz grain size proxies in the studied sequence.

Figure 18. Relationships between coarse and fine fractions in the U-ratio and the grain size index (GSI) in the Dunaszekcső sequence.

Figure 19. Minimally and fully dispersed particle size distributions of three loess samples from the studied section. 


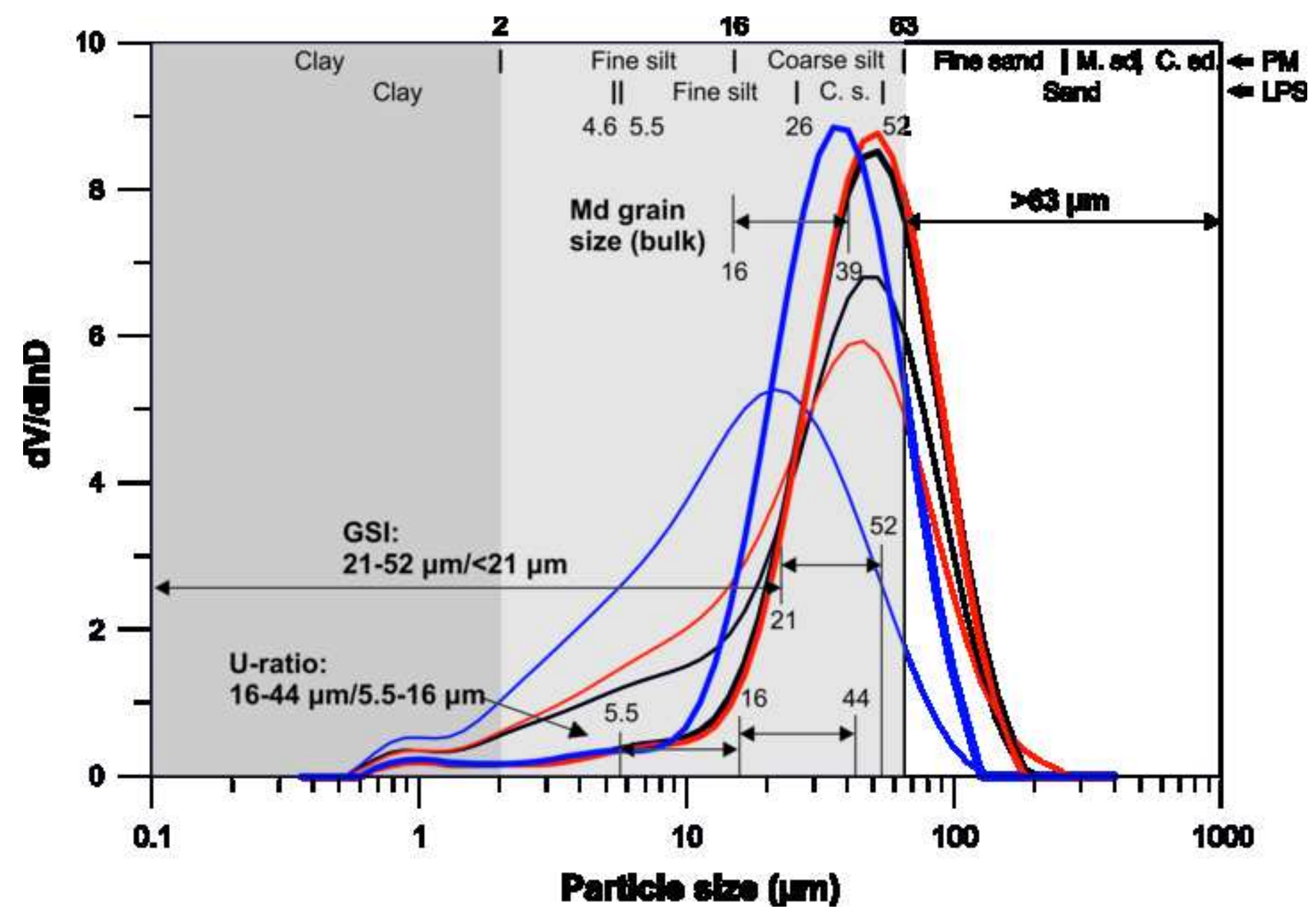




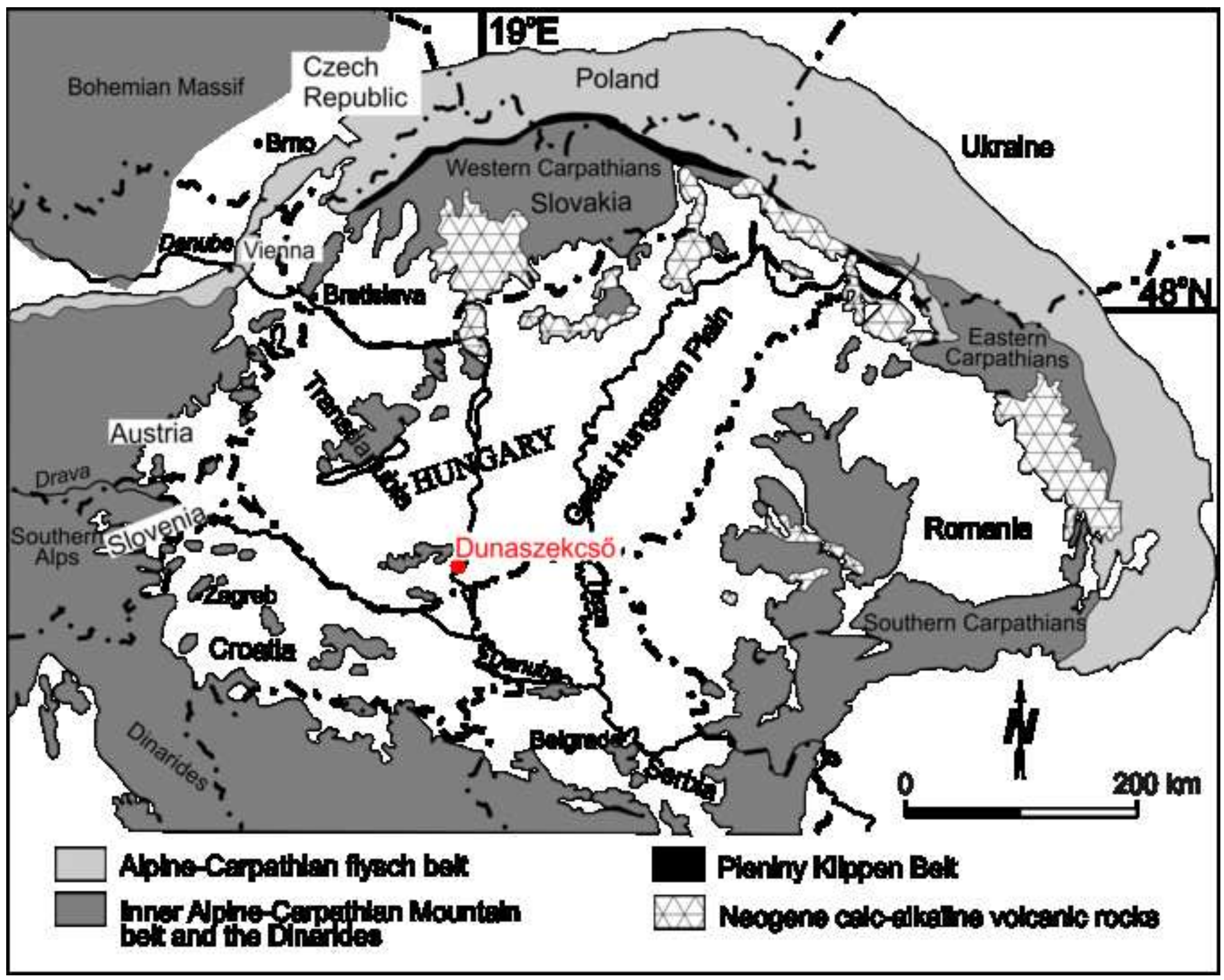


Click here to download high resolution image
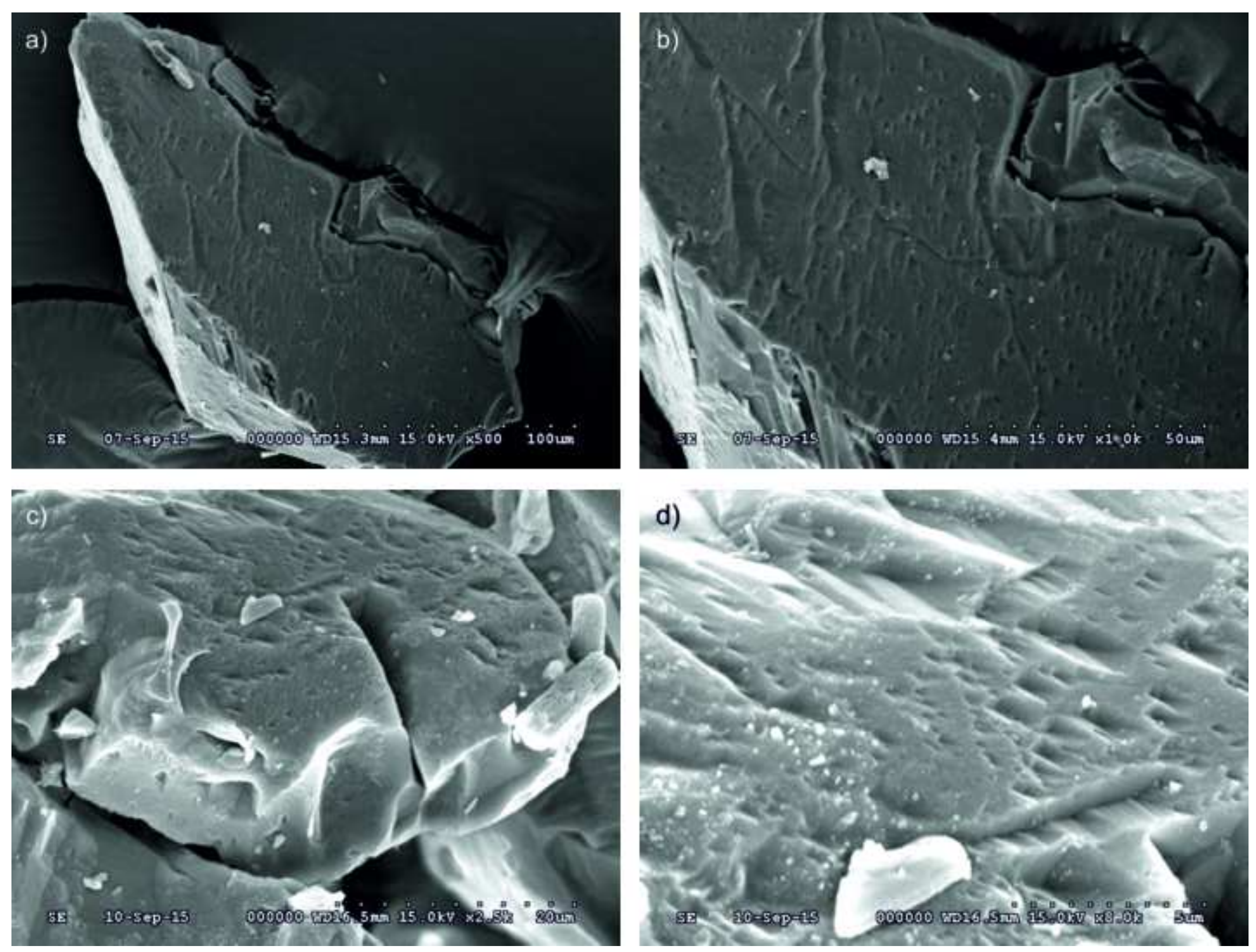
Figure 4
Click here to download high resolution image

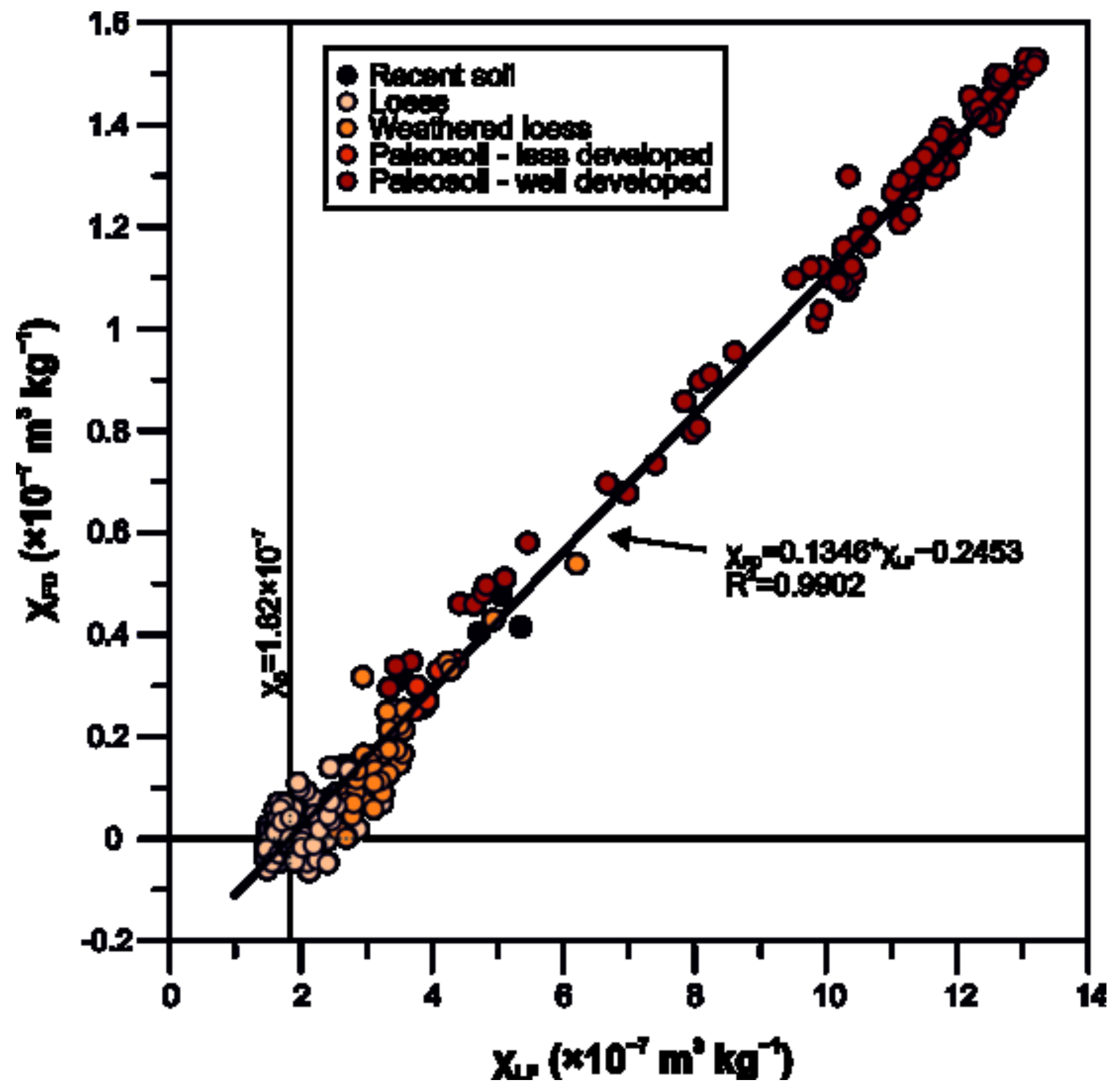




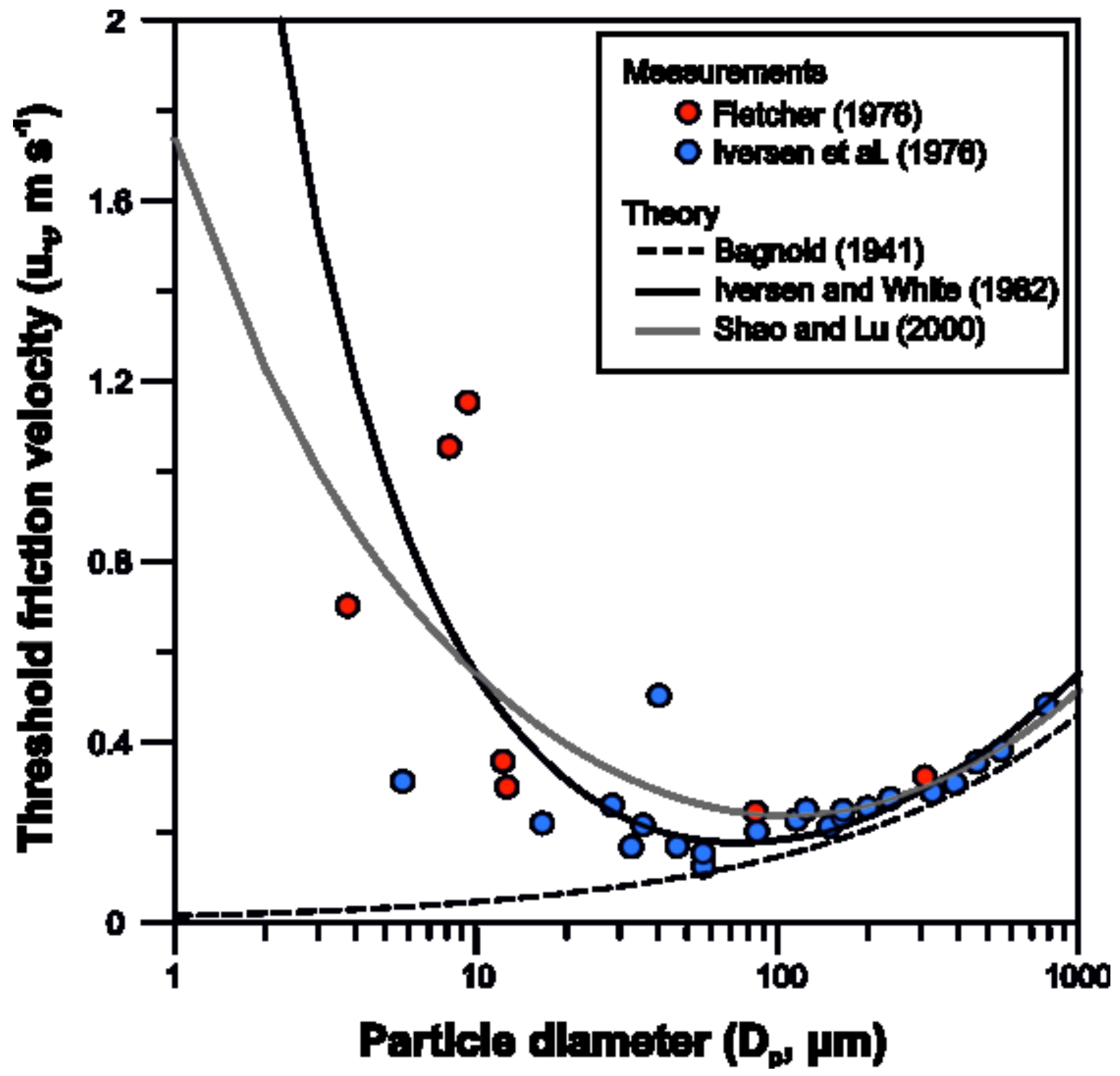


Figure6

Click here to download high resolution image
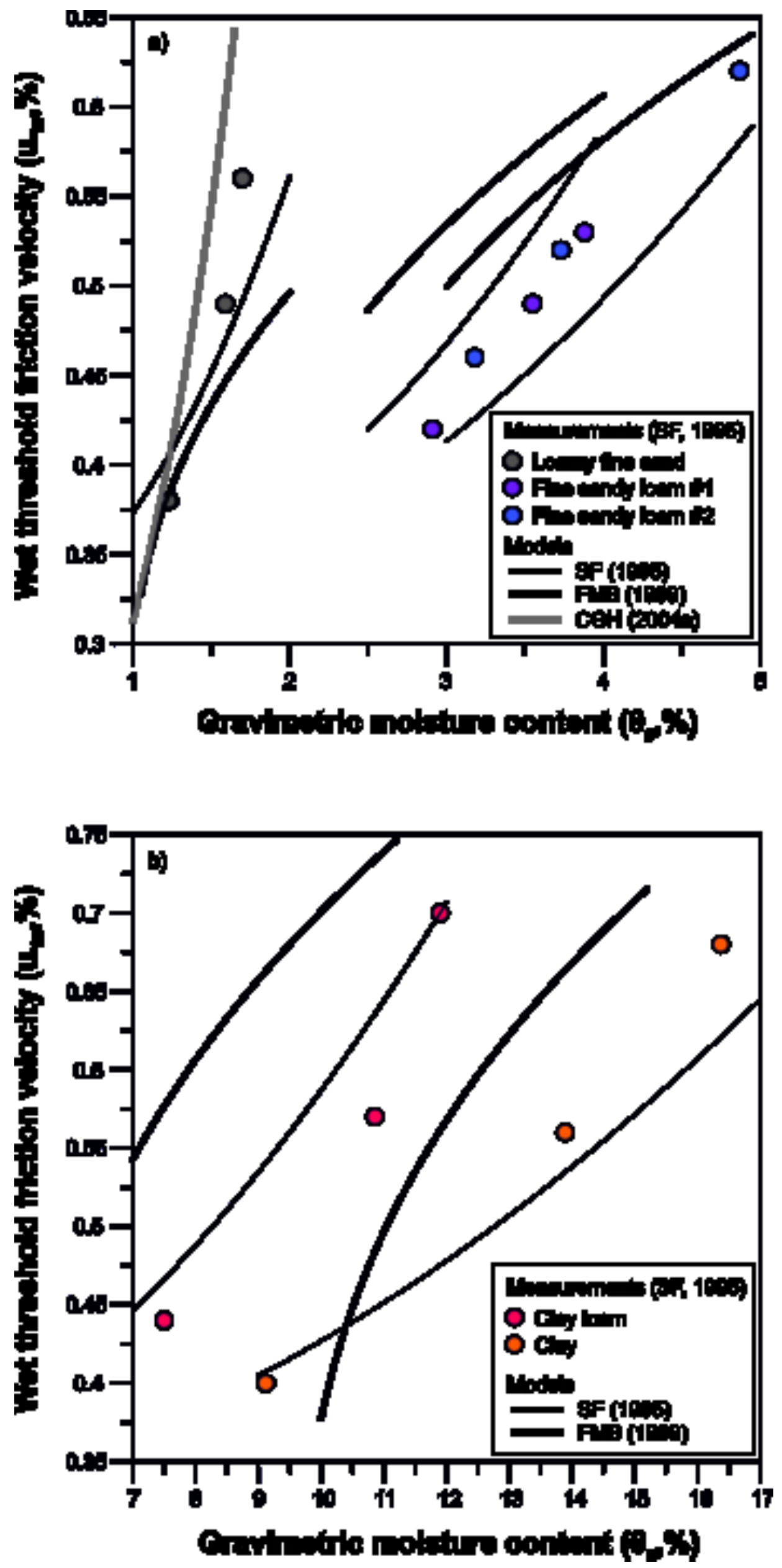


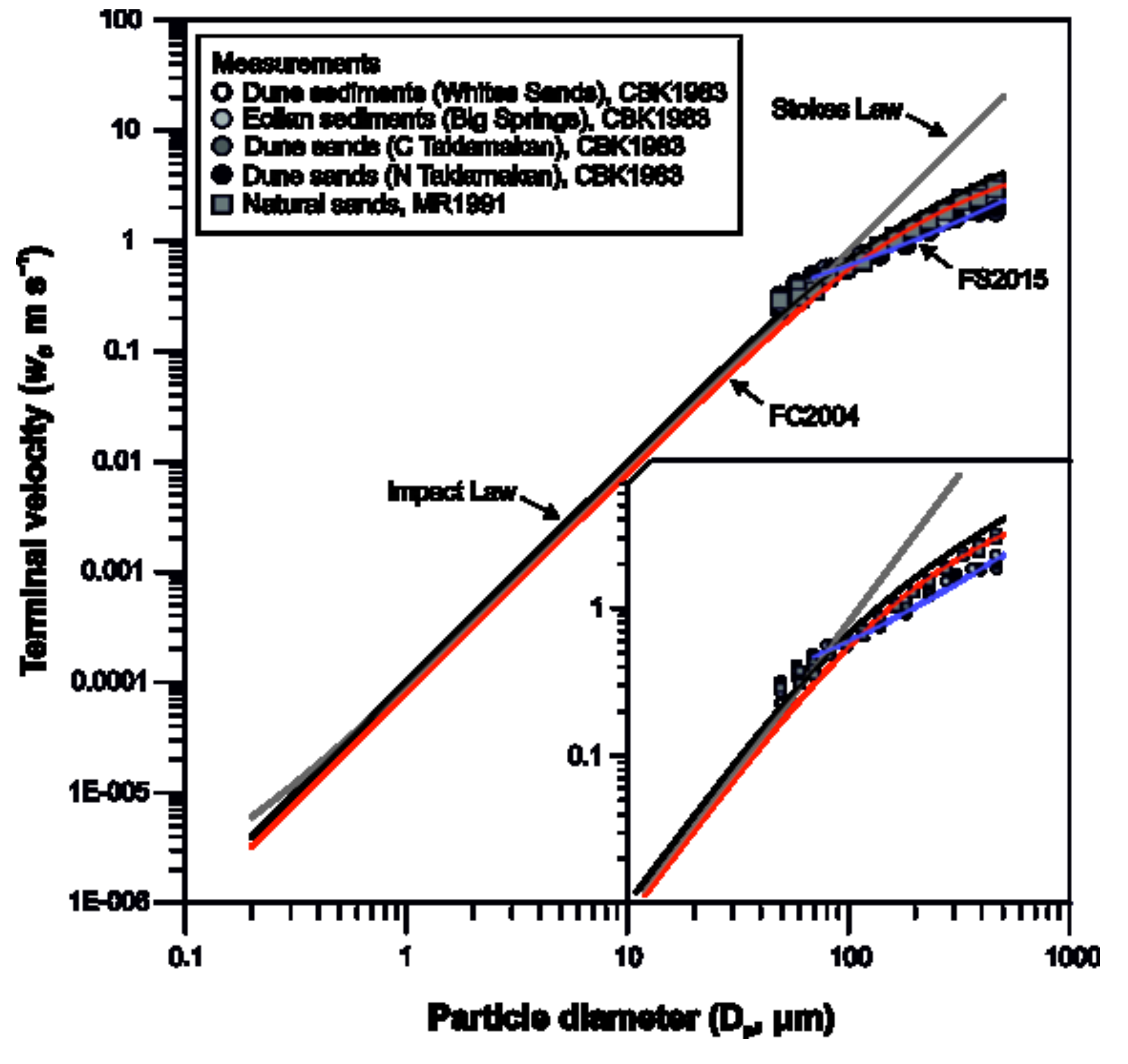

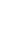




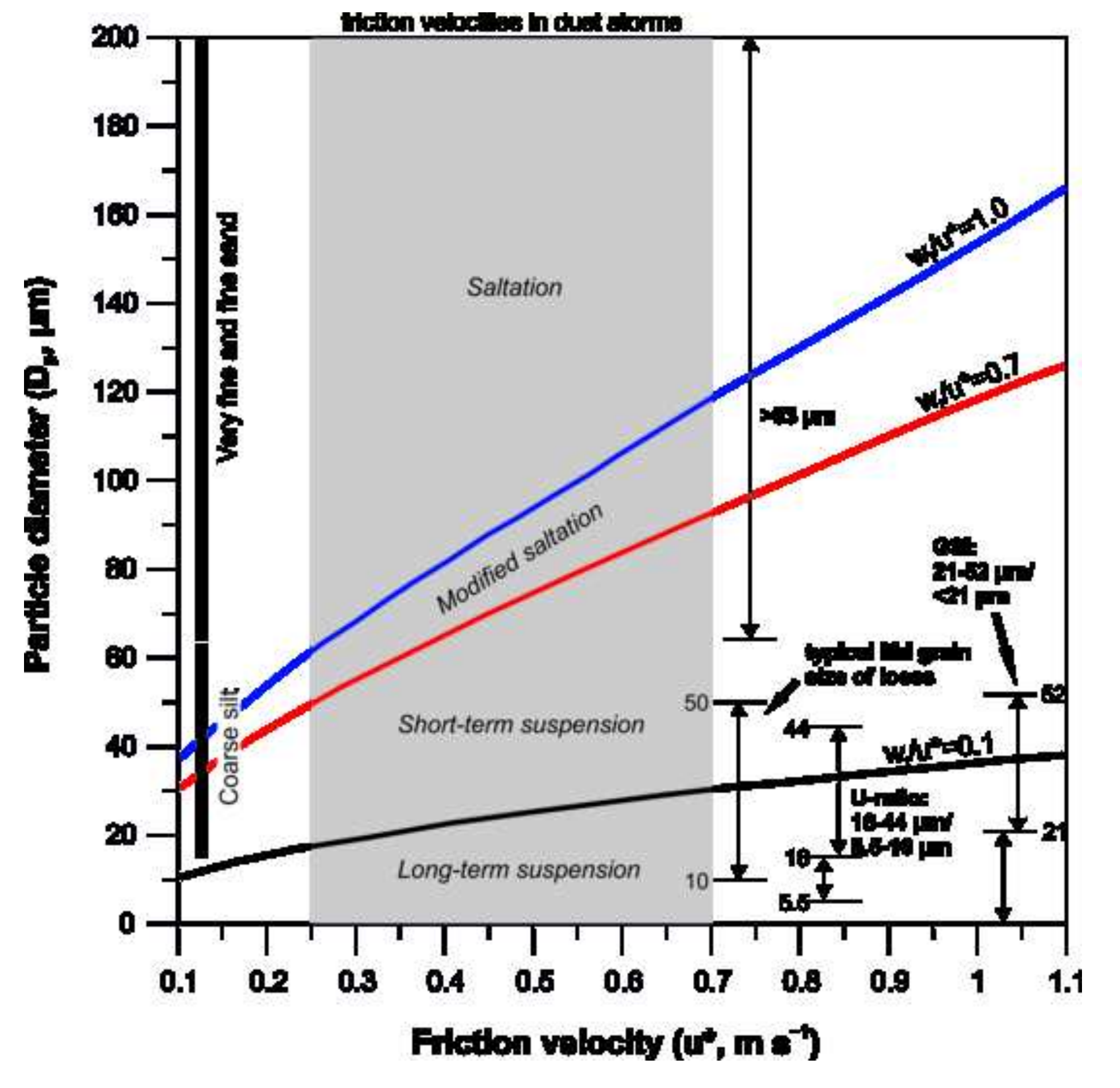

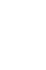




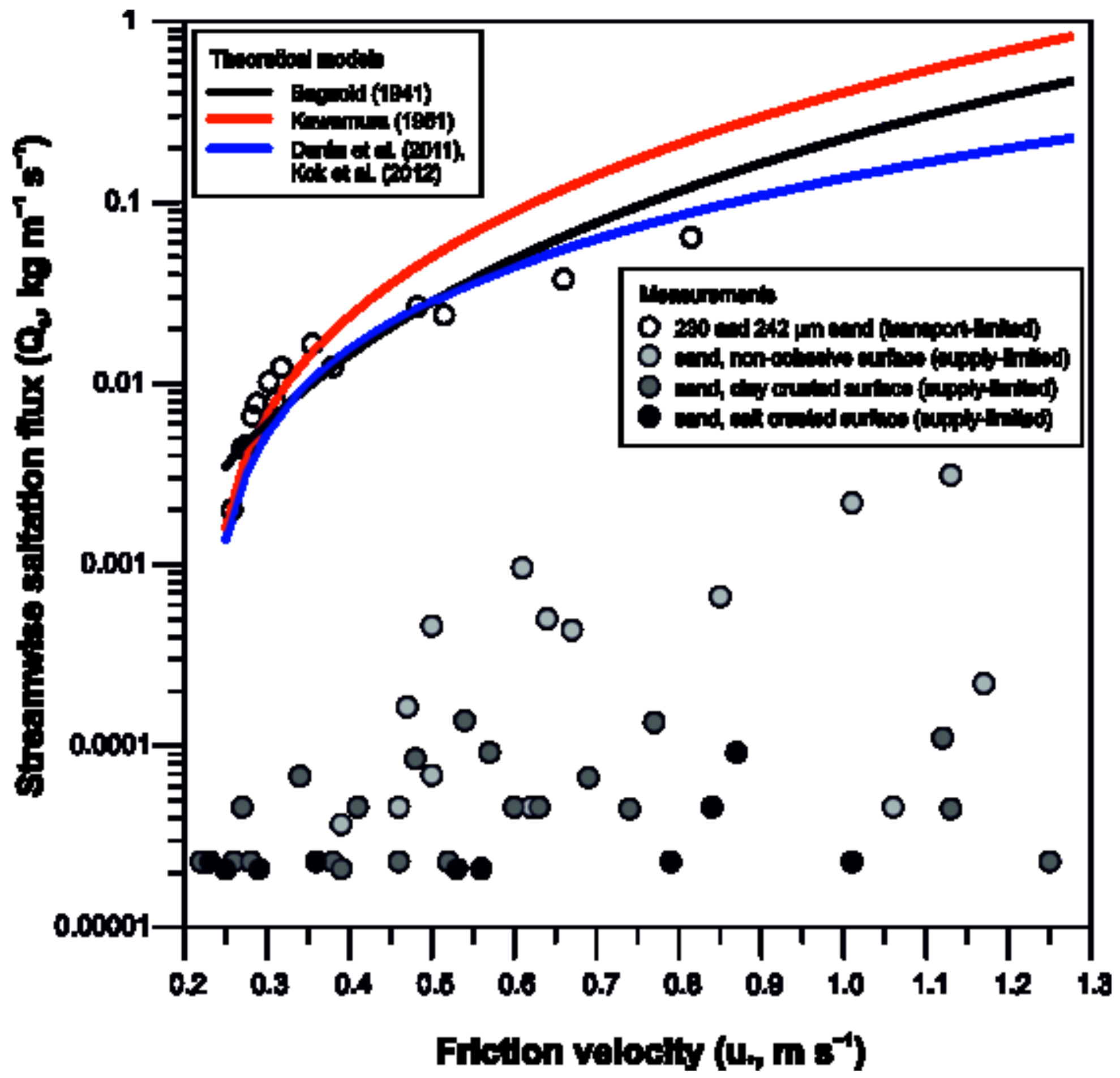


Figure10

Click here to download high resolution image
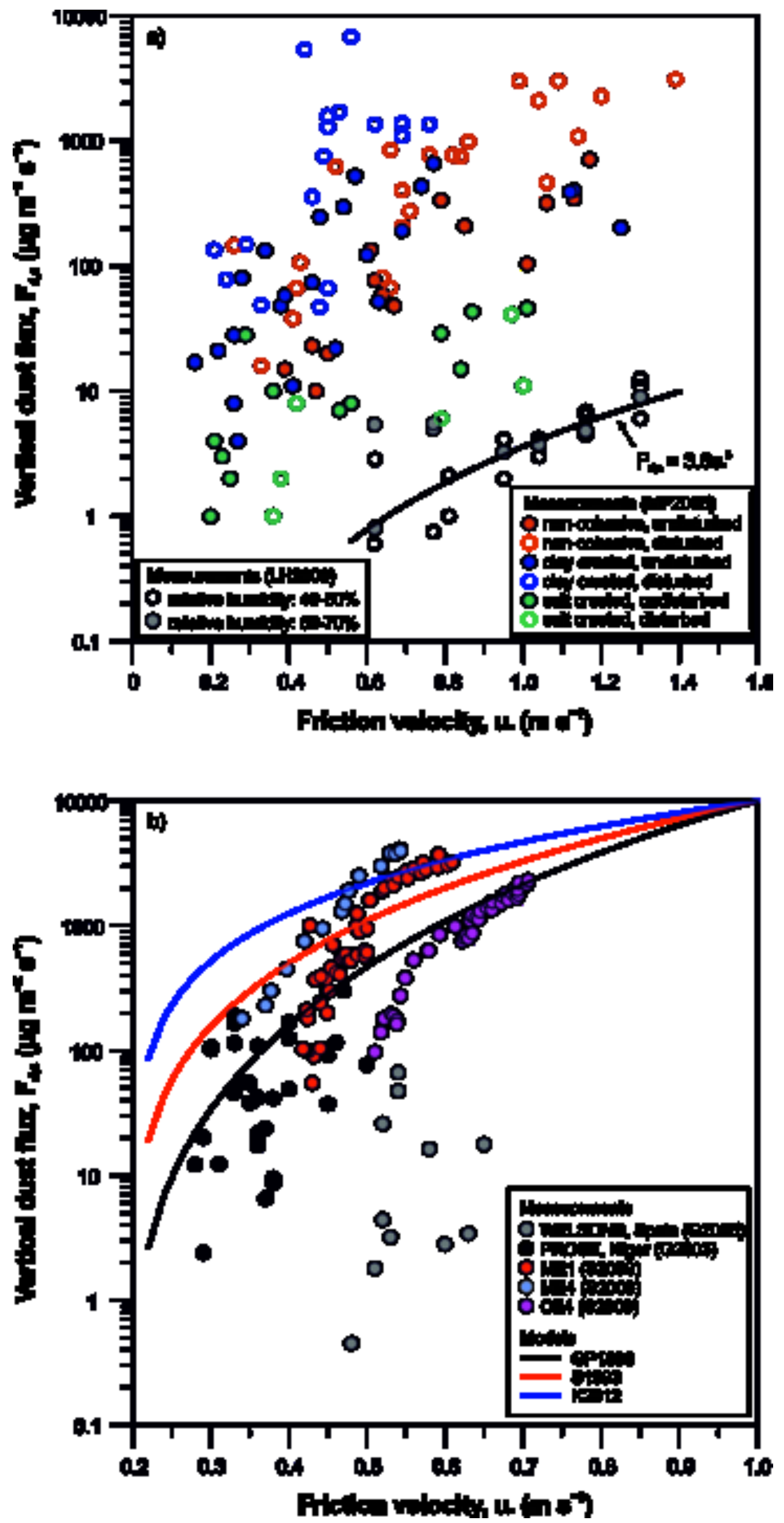
Figure11

Click here to download high resolution image
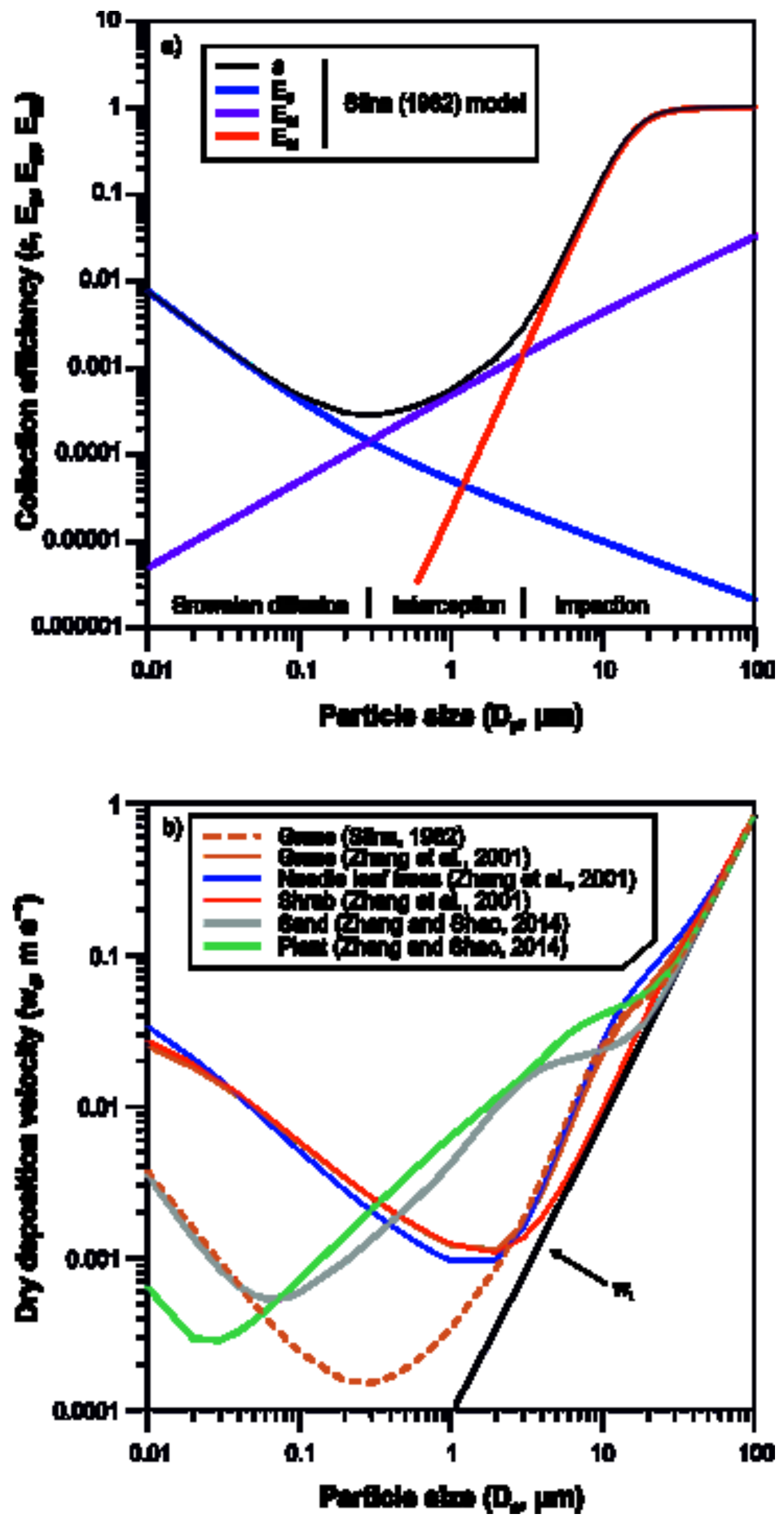
Figure12

Click here to download high resolution image
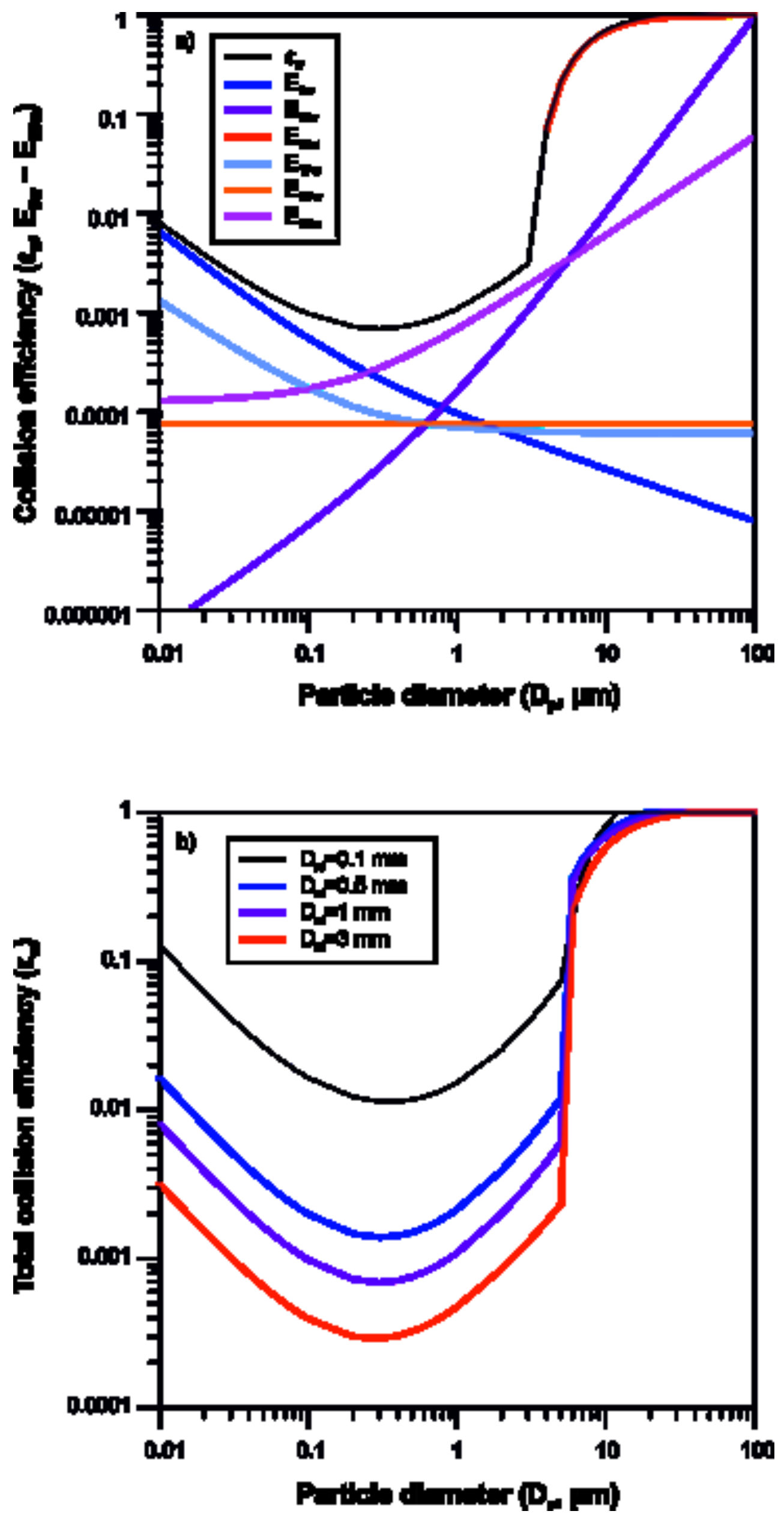


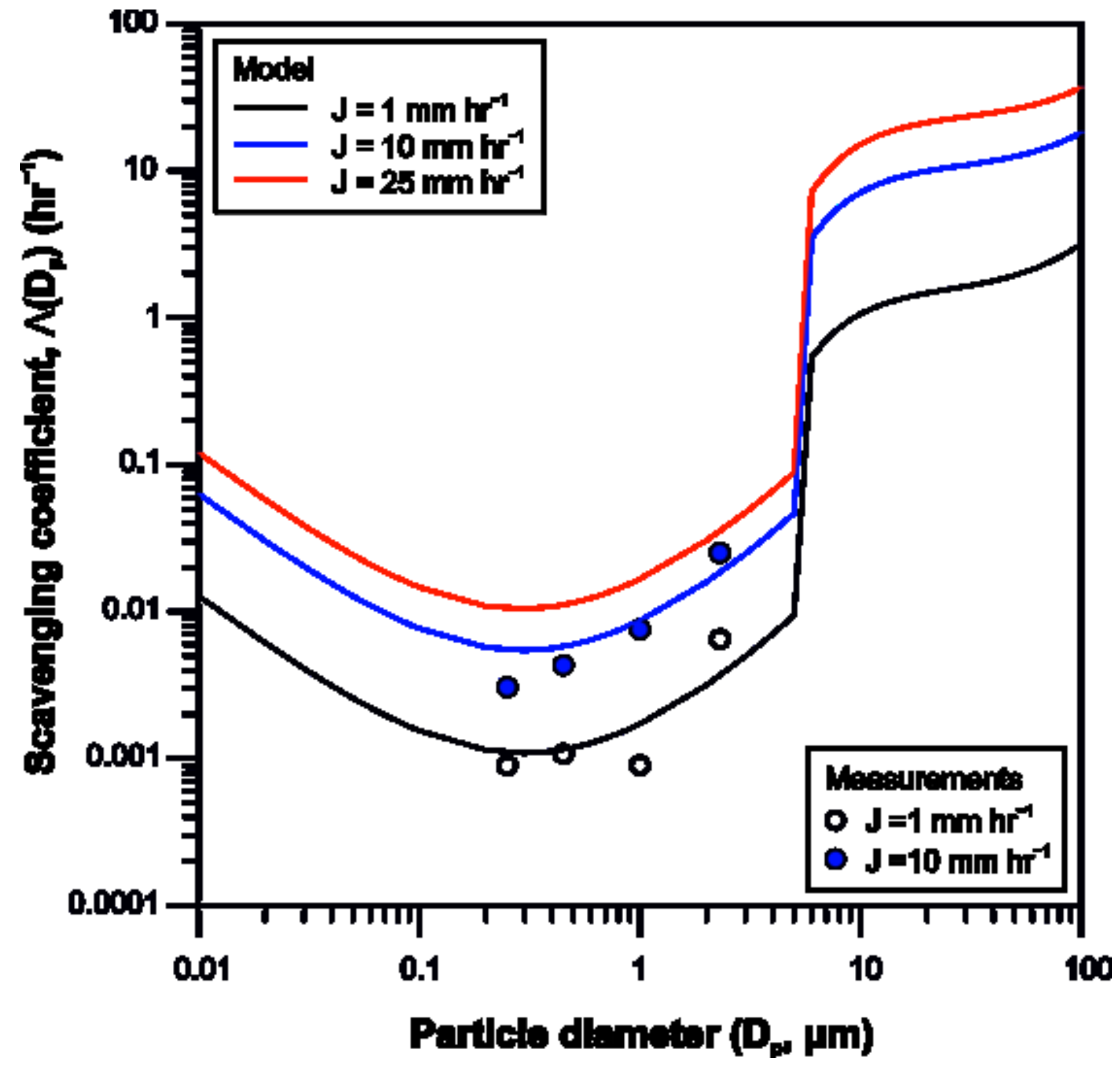




$$
A
$$


Click here to download high resolution image

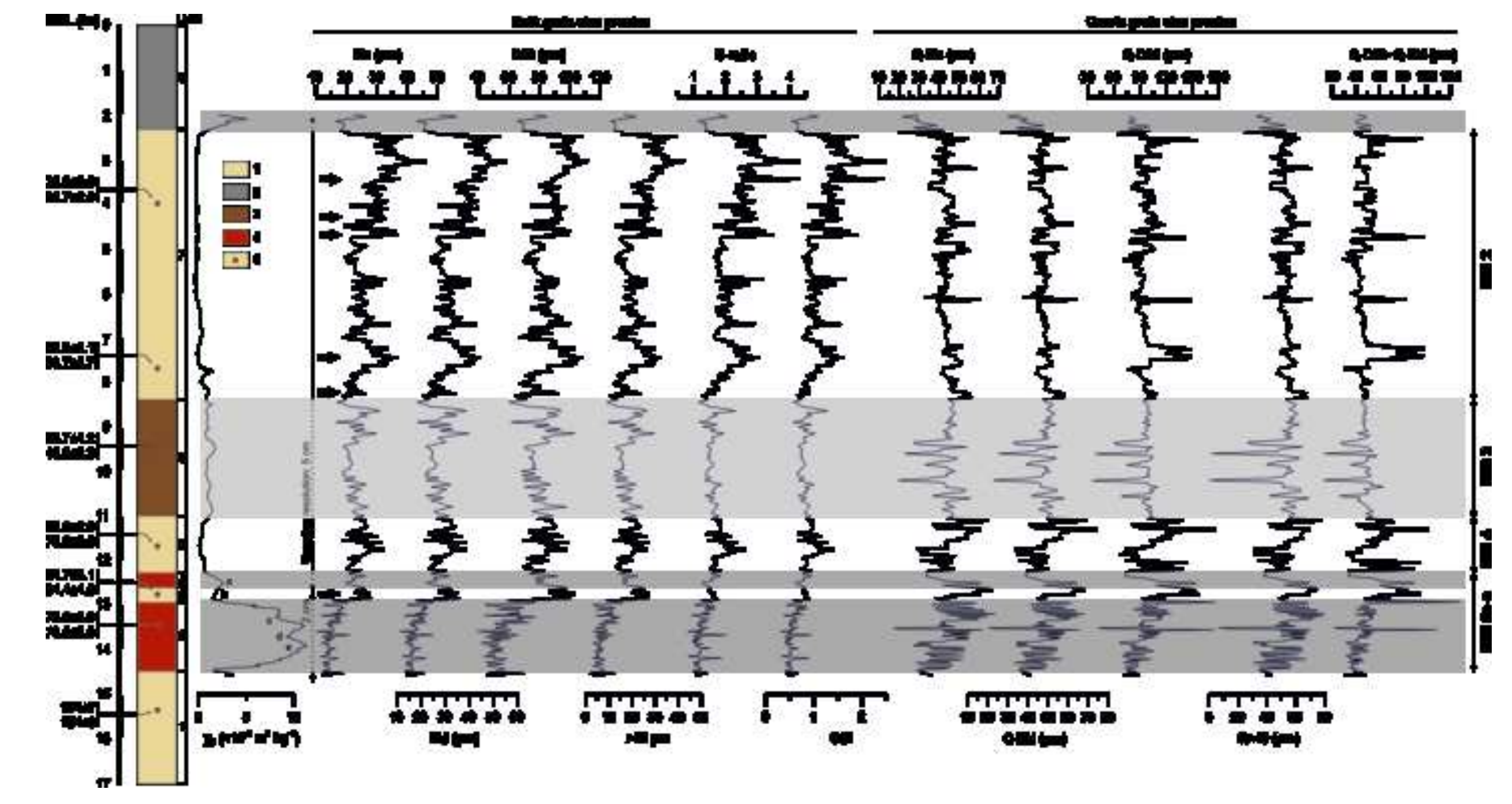

Click here to download high resolution image 
Figure 16
Click here to download high resolution image
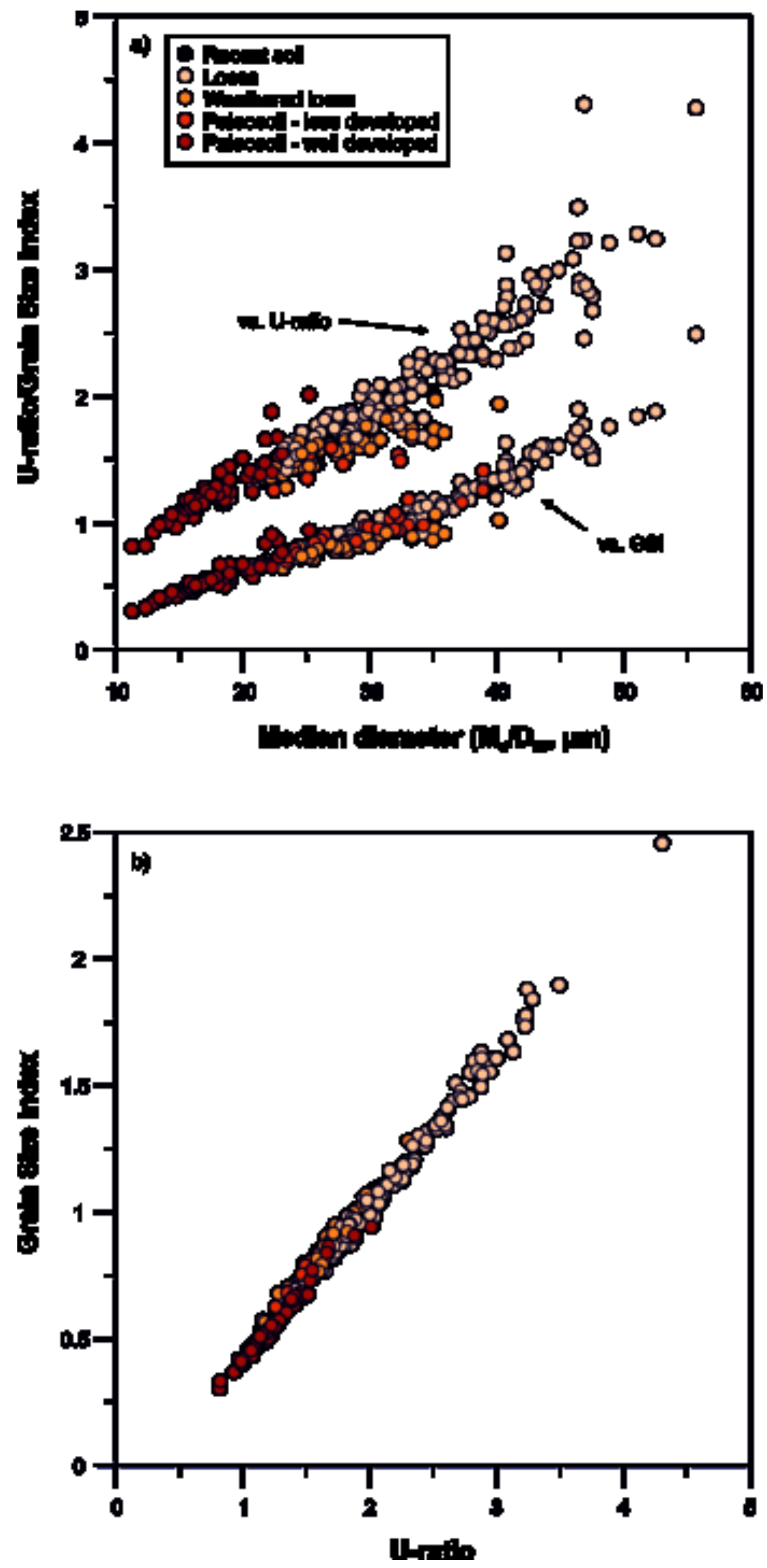
Figure17

Click here to download high resolution image
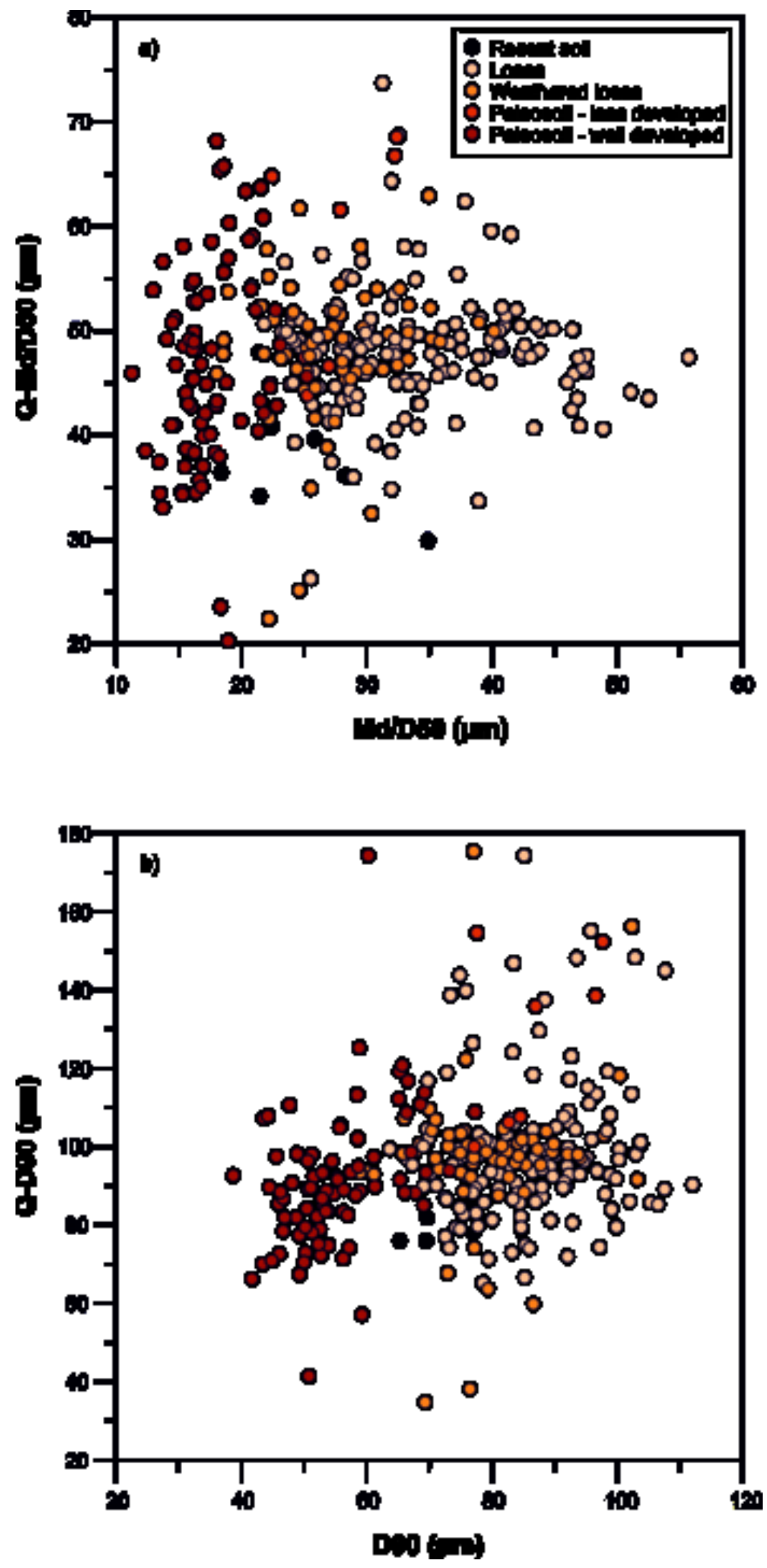
Figure18

Click here to download high resolution image
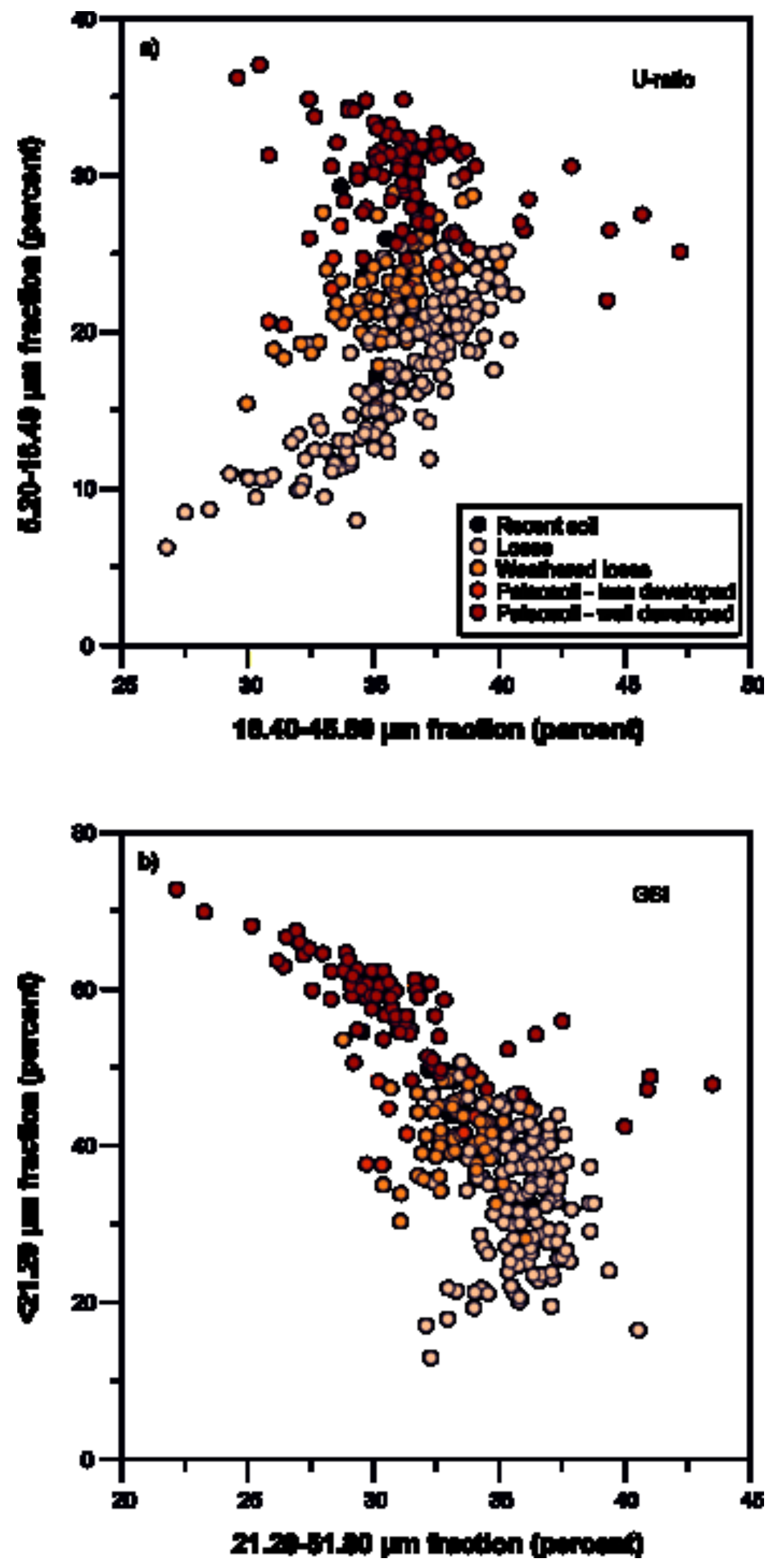


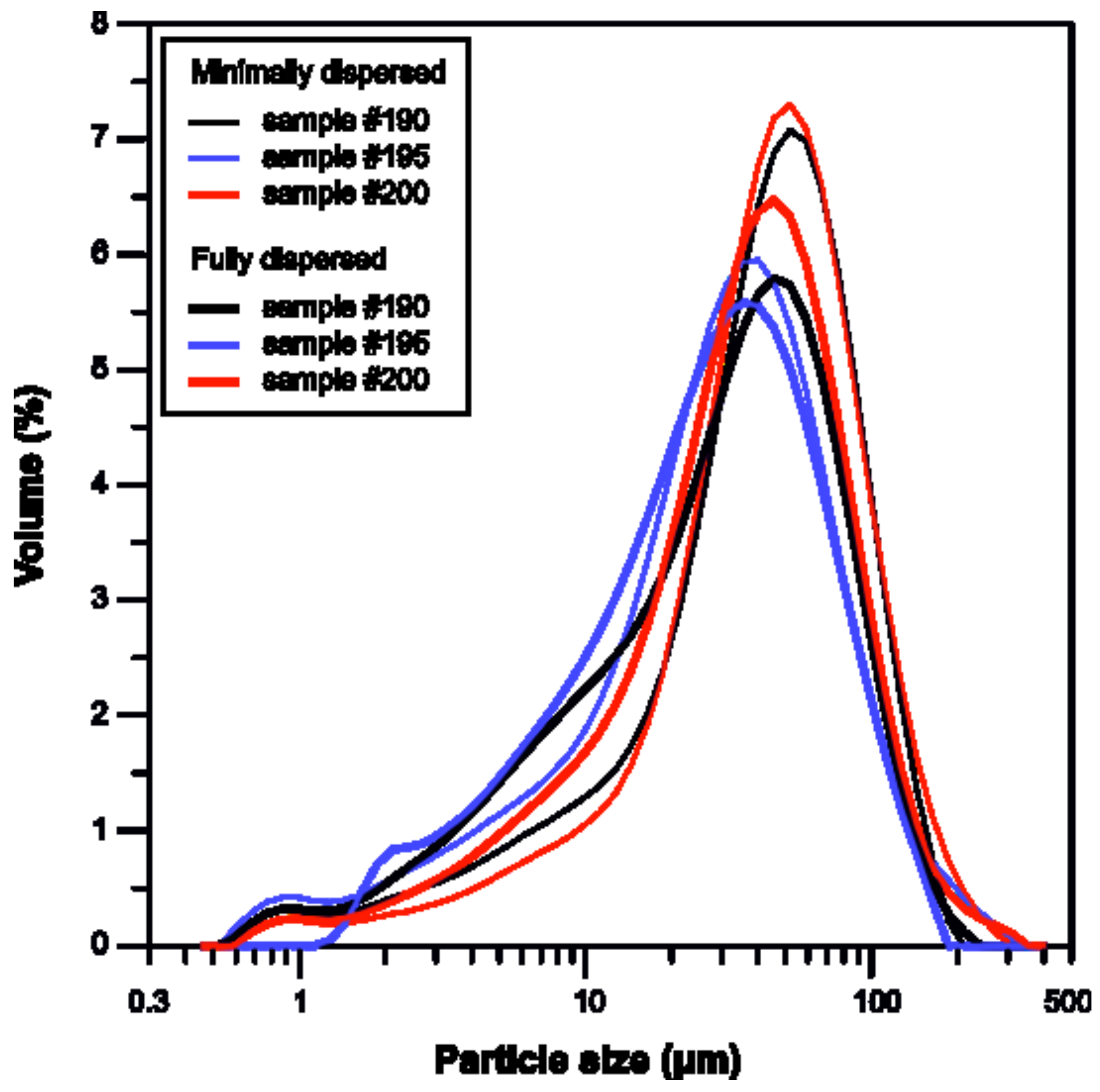

